NBER WORKING PAPER SERIES

\title{
MANAGEMENT AND MISALLOCATION IN MEXICO
}

\author{
Nicholas Bloom \\ Leonardo Iacovone \\ Mariana Pereira-Lopez \\ John Van Reenen \\ Working Paper 29717 \\ http://www.nber.org/papers/w29717
}

\author{
NATIONAL BUREAU OF ECONOMIC RESEARCH \\ 1050 Massachusetts Avenue \\ Cambridge, MA 02138 \\ February 2022
}

We thank the National Institute of the Entrepreneur (INADEM), the Ministry of Finance (SHCP), the National Bank of Foreign Trade (BANCOMEXT), and the National Financing Institute (NAFIN) for leading and funding this survey and for their comments and suggestions. We also thank the National Institute of Statistics and Geography (INEGI) for funding and implementing the survey. We are grateful to Gerardo Durand, Santiago Avila, Araceli Martinez-Gama, Fernando De Lira, Gabriel Romero, and Natalia Volkow from INEGI for their support with the data use in compliance with the confidentiality requirements set by the Mexican Laws. Bloom and Van Reenen thank the ESRC for funding through POID. Helpful comments have been received from participants in workshops at the 2022 American Economic Association, the Census Bureau, Empirical Management Conference, Lazaridis School of Business and Economics, LSE, Society for Economic Dynamics conference, and World Bank, in particular, Louise Guillouet and Diego Restuccia. The views expressed herein are those of the authors and do not necessarily reflect the views of the National Bureau of Economic Research. The findings, interpretations, and conclusions expressed in this paper are entirely those of the authors. They do not necessarily represent the views of the International Bank for Reconstruction and Development/World Bank and its affiliated organizations, or those of the Executive Directors of the World Bank or the governments they represent.

NBER working papers are circulated for discussion and comment purposes. They have not been peer-reviewed or been subject to the review by the NBER Board of Directors that accompanies official NBER publications.

(C) 2022 by Nicholas Bloom, Leonardo Iacovone, Mariana Pereira-Lopez, and John Van Reenen. All rights reserved. Short sections of text, not to exceed two paragraphs, may be quoted without explicit permission provided that full credit, including $\odot$ notice, is given to the source. 
Management and Misallocation in Mexico

Nicholas Bloom, Leonardo Iacovone, Mariana Pereira-Lopez, and John Van Reenen

NBER Working Paper No. 29717

February 2022

JEL No. J0

\begin{tabular}{|c|c|}
\hline \multicolumn{2}{|l|}{ 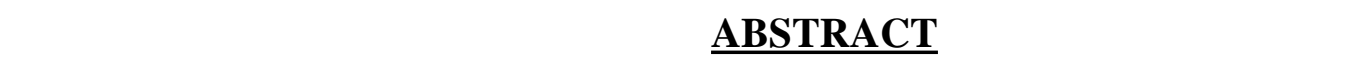 } \\
\hline \multicolumn{2}{|c|}{$\begin{array}{l}\text { We argue that greater misallocation is a key driver of the worse management pra } \\
\text { compared to the US. These management practices are strongly associat } \\
\text { productivity, growth, trade, and innovation. One indicator of greater misallocat } \\
\text { the weaker size-management relationship compared to the US, particularly in the } \\
\text { Mexican service sector. Second, the size-management relationship is weaker in } \\
\text { measured by distance to the US for manufacturing firms and population density } \\
\text { Third, municipalities with weaker institutions, measured by contract enforcer } \\
\text { corruption, have a weaker size-management relation. These results are consiste } \\
\text { lowering aggregate management quality and productivity. }\end{array}$} \\
\hline Nicholas Bloom & Mariana Pereira-Lopez \\
\hline Stanford University & World Bank \\
\hline Department of Economics & mpereiralopez@worldbank.org \\
\hline 579 Serra Mall & \\
\hline Stanford, CA 94305-6072 & John Van Reenen \\
\hline and NBER & Department of Economics \\
\hline nbloom@stanford.edu & $\begin{array}{l}\text { London School of Economics } \\
\text { Houghton Street }\end{array}$ \\
\hline Leonardo Iacovone & London, WC2A $2 \mathrm{AE}$ \\
\hline World Bank & United Kingdom \\
\hline 1818 H St NW & and NBER \\
\hline Washington, DC 20433-0001 & j.vanreenen@lse.ac.uk \\
\hline
\end{tabular}

A data appendix is available at http://www.nber.org/data-appendix/w29717 


\section{Introduction}

Economists have long been interested in firms' management and organization as key drivers of productivity and growth. Adam Smith's pin factory focused on the impact of organizational specialization on productivity, while Walker (1887) claimed the single largest driver of business performance was management quality. ${ }^{1}$ While this interest in management faded after the 1930s, there has been a resurgence of interest in the last decade, driven by the recent availability of microdata on management (Roberts, 2018). However, this work has tended to focus mainly on manufacturing firms in developed countries. This paper presents the first large scale and nationally representative analysis of management practices in a major developing country, Mexico, covering both manufacturing and service sectors.

Our analysis is based on a novel firm-level survey implemented by the National Institute of Statistics and Geography (INEGI). To ensure survey quality and international comparability, the management part of the survey followed as closely as possible (given the English to Spanish translation) the US MOPS 2010 and 2015 surveys (Buffington et al., 2018). The survey was then matched to the Census administrative data, providing additional and rich measures of performance, demographics, and other firms and area characteristics.

We find more structured management - that is, more systematic collection and use of data through monitoring, goal-setting, and stronger use of incentives in Human Resource practices (e.g., over hiring, firing, pay, and promotions) - is associated with superior firm performance (in terms of size, productivity, profitability, and innovation) in both manufacturing and services. This result is robust to a wide variety of checks and controls. While this does not imply any causal relationship, it does suggest these management practices are tightly associated with firm-level performance. ${ }^{2}$

We first document that aggregate Mexican management scores, like productivity, are well below those in the US. We then focus on whether this is driven by greater market frictions

\footnotetext{
${ }^{1}$ Walker was the founding president of the American Economic Association and ran the 1870 and 1880 Census that formed the basis of his views.

${ }^{2}$ Below, we discuss randomized control trials around introducing more structured management practices that also seem to find significant performance improvements (e.g., Bruhn, Karlan and Schoar, 2018, on Mexican firms).
} 
reflected in the fact that well-managed Mexican firms are unable to reap the returns of their managerial practices in terms of greater scale because of these distortions.

To examine this, we perform a number of tests. First, we show that although firms with higher management scores attain larger size in Mexican manufacturing, the size-management relationship is half as strong as it is in US manufacturing. Moreover, the size-management relationship is much weaker among firms in the services sector than among those in the more competitive and open manufacturing sector. ${ }^{3}$ Mexican services are more shielded from international competition (especially since Mexico's accession to GATT in 1986, and NAFTA in 1994) and have greater idiosyncratic regulations than manufacturing. ${ }^{4}$

This comparison across countries and broad sectors is suggestive but coarse. Our second test focuses on market size. A wide class of trade and IO models suggest that reallocation should increase with integration and market size (e.g., Melitz, 2003). We measure market access (trade costs) by drive times to the US border for manufacturing firms, and by incomeweighted population density for services firms. We find that proximity to the US border increases the size-management relationship for manufacturing (which relies heavily on exports to US markets), but has no effect on services. We also find that this reallocation effect is driven by the manufacturing industries that are more export-intensive. For services, we find that local market size strengthens the size-management relationship, whereas this local market size indicator has no effect on manufacturing firms. Again, this is consistent with our priors, as reallocation among service firms should be affected by local market size and not international market access.

\footnotetext{
${ }^{3}$ In particular, the regression coefficient of firm log (employment) on the management score is 1.62 in Mexican services, is 2.75 in Mexican manufacturing, and is 3.36 in US manufacturing. Hence, for every 0.1 -point change in the management score, the associated change in firm employment size over twice as large in US manufacturing as it is in Mexican services.

${ }^{4}$ See Goodwin et al. (2018) and Levy (2018). A recent World Bank report assessing the regulations at subnational level in various Mexican States (e.g., Mexico State, Tabasco, Oaxaca, etc.) found for instance that firms in the retail sector face various types of barriers at entry (e.g., municipal licenses for which there are not clearly established time terms and for which the granting criteria are not fully transparent - for instance the declaration of "urban impact" can take between 1 month and 6 years), and during operations (limitations to use of English placards and promotional boards, renovation of licenses, limitations to the hours in which retailers are allowed to be open, etc.). In the transport sector, the report found that the state law in Tabasco does not allow a private company to propose starting a service to serve a new route but only the Government can propose a new route and open a market. Similarly, the state law not only prohibits foreign companies from concessions for local transport services, but even favors local companies against those from other states of Mexico - see Goodwin et al. (2018).
} 
Our final test focuses on institutional frictions. We measure different measures of institutional frictions relying on data that measures contract enforcement, crime, and government corruption at the local (municipality) level. We find that reallocation is significantly greater where these institutional frictions are lower.

All three designs: across countries and sectors; across market sizes; and across local institutions suggest that frictions are a major factor in depressing the performance of the Mexican economy.

The paper is structured with a detailed description of the data in section II, including some basic results on management practices and firm performance. We discuss the distribution of Mexican management practices and how they compare with the US in section III. Section IV focus on misallocation, wedges, and the importance of market frictions, international exposure for manufacturing, and market density for services, while section V concludes. ${ }^{5}$

\section{I.1 Relation to Existing Literature}

We contribute to several strands of the literature. First, we add to the vast and rapidly growing literature on misallocation and aggregate productivity, including Hsieh and Klenow (2009). Several recent studies have specifically focused on extensive misallocation in Mexico as a barrier to aggregate productivity (e.g., Hsieh and Klenow, 2014; Misch and Saborowski, 2020; and Levy, 2018). Methodologically we focus on the covariance between a measure of fundamental firm capability (management quality) and firm size (as indicated by the allocation of labor, a key input). The original "Olley-Pakes" (1996) covariance term (between productivity and market share.) has been found to be a robust measure of misallocation in many parts of the literature, although typically, firm capability has been measured by proxies for Total Factor Productivity (TFP). TFP is notoriously hard to measure as it is a residual,

\footnotetext{
${ }^{5}$ Online Appendices include the (translated English version) of the survey questionnaire (A), Data Details (B), other empirical results (C), a municipality-level analysis (D), and the model (E).
} 
however, and even though it is likely to be correlated with fundamental capabilities, ${ }^{6}$ this relationship may be weak. In this paper, we draw on the idea in Lucas (1978) defining capability as management and measure it directly.

Second, we relate to the literature on the drivers of management practices. One strand of this has focused on the role of competitive frictions. There are a large number of papers pointing to the importance of competitive pressure for productivity (e.g., the survey by Holmes and Schmitz, 2010). One of the mechanisms is that a positive impact of competition on productivity may be due to competition increasing management quality (see Leibenstein, 1966 and the survey by Van Reenen, 2011). Other strands of literature analyzing drivers of management have focused more on information and learning spillovers (e.g., Cai and Szeidl, 2017) and regulations (e.g., Bloom et al., 2019).

Third, we contribute to the large and growing literature on the effects of management on productivity. Early studies used cross-sectional or occasionally panel data (e.g., Black and Lynch, 2001; Capelli and Neumark, 2001; Huselid, 1995; and Osterman, 1994). These studies tend to find positive associations in the cross-sections, but they tend to disappear in the panel dimension. Another group of studies focuses on smaller numbers of firms, sometimes even looking across sites in a single firm. ${ }^{7}$ These "insider econometric" studies tend to find more positive effects of management practices. More recent studies have used randomized control trials and (more rarely) quasi-experiments (Giorcelli, 2019), which also tend to find positive results. ${ }^{8}$ Bruhn, Karlan, and Schoar (2018) is particularly relevant as it focuses on Mexico and finds that firms that received management consulting exhibited a much stronger job growth over the medium term (2-5 years), though they find heterogeneity in the practices that have a high impact on firm performance.

\footnotetext{
${ }^{6}$ In the model of Hsieh and Klenow (2009) firm-level revenue based TFP measured (TFPR) are unrelated to fundamental firm capability, quantity based TFP (TFPQ) due to the unobservability of firm level prices. In more general models, however, which allow for fixed costs of labor or adjustment costs there $i$ a correlation between TFPQ and TFPR (Bartelsman, Haltiwanger and Scarpetta, 2013 or Asker, Collard-Wexler and De Loecker 2014). Nonetheless, the empirical and theoretical issues with TFP measurement make more direct measurements attractive.

${ }^{7}$ For example, Bartel, Ichniowski and Shaw (2007); Bandiera et al. (2005, 2007); Hamilton et al. (2003) and Lazear (2000). See Bandiera et al. (2020) for a study focusing on CEOs and performance.

${ }^{8}$ Examples of RCTs include Anderson et al. (2018), Bloom et al. (2013), Brooks et al. (2018); Fryer (2017); Gosnell et al. (2020), Higuchi et al. (2017, 2019); Karlan, Knight and Udry (2015); McKenzie and Woodruff (2013). See McKenzie and Woodruff (2017) for a survey and Bandiera et al. (2017) for a meta-study.
} 


\section{Measuring management practices}

We start by describing the basic survey process and then validate our management scores by comparing them to firm performance data.

\section{II.1 Sample and survey process}

Our data comes from the National Survey on Productivity and Competitiveness of Micro, Small and Medium-size Enterprises in Mexico (ENAPROCE 2015 and 2018). This is the first large-scale and representative management survey conducted in Mexico. This was implemented by the National Institute of Statistics and Geography (INEGI), using the 2014 Economic Census as the sampling frame. The data was collected by enumerators visiting in person the physical location of each firm in the survey. ${ }^{9}$

The 2015 survey wave had a sample frame of 4,049,051 firms, from which 26,538 were chosen by random stratification (stratified to yield representative coverage of states and industries). From this, a sample of 25,456 firms responded: a response rate of $96 \%$. This extremely high response rate was achieved because of the mandatory nature of the surveys implemented by INEGI ${ }^{10}$ and the repeated in-person visits by enumerators. The second wave of the survey was implemented in 2018, and it was designed as a panel. Due to this design, the response rate fell to $90 \%$, as some of the firms could not be found or were closed. ${ }^{11}$ Of the firms that were located, $13.3 \%$ had problems with incomplete information due to strikes, temporary closings, and other problems that affected data collection.

The management part of ENAPROCE was designed to replicate the US Census Management and Organizational Practices Survey (MOPS) ${ }^{12}$. For manufacturing, it was translated directly

\footnotetext{
${ }^{9}$ For firms with multiple locations the enumerators would visit the headquarters. $90 \%$ of the firms are singlesite.

${ }^{10}$ As stated in article 45 of the Mexican Law of the National System of Statistical and Geographic information (Appendix Figure A1).

${ }^{11}$ Among the $4 \%$ of firms that did not respond in 2015 , only $2 \%$ were due to real refusals and the other $2 \%$ were due to firms that had closed down. Of the firms that responded in $2018,13.3 \%$ provided incomplete information, due to closing, strikes, or other problems. On the other hand, of the firms that did not respond in this second wave of the survey, half had either closed or could not be located by the Census enumerators.

${ }^{12}$ See details on US MOPS surveys back to $2010 \mathrm{https}$ ://www.census.gov/programs-surveys/mops.html
} 
from English without any modifications. For Services, ${ }^{13}$ it was slightly adapted to reflect differences in operations - for example, the question about "problems in the production process" was replaced by a question about "problems with customer service" (see Appendix A for an English translation of the services questions). The reason to exactly replicate the US MOPS was to maximize the comparability of Mexican management practices to the US MOPS 2010 and 2015 samples. After data cleaning, we end up with a sample of 16,100 firms with ten or more employees and 8,497 microenterprises with fewer than ten employees. ${ }^{14}$

For every firm, a management score was constructed following Bloom et al. (2019). The responses for each of the 16 questions included in the management section are normalized to obtain a score that ranges between zero and one, where the more structured management practices (the ones that are more specific, formal, frequent, or explicit) are associated with a value of one, while the less structured practices obtain a value of zero. The responses located in between these two extreme values obtain a fraction depending on the number of categories. Once every question is scored, we calculate an unweighted average of the 16 questions to construct the management score. We also separate the overall management index into two sub-indexes assessing monitoring practices and human resource practices (i.e., incentives and targets). Our index of structured management practice is not necessarily "better" or "worse," although, as we shall see, they are strongly correlated with a wide variety of performance measures.

For the case of microenterprises, only four questions from the US MOPS were included in the shorter survey form. The correlation between the management score calculated with this subsample of questions and the overall management score for the non-microenterprises sample is 0.86 , indicating that this short score is a reasonable approximation for the overall score. To reduce respondent burden, we did not ask questions on various other aspects such as exports and FDI. Consequently, the main part of the analysis drops microenterprises, although we do show robustness to including them in the Online Appendix.

\footnotetext{
${ }^{13}$ The definition of sectors (Manufacturing and Services) is shown in the Online Appendix (Appendix B).

${ }^{14}$ See Online Appendix (Appendix B) for further details on the construction of the sample.
} 


\section{II.2 Management and firm performance}

As an initial validation of the data, we compare the management scores to a range of firm performance measures. While this analysis is only correlational, it is helpful for establishing that in Mexico (as in the US), these types of practices are associated with better performance. In Figure 1, we pool the data from the 2015 and 2018 surveys ${ }^{15}$ and present various measures of performance by deciles of the management score. Moving from the top left to the bottom right panel, we observe that higher management scores are associated with greater labor productivity, profitability (as measured by gross operating profits divided by sales), exporting, $R \& D$ expenditure per worker, patenting, and size (as measured by the number of employees).

Table 1 presents some initial estimates, where the dependent variable in the first two columns is $\log$ (value added per worker). In column (1), we allow the coefficient on management to be different in manufacturing than services, and although it is positive and significant in both sectors, it appears to be stronger in the former. However, in column (2) where we also control for capital per worker, human capital (the fraction of employees with degrees and the proportion of white-collar workers), a full set of industry dummies (6-digit NAICS), a time dummy, and allow for non-constant returns (by including size on the right-hand side), there are no significant differences across the two sectors. Based on the results from column (2), the magnitude of the coefficient of management implies that a movement from the $10^{\text {th }}$ to the $90^{\text {th }}$ percentile of the management score is associated with about a $30 \%$ increase in productivity in both sectors. In column (3), we use Total Factor Productivity (TFPR) as the dependent variable, measured using a Törnqvist index. ${ }^{16} \mathrm{We}$ again find evidence of a strong and positive relationship of productivity with management practices. Finally, columns (4) and (5) re-estimate column (3), but splits the sample into manufacturing and services and

\footnotetext{
${ }^{15}$ The main results use pooled data for the 2015 and 2018 waves of the survey due to the short period of time between the two waves. See Online Appendix Table A1 for descriptive statistics of all the variables included in the analysis.

${ }^{16}$ This is consistent with a translog production function. This is constructed in the same way as Aw et al. (2000) - see Online Appendix B for more detail.
} 
confirm that management is positively and significantly correlated to productivity in both sub-samples with similar coefficients. ${ }^{17}$

In summary, these results show that structured management practices are tightly and robustly linked to productivity even when we control for a large range of controls. ${ }^{18}$ Moreover, the relationship in both sign and magnitude looks similar in both the manufacturing and service sectors. While the evidence is not causal, it is consistent with the studies discussed earlier, which rely on stronger identification schemes.

\section{Management Practices in Mexico compared to the US}

We first describe the distribution of management practices and perform basic comparisons with the US. Then, we analyze misallocation using management as a proxy of firm-level productivity and employment as the key firm size variable.

\section{III.1 The Dispersion of Management Practices across Mexican firms}

Figure 2 shows how Mexican manufacturing management scores (shown in solid) are more dispersed, a result echoing the wide dispersion of TFP reported for Mexico in Hsieh and Klenow (2014) and Levy (2018). ${ }^{19}$ We also plot the US manufacturing management score (shown in thinner grey), which has both a higher mean (the Mexican mean is 0.47 vs. 0.64 for the US - see Table A1 and Bloom et al., 2019) and a lower variance (the Mexican standard deviation is 0.171 vs. 0.152 in the US). Turning to Mexican services, we see the management score is even lower, with a mean value of 0.44 and marginally more dispersed. ${ }^{20}$ This points to more market frictions in Mexico than in the US and, within Mexico, more relative frictions in services than in manufacturing. One possible explanation that we discuss later is that

\footnotetext{
${ }^{17}$ As a robustness test, we merged our management data with the 2014 Economic Census and constructed the same outcome variables (value added-per-worker, TFP indexes and profitability), finding very similar results as shown in Online Appendix Table A2.

${ }^{18}$ The analysis of labor productivity for microenterprises (Online Appendix Table A3) shows that management is also informative for these very small firms as well.

${ }^{19}$ Furthermore, as shown in Online Appendix Figures A3 and A4, neither manufacturing nor services, exhibit much improvement in the last few years.

${ }^{20}$ Note there is no US management survey of services - indeed one of the unique things about the Mexican survey is the coverage of the services sector.
} 
service sector firms have less exposure to international competition due to lower tradabilty and a greater degree of regulation.

If we consider other differences in firm characteristics between the manufacturing and services sectors, we observe that manufacturing companies tend to be larger and older, while workers in the services sector tend to be more educated, with a higher share of workers with a college degree. This is consistent with the analysis of Zahler et al. (2014) for Chile, in which firms in the service sector tend to be more skill-intensive while manufacturing firms are larger. $^{21}$

\section{III.2 Management and Reallocation across countries and industries}

One interpretation of our results so far is that reallocation through market forces is weaker in Mexico than in the US, especially in services. To investigate this hypothesis, we look at the relationship between firm size and management. In environments where market frictions are lower, we would expect better-managed firms to be relatively larger. We detail a model in Appendix E which formalizes this intuition in a simple framework with heterogeneous firms, imperfect product market competition, and regulatory/institutional distortions (modelled as an implicit revenue tax). This delivers the intuitive proposition that firm size (as measured by employment) is increasing with management, but this relationship is attenuated when distortions are higher and/or competition is weaker.

To confront these ideas with the data, Figure 3 presents the size-management relationship in (i) Mexican services, (ii) Mexican manufacturing, and (iii) US manufacturing. ${ }^{22}$ The slope of the regression line of $\ln ($ employment) on our management index is 3.4 for US Manufacturing, 2.7 for Mexican Manufacturing, and 1.6 for Mexican services. This is consistent with the strongest reallocation being in US manufacturing, followed by Mexican manufacturing, and the weakest reallocation occurring in the Mexican service sector.

\footnotetext{
21 If we split our service sector firms into knowledge intensive business services (e.g., law, consulting, engineering) and the rest, we find the former comprise $16 \%$ of firms with almost $60 \%$ of employees being graduates. In comparison this is $20 \%$ in the remaining $84 \%$ of services, which includes much more traditional activities like retail, wholesale etc.

22 The figure plots a 50-bin scatter for each of these sectors, with the linear regression line coefficients reported below the graph. Because of Census and INEGI disclosure rules individual data points cannot be disclosed.
} 
These relationships are confirmed within the Mexican data in a firm-level regression with $\ln ($ employment) as the dependent variable in Table 2. Consistent with Figure 3, column (1) shows that the coefficient on management in services is 1.6, while for manufacturing, it is significantly higher at $2.752(2.752=1.622+1.131)$. Column $(2)$ controls for education, region, industry, and time dummies and again finds the same ranking. Columns (3) through (6) repeat the analysis but split the samples into manufacturing and services and confirm the result of a stronger management-size relationship in manufacturing.

Another piece of evidence pointing towards the existence of misallocation in Mexico, especially in the services sector, is the relationship between management and firm age that we again show separately for US manufacturing, Mexican manufacturing, and Mexican services in Figure 4. Here, each age bin plots the average management score in deviations from each sample mean. Dynamic reallocation implies older firms should have higher management scores as the poorly managed firms should have been selected out at a younger age (or improved their management quality as time passes). Consistent with this, we see in Panel (a) that older American manufacturing firms have higher management scores, with the implied "shakeout" being particularly strong over the first five years. Similarly, there is an upwards slope in Panel (b) between management and age in Mexican manufacturing firms, albeit slightly weaker than in the US. In principle, this could also be due to learning as firms get better with age. What is striking is that in Panel (c), there is actually a negative gradient between management scores and age in Mexican firms in the service sector. Since it is unlikely that service firms have nothing to learn, this seems more likely to be signaling the absence of strong selection effects in Mexican services.

This is consistent with Hsieh and Klenow (2014), who argue that the size-age relationship is an indicator of misallocation, as in services, clearly, market selection is not effectively leading inefficiently managed (smaller) firms to exit across their life cycle. ${ }^{23}$

\footnotetext{
${ }^{23}$ This is also consistent with the observation that Levy (2018) makes about observing higher misallocation in the services sector as the productivity gap for firms within this sector is higher than in manufacturing. Regressing the TFP index over age groups, productivity appears to decrease over age groups, especially in the case of services, starting at 16 years of age. In the case of manufacturing, mostly non-significant coefficients are observed.
} 
A further piece of evidence is shown in Figure 5. If selection is important, we would expect that the variance of management across firms falls in older cohorts as the worst managed tail is selected out. This is certainly the case in US manufacturing in Panel (a) where the standard deviation falls sharply in older age bins. By contrast, in Panel (b) for Mexican manufacturing, the spread of practices within each age bin is not decreasing. Finally, in Panel (c) for Mexican services, the spread of management practices is actually rising with age.

To summarize, we have shown that despite a similarly strong association of productivity with management across countries (US vs. Mexico) and sectors (manufacturing vs. services), the reallocation of economic activity to better managed firms appears (i) weaker in Mexico than in the US and (ii) weaker in Mexican services than in Mexican manufacturing. We see this when looking at the size-management correlation and the relationship between firm age and the first moment (mean) and second moment (variance) of management.

We also consider some more dynamic indicators of misallocation in Online Appendix Table A4. ${ }^{24}$ In the first two columns of Panel (a), we see that employment growth is higher for firms with greater management scores for both manufacturing and services, but it is significantly higher for manufacturing (test of the difference $\mathrm{p}$-value $=0.008$ ). Similarly, the last two columns indicate that better-managed firms are significantly less likely to exit, but this relationship is stronger for manufacturing than services ( $p$-value $=0.028)$. Panel $(b)$ shows that there are similar patterns when using productivity instead of management, but the relationship is weaker (e.g., the difference is not statistically significant for employment growth). ${ }^{25}$ These dynamic effects corroborate the selection mechanisms underlying our interpretation of Figures 4 and 5.

\section{III.3 Misallocation and Output Losses}

How much does misallocation matter? We consider a simple semi-parametric re-weighting approach in the style of DiNardo, Fortin, and Lemieux (1996, "DFL"). Imagine a

\footnotetext{
${ }^{24}$ The description of how exit is defined and the characteristics of exit between the two waves of the survey are shown in Online Appendix Figure A2.

${ }^{25}$ These results are robust to including labor productivity and management simultaneously (e.g. the coefficient on management in column (1) falls from 0.16 to 0.12 , but remains highly significant) and alternative definitions of exit.
} 
counterfactual where we "assign" to firms in the services sector the same degree of reallocation as Mexican manufacturing by fixing the firm management score distribution, but reallocating job shares across this distribution to the same extent as exists in manufacturing. Intuitively, since more employment is allocated to the relatively better-managed firms in the sector, this will raise the size-weighted average management score.

To implement this, we split the services sector into twenty quantile bins and calculate the fraction of employment in the twenty quantiles of the manufacturing firm distribution. The unweighted mean management in the service sector is 0.446 , which rises to 0.520 when weighted by firm employment size in services. The difference of 0.074 shows substantial reallocation towards better-managed firms in the service sector, albeit less so than in manufacturing. ${ }^{26}$ Re-weighting by manufacturing shares implies an increase in the weighted management score in services of 0.039 (from 0.520 to 0.559 ). Using results from column (1) of Table 1, such an increase of management is associated with an increase in labor productivity of $4.5 \%$ or (using the last column of Table 1) an increase in TFP of $2.2 \%$. These might seem like small amounts, but consider that the GDP of the Mexican service sector was US $\$ 762$ billion in 2019 . This implies a growth in output of between $\$ 34.2$ and $\$ 16.7$ billion due to reallocation, which is non-trivial.

\section{Misallocation in Mexico: competitive frictions and wedges}

Our results indicate that frictions and wedges are important in Mexico. In this section, we consider some sharper tests by using more direct measures of these frictions.

\section{IV.1 Proximity to the US Border}

\section{Why proximity matters (for manufacturing firms)}

One striking finding in the data is the importance of proximity to the US for the management practices in Mexican manufacturing firms. In particular, Panel (a) of Figure 6 highlights how

\footnotetext{
${ }^{26}$ The equivalent increase between unweighted and size-weighted management mean is 0.091 in manufacturing.
} 
the US bordering states, which contain maquiladoras - the Mexican firms particularly focused on US exports - have the highest management scores.

There are several reasons why proximity to the US might matter. Our main hypothesis is that being closer to Mexico's main export market will strengthen competitive pressure on Mexican firms, raising their management quality. In other words, proximity reduces market frictions, raising management through a selection effect (the worst managed firms exit) and potentially an incentives effect (e.g., fear of losing some or all market share increases managerial effort). An implication of this hypothesis is that proximity should matter much more for firms that are more exposed to international trade with the US. For example, it should be much stronger for manufacturing firms (which generally trade internationally) than for service firms (who generally trade domestically). A corollary of this is that within manufacturing, the proximity effect should be more important for export-intensive industries compared to those that do not.

An alternative hypothesis on why proximity might matter for management is that being closer to the US raises management through learning. This might be because of faster flows of information on managerial best practices, and/or through the managerial labor market with American managers working in Mexican firms. Note that this story is based primarily on labor markets that are geographical in nature - there is no obvious reason why it should be different for sectors that are more or less exposed to trade. We shall test this idea directly by looking for heterogeneity in the proximity to the US effect across industries with different degrees of international exposure to trade.

A third hypothesis, popular in international economics, is that higher trade with the US could benefit Mexican firms through the use of higher-quality intermediate inputs (e.g., De Loecker et al., 2016). Consistent with this, we show that all our proximity results do also raise productivity. But it is less clear why better intermediate inputs would raise management quality. ${ }^{27}$ This is one reason why having access to management data is an advantage over just using productivity data: it enables us to help disentangle the mechanisms through which trade effects on productivity may be occurring.

\footnotetext{
${ }^{27}$ Service inputs could help as discussed in the previous mechanism - e.g., easier access to the managerial labor market or better consultants. Trade and management are discussed in more detail in Bloom et al. (2018).
} 
In Panel (b) of Figure 6, we reproduce Panel (a) for services. In contrast to manufacturing, areas near the US do not have systematically higher management scores. Instead, the service sector shows the highest management scores in locations close to the largest Mexican cities (i.e., Mexico City, Guadalajara, Querétaro, and Monterrey). One interpretation of this, which we will pursue in the next subsection, is that local market size and competition is much more important for service firms (who typically sell non-tradeable outputs and are more locally oriented) than manufacturing firms.

\section{Evidence on proximity}

To measure the geographical proximity of Mexican firms to US markets, we calculate the drive time, measured in hours, between the municipality where the firm is located and the closest of the three main border crossings between Mexico and the US (i.e., Tijuana, El Paso, and Nuevo Laredo). Given that the exact location of each firm is not disclosed for confidentiality reasons, we calculate the centroid of each municipality and then calculate the time between this and each of the three border crossings. ${ }^{28}$

Our results indicate that the relationship between management and proximity differs across these two broad sectors, as the drive time to the border matters for firms in manufacturing, but not for those in services. As shown in Figure 7, where we present the CDFs of management across groups of drive time to the border, management score is higher among firms with a drive time to the border below the median, that is, closer to the border. ${ }^{29}$

Figure 8 Panel (a) shows that although there is a positive relationship between firm size and management, the gradient is steeper for firms closer to the border, indicating stronger forces of selection. The same is not true for services, where the slope is similar regardless of the distance to the US border. This suggests proximity to US markets increases both the mean management score and its covariance with size for Mexican manufacturing firms.

We show these results in a regression framework in Table 3. Column (1) for manufacturing firms shows that for firms located close to the US border, management is positively and

\footnotetext{
${ }^{28}$ We use Open Street Map to calculate the distances by using the command "osrmtime" in STATA. Similar results obtain from using GoogleMaps. An analysis of the municipalities is shown in Appendix D.

${ }^{29}$ Figure 7 is weighted by employment size. In Online Appendix Figure A10, we present the unweighted results, which are very similar.
} 
highly significantly related to size (as usual). However, we also identify a significantly positive coefficient on the interaction between management and proximity to the border, indicating that the covariance between size and management is much stronger for firms closer to the border. In column (2), we repeat the same specification for service firms which shows a positive relationship between size and management, but no significant interaction with proximity. This is a placebo test, and is consistent with our priors that distance to the US border should not matter for service firms, whose outputs are generally non-tradable.

Column (3) of Table 3 subjects the results to a tougher test. If it really is the closeness to the US export market which drives the results in column (1), we would expect the interaction to be stronger for export-intensive industries. Industries that are not export intensive are more like the service firms of column (2). We build a NAICS-6 digit industry-level indicator of the export share of sales and include the triple interaction of an industry level variable of export intensity with the management*proximity variable (as well as the pairwise interactions). Consistent with our main hypothesis, there is a positive and (weakly) significant coefficient on this triple interaction.

Online Appendix $\mathrm{C}$ investigates a number of robustness tests. For example, we drop all firms owned by foreign companies and further control for interactions between proximity and market size with other variables correlated with management (capital, share of white-collar workers, and education), and the results do not materially change. We also show how closeness to the US border affects unweighted average management practices (reflecting selection on the extensive margin) as shown in Figure 7 as well as discontinuity designs of being right at the border.

\section{IV.2 Local market size}

We have established that the distance to the US market is a factor that matters for management practices of Mexican manufacturing companies, and interpreted this as reflecting competitive pressures from the integration with the larger and more demanding US market. An implication of this hypothesis is that for service sector firms, whose competition is mainly domestic, it should be the size of the local market that influences managerial 
practices. In the presence of sunk costs of entry, a larger market size can sustain more firms and so engender more local competition (for example, see Bresnahan and Reiss, 1991; Syverson, 2004, and Aghion et al., 2008).

We measure market size at the level of metropolitan areas by population density multiplied by average income. Figure 9 shows that local market size does matter for services firms but does not for manufacturers (indeed, the relationship is reversed for manufacturing firms). ${ }^{30}$ As shown in Panel (b) of Figure 10, market reallocation appears to improve with market size for services firms, but is not observed for manufacturing firms.

We put these results in a regression framework in the last two columns of Table 3 . In the final columns for services, the interaction between market size and management is positive and significant, suggesting greater pressures for reallocation in the denser cities. By contrast, in column (4), this interaction is insignificant for the manufacturing sector. ${ }^{31}$

We subjected these results to many robustness tests in Online Appendix C. There, we show that there is also a relationship of density with unweighted management suggesting selection on the extensive margin. We also show that the results are robust using alternative measures of city size, productivity measures instead of management, and dropping very large cities like Mexico City and Nuevo Leon.

\section{IV.3 Institutional Frictions and misallocation}

As Restuccia and Rogerson (2017) argue, misallocation can be the result of different types of distortions (wedges), which can be divided into three groups. First, statutory distortions, including the regulatory framework. Second, discretionary distortions made by the government, which include the case of government corruption. Finally, there are the market frictions that we covered in the previous sections. These distortions not only contribute to the misallocation of resources, but also have potentially large effects on the productivity distribution. These distortions affect how productivity relates to size, particularly in

\footnotetext{
${ }^{30}$ Figure 9 is weighted by employment size, but the results are qualitatively similar if unweighted.

${ }^{31}$ These results are robust to dropping all controls and/or using continuous variables instead of the binary indicators. For example, the interaction of management with a continuous drive time measure in an equivalent of column (1) of Table 3 , has a coefficient of -0.064 and a standard error of 0.017 .
} 
developing countries, which, consequently, tend to exhibit a larger proportion of smaller firms (Bento and Restuccia, 2017).

One wedge that deserves attention for Mexico's case, as Levy (2018) and Misch and Saborowski (2020) argue, is contract enforcement, which is a factor that, according to Boehm and Oberfield (2020), can affect value chains, primarily through the costs of sourcing inputs. We test the relationship of misallocation with this wedge in a regression framework in column (1) of Table 4 by using information from the National Survey on Regulatory Quality and Government Impact on Enterprises (ENCRIGE) 2016. As shown in the table, firms in the top $10 \%$ of municipalities with contract enforcement problems have a lower slope of $\log ($ employment) on the management score. This indicates that, in the presence of poor regulatory frameworks, better-managed firms tend to be relatively smaller.

Second, we test the case of high levels of crime. As noted by Dell et al. (2019), violence in Mexico has escalated in the past decade. In 2017, Mexico was ranked as the second deadliest conflict zone in the world. Crime can affect business operations, investment, and growth, as it increases costs for firms due to the need to invest in crime prevention, represent direct losses, alter hours of business operation, and impact behavior to hide revenues. According to the National Survey of Business Victimization (ENVE in Spanish), one-fifth of firms were forced to reduce their hours of operations due to crime. Considering the prevalence of crime in Mexico, we analyze firms located in municipalities with high crime (top 10\%) using administrative records of kidnapping, which often targets wealthy executives or their families, from the Ministry of the National System of Public Security. The results show that firms in municipalities with high levels of crime tend to have a weaker relationship between size and management, consistent with the hypothesis that crime contributes to misallocation. In column (2) of Table 4, the coefficient of the interaction between management and kidnapping is significantly negative.

Third, corruption is a pervasive problem in Mexico, as according to the Corruption Perception Index of Transparency International, Mexico is ranked in $130^{\text {th }}$ place out of 180 countries. Using information from ENGRIGE regarding the perceptions of government corruption, column (3) of Table 4 shows a negative and significant sign of the interaction between management and high corruption. 
Finally, we construct a composite business crime index merging information on contract enforcement, kidnapping, and corruption. To do this, we standardize each indicator (share of firms with contract enforcement problems, kidnapping rate, and share for firms that report corruption), take their average, and define the top 10\% municipalities based on this average composite indicator. ${ }^{32}$

For all of these business contract-problem and crime measures, as shown in the CDFs depicted in Figure 11, we observe that firms located in the top 10\% exhibit worse management practices. The regression results from Table 4 are confirmed in Figure 12, where we observe that firms in the top $10 \%$ of these contract-problem and crime measures have a flatter slope in the relationship between management practices and size.

In summary, we have provided evidence consistent with the hypothesis that institutional frictions such as contract enforcement, crime, and corruption all explain the higher level of misallocation in Mexico, by making it hard for well-managed firms to grow.

\section{Conclusions}

This paper analyzed management practices in a new manufacturing and services firm-level survey in Mexico. First, we confirm that more structured management is positively associated with superior firm performance (higher productivity, profitability, innovation, size, and exporting) in both the manufacturing and services sector. This is the first time that these relationships have been confirmed in a largescale survey also for firms in the services sector. Mexican management scores have a lower mean than their US equivalents and a greater dispersion. One explanation of this is that market frictions are higher in Mexico, particularly in services that are less exposed to international trade. We document that reallocation, as measured by the relationship between size and management quality (and firm age and management quality), is weaker in Mexican manufacturing than US manufacturing, and is weaker still in Mexican services. A counterfactual exercise indicates that improving market

\footnotetext{
${ }^{32}$ All results in Table 4 are robust to using other reasonable thresholds (e.g. using the top $5 \%$ instead of the top $10 \%$ of municipalities).
} 
reallocation in the Mexican services sector to the level we see in the manufacturing sector could raise GDP by US $\$ 34.2$ billion.

To investigate more deeply the factors that drive misallocation, we examine the relationship between firm size and management using several observable measures of frictions. First, we use insights from the trade literature and look at the role of market size. For manufacturing, proximity to the US (as measured by drive time between our Mexican firms and the US border) is likely to matter most. We found that for manufacturing firms (especially in exportexposed industries), the size-management relationship was particularly strong when this proximity was high. By contrast, for Mexican manufacturing plants in less export-exposed industries, there was a weaker effect of proximity, and for services firms, there was no effect. Instead, for Mexican service firms we found that local market competition mattered. Metropolitan areas with larger markets had a strong size-management relationship for service firms, but did not for manufacturers who tend to sell their goods beyond the limits of the local metropolitan area (i.e., nationally or internationally). Finally, we turned to institutional factors and found that the size-management relationship was weaker in areas with low contract enforcement, high perceived corruption and/or high crime.

These results imply that competitive and regulatory reforms in Mexico and other middleincome countries could have important effects on raising productivity, allocation, and material wellbeing. Making US market access worse through increasing border frictions, by contrast, will damage management, productivity, and wellbeing. 


\section{References}

Aghion, P., Bergeaud, A., Lequien, M., and Melitz, M. J. (2018). The impact of exports on innovation: Theory and evidence (No. w24600). National Bureau of Economic Research.

Anderson, S. J., Chandy, R., and Zia, B. (2018). Pathways to profits: the impact of marketing vs. finance skills on business performance. Management Science, 64(12), 5559-5583.

Asker, John, Allan Collard-Wexler, and Jan De Loecker. 2014. "Dynamic Inputs and Resource (Mis) Allocation.” Journal of Political Economy 122 (5): 1013-63

Aw, B. Y., Chung, S., and Roberts, M. J. (2000). Productivity and turnover in the export market: micro-level evidence from the Republic of Korea and Taiwan (China). The World Bank Economic Review, 14(1), 65-90.

Bandiera, O., Barankay, I., and Rasul, I. (2005). Social preferences and the response to incentives: Evidence from personnel data. The Quarterly Journal of Economics, 120(3), 917-962.

Bandiera, O., Barankay, I., and Rasul, I. (2007). Incentives for managers and inequality among workers: Evidence from a firm-level experiment. The Quarterly Journal of Economics, 122(2), 729-773.

Bandiera, O., Hansen, S., Prat, A., and Sadun, R. (2020). CEO behavior and firm performance Journal of Political Economy 128(4), 1325-1369

Bartel, A., Ichniowski, C., and Shaw, K. (2007). How does information technology affect productivity? Plant-level comparisons of product innovation, process improvement, and worker skills. The Quarterly Journal of Economics, 122(4), 1721-1758.

Bartelsman, Erik, Haltiwanger, John and Scarpetta, Stefano (2013) "Cross Country Differences in Productivity: The Role of Allocation and Selection" American Economic Review, 103(1) 305-334

Bento, P., and Restuccia, D. (2017). Misallocation, establishment size, and productivity. American Economic Journal: Macroeconomics, 9(3), 267-303.

Black, S. E., and Lynch, L. M. (2001). How to compete: the impact of workplace practices and information technology on productivity. Review of Economics and Statistics, 83(3), 434-445.

Bloom, N., Brynjolfsson, E., Foster, L., Jarmin, R., Patnaik, M., Saporta-Eksten, I., and Van Reenen, J. (2019). What drives differences in management practices? American Economic Review, 109(5), 1648-83.

Bloom, N., Eifert, B., Mahajan, A., McKenzie, D., and Roberts, J. (2013). Does management matter? Evidence from India. The Quarterly Journal of Economics, 128(1), 1-51.

Bloom, N., Floetotto, M., Jaimovich, N., Saporta-Eksten, I., and Terry, S. J. (2018b). Really uncertain business cycles. Econometrica, 86(3), 1031-1065.

Bloom, N., Manova, K., Van Reenen, J., Sun, S. T., and Yu, Z. (2018). Managing trade: evidence from China and the US (No. w24718). National Bureau of Economic Research.

Boehm, J., and Oberfield, E. (2020). Misallocation in the Market for Inputs: Enforcement and the Organization of Production. The Quarterly Journal of Economics, 135(4), 20072058.

Bresnahan, T. F., and Reiss, P. C. (1991). Entry and competition in concentrated markets. Journal of Political Economy, 99(5), 977-1009.

Brooks, W., Donovan, K., and Johnson, T. R. (2018). Mentors or teachers? Microenterprise training in Kenya. American Economic Journal: Applied Economics, 10(4), 196-221. 
Bruhn, M., Karlan, D., and Schoar, A. (2018). The impact of consulting services on small and medium enterprises: Evidence from a randomized trial in Mexico. Journal of Political Economy, 126(2), 635-687.

Buffington, Catherine, Andrew Hennessy and Scott Ohlmacher (2018) "The Management and Organizational Practices Survey (MOPS): Collection and Processing” Working Papers 18-51, Center for Economic Studies, U.S. Census Bureau.

Cai, J., and Szeidl, A. (2017). Interfirm relationships and business performance. The Quarterly Journal of Economics, 133(3), 1229-1282.

Cappelli, P., and Neumark, D. (2001). Do "high-performance" work practices improve establishment-level outcomes? ILR Review, 54(4), 737-775

Combes, P. P., Duranton, G., Gobillon, L., Puga, D., and Roux, S. (2012). The productivity advantages of large cities: Distinguishing agglomeration from firm selection. Econometrica, 80(6), 2543-2594.

De Loecker, J., Goldberg, P. K., Khandelwal, A. K., and Pavcnik, N. (2016). Prices, markups, and trade reform. Econometrica, 84(2), 445-510.

DiNardo, J., Fortrin, and Lemieux, T. (1996) "Labor Market Institutions and the Distribution of Wages: A Semi-parametric approach" Econometrica, 64(5) 1001-1044

Dell, M., Feigenberg, B., and Teshima, K. (2019). The violent consequences of trade-induced worker displacement in Mexico. American Economic Review: Insights, 1(1), 43-58.

Fryer Jr, R. G. (2017). Management and Student Achievement: Evidence from a Randomized Field Experiment (No. w23437). National Bureau of Economic Research.

Giorcelli, M. (2019) The Long-Term Effects of Management and Technology Transfers American Economic Review, 109(1): 1-33

Giroud, X. (2013). Proximity and investment: Evidence from plant-level data. The Quarterly Journal of Economics, 128(2), 861-915.

Goodwin, T. K., Martinez Licetti, M., Villaran, L., Gramegna Mesa, S.F. (2018). Promoting Competition in Local Markets in Mexico: A Subnational Application of the World Bank Group's Markets and Competition Policy Assessment Tool (English). Washington, DC: World Bank Group.

Gosnell, G., List, J., and Metcalfe, R. (2020). The Impact of Management Practices on Employee Productivity: A Field Experiment with Airline Captains. Journal of Political Economy. 128 (4) 1195-1233

Hamilton, B. H., Nickerson, J. A., and Owan, H. (2003). Team incentives and worker heterogeneity: An empirical analysis of the impact of teams on productivity and participation. Journal of Political Economy, 111(3), 465-497.

Higuchi, Y., Nam, V. H., and Sonobe, T. (2017). Management skill, entrepreneurial motivation, and enterprise survival: Evidence from randomized experiments and repeated surveys in Vietnam. Technical report. Nagoya City University

Higuchi, Y., Mhede, E. P., and Sonobe, T. (2019). Short-and medium-run impacts of management training: An experiment in Tanzania. World Development, 114, 220-236.

Holmes, T. J., and Schmitz Jr, J. A. (2010). Competition and productivity: A review of evidence. Annu. Rev. Econ., 2(1), 619-642.

Hsieh, C. T., and Klenow, P. J. (2009). Misallocation and manufacturing TFP in China and India. The Quarterly Journal of Economics, 124(4), 1403-1448.

Hsieh, C. T., and Klenow, P. J. (2014). The life cycle of plants in India and Mexico. The Quarterly Journal of Economics, 129(3), 1035-1084. Chicago

Huselid, M. A. (1995). The impact of human resource management practices on turnover, 
productivity, and corporate financial performance. Academy of Management Journal, 38(3), 635-672.

Karlan, D., Knight, R., and Udry, C. (2015). Consulting and capital experiments with microenterprise tailors in Ghana. Journal of Economic Behavior and Organization, 118, 281-302.

Lazear, E. P. (2000). Performance pay and productivity. American Economic Review, 90(5), 1346-1361.

Leibenstein, Harvey (1966), “Allocative Efficiency vs. X-Efficiency”, American Economic Review, 56 (3): 392-415

Levy, S. (2018). Under-Rewarded Efforts: The Elusive Quest for Prosperity in Mexico. InterAmerican Development Bank.

Lucas, Robert E. (1978) "On the Size Distribution of Business Firms" Bell Journal of Economics, 9(2), 508-523.

McKenzie, D., and Woodruff, C. (2013). What are we learning from business training and entrepreneurship evaluations around the developing world? The World Bank Research Observer, 29(1), 48-82.

McKenzie, D., and Woodruff, C. (2017) Business Practices in Small Firms in Developing Countries. Management Science, 63(9), 2967-2981.

Melitz, Marc (2003) "The Impact of Trade on Intra-Industry Reallocations and Aggregate Industry Productivity" Econometrica 71 (6) 1695-1725

Misch, F., and Saborowski, C. (2020). The Drivers and Consequences of Resource Misallocation: Exploiting Variation Across Mexican Industries and States. Economía 20(2) 61-96

Osterman, P. (1994). How common is workplace transformation and who adopts it? Industrial and Labor Relations Review, 47(2), 173-188.

Restuccia, D., and Rogerson, R. (2017). The causes and costs of misallocation. Journal of Economic Perspectives, 31(3), 151-74.

Roberts, J. (2018). Needed: More Economic Analyses of Management. International Journal of the Economics of Business, 25(1), 3-10.

Syverson, C. (2004). Market structure and productivity: A concrete example. Journal of Political Economy, 112(6), 1181-1222.

Van Reenen, J. (2011). Does competition raise productivity through improving management quality? International Journal of Industrial Organization, 29(3), 306-316.

Walker, F. A. (1887). The source of business profits. The Quarterly Journal of Economics (1886-1906), 265.

Zahler, A., Iacovone, L., and Mattoo, A. (2014). Trade and innovation in services: Evidence from a developing economy. The World Economy, 37(7), 953-979. 
Figure 1: Firm performance and management practices in Mexico
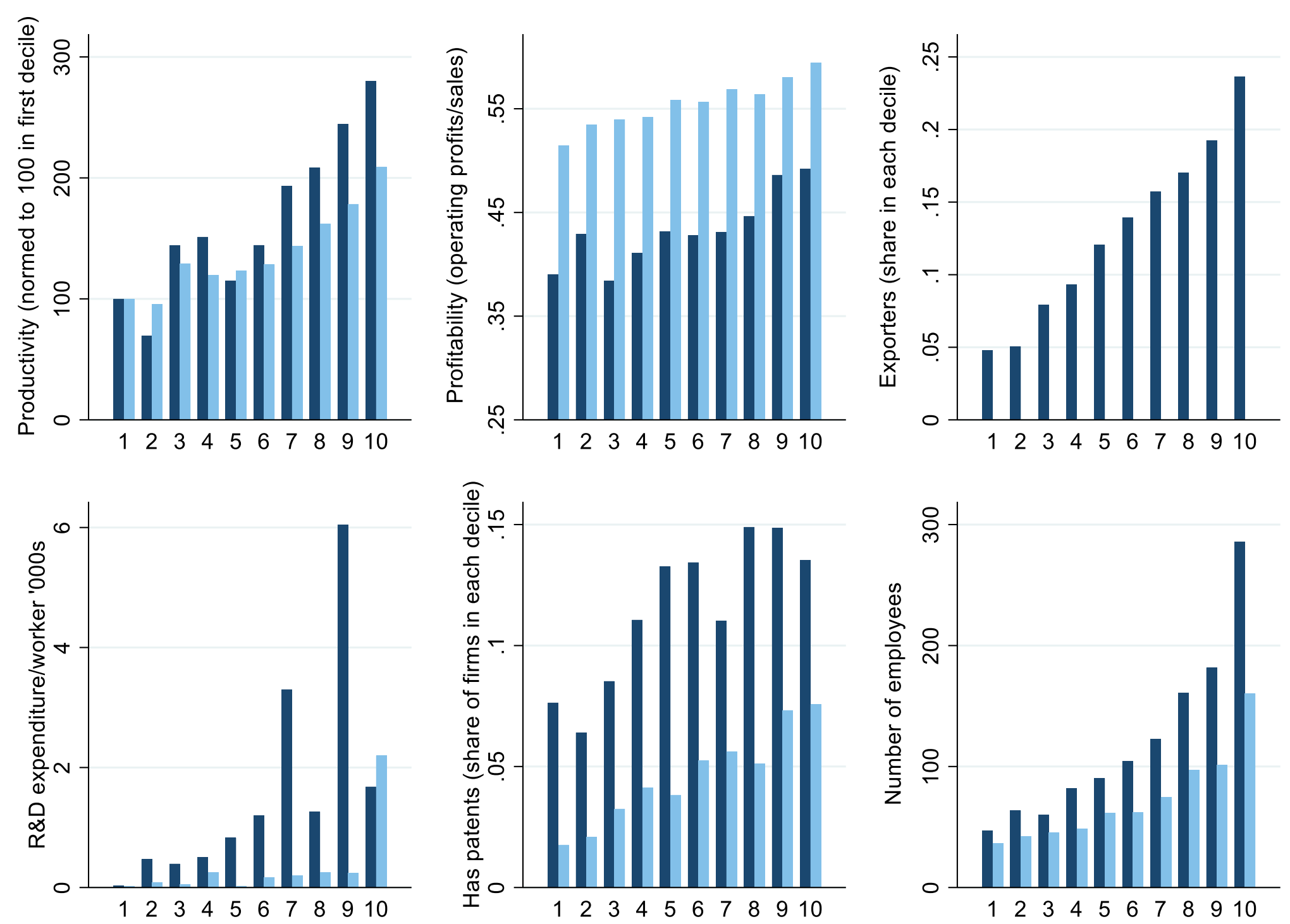

Manufacturing

\section{Services}

Notes: 6,643 observations on manufacturing firms and 17,684 observations on service firms.

Along the $x$-axis, we measure deciles of the management score. 
Figure 2: Management distributions across firms

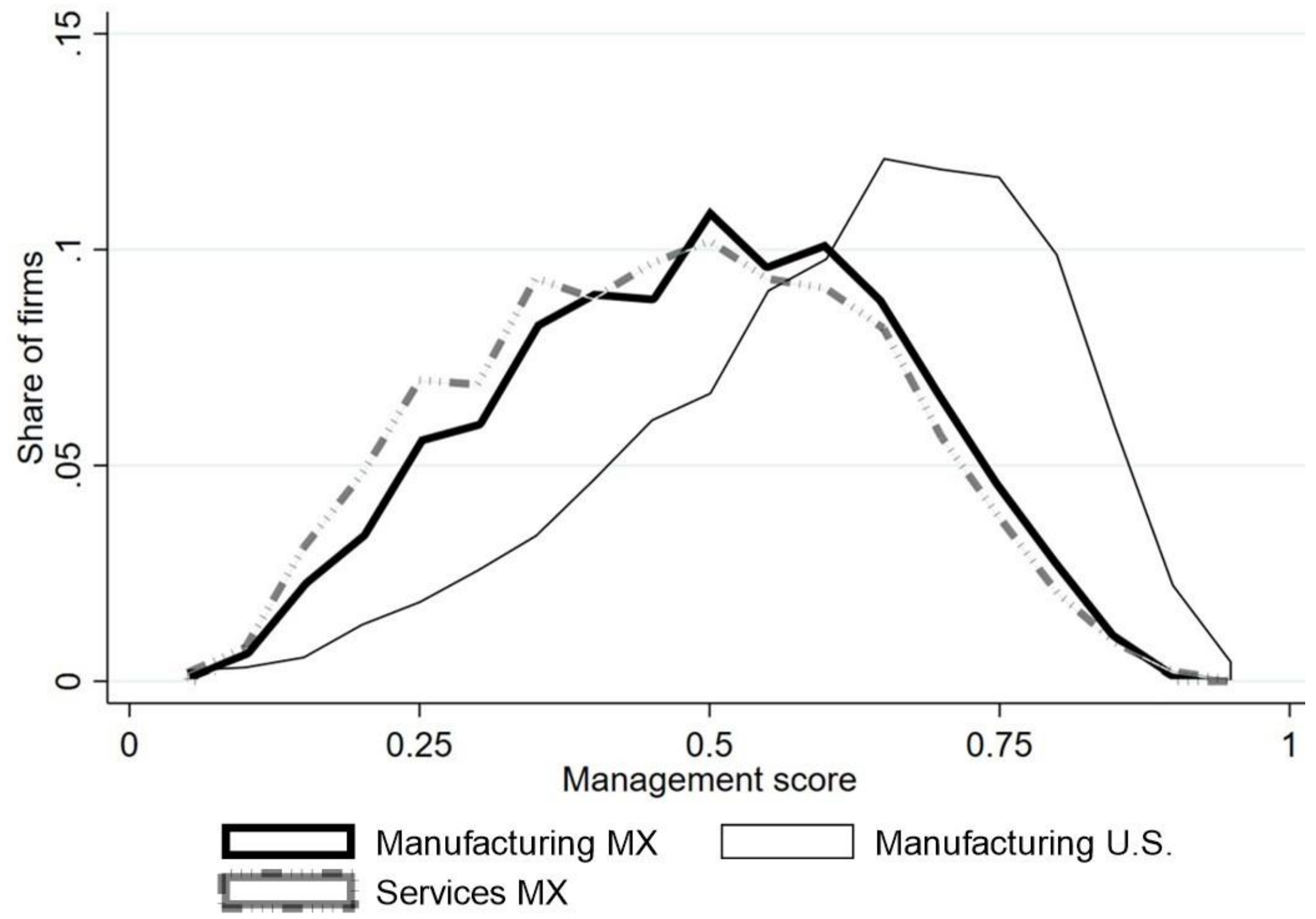

Notes: Management score distributions. 6,643 observations on Mexican manufacturing firms; 17,684 observations on Mexican services firms; 32,000 U.S. establishments from Bloom et al. (2019) 


\section{Figure 3: Reallocation - Manufacturing and Services 2014 and 2017}

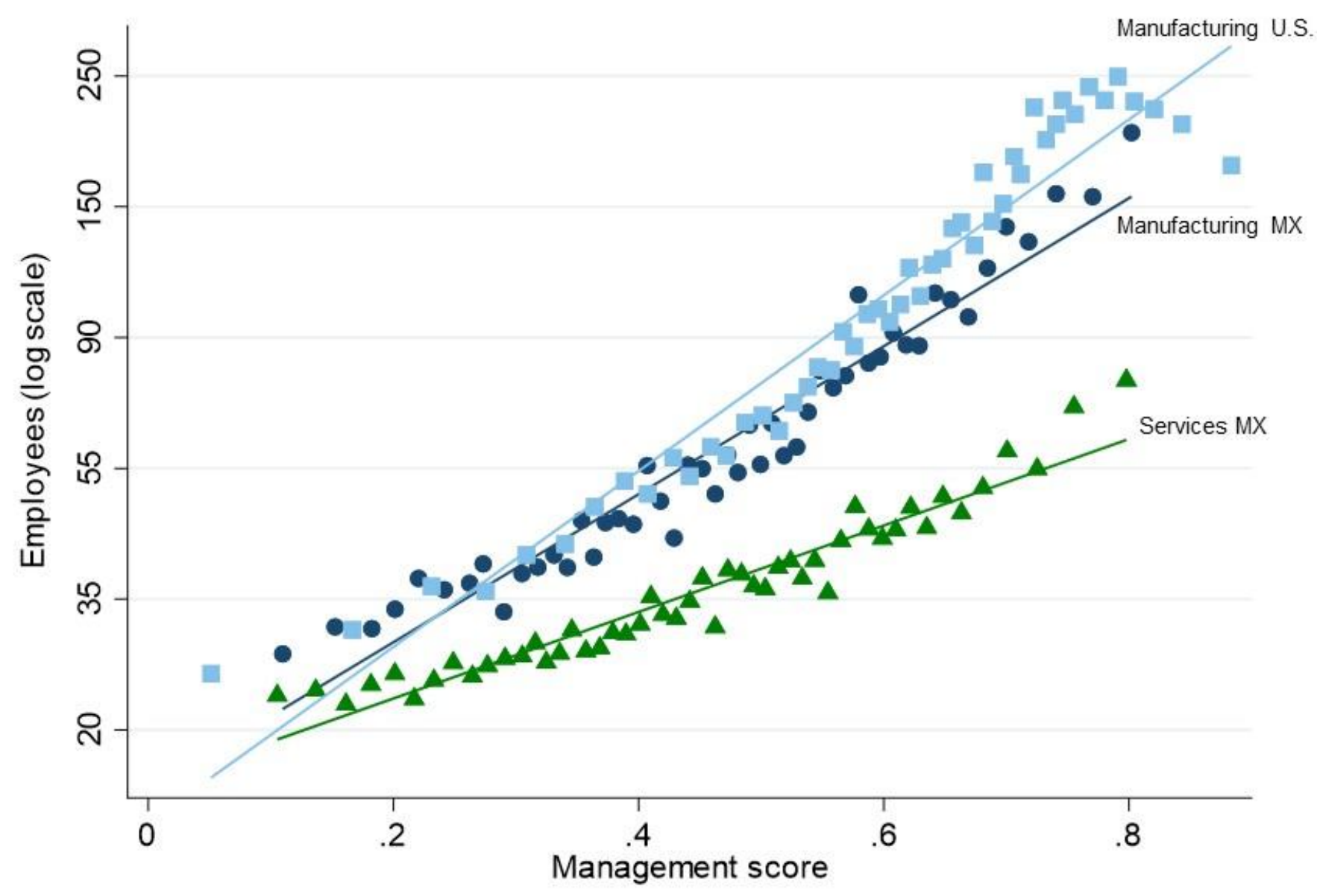

Slope

- Manufacturing MX 2.752*** (0.0837)

- Services MX $1.621 * * *$ (0.0475)

Manufacturing U.S. 3.360***

Notes: Bin scatter with 50 quantiles from Mexican and U.S. firm-level management data. Lines are OLS regressions for log(employment) on management scores. 6,643 observations on Mexican manufacturing; 17,684 observations on Mexican services; and 32,000 US manufacturing plants (Bloom et al., 2019). aggregated into 18,000 firms.

(0.123) 


\section{Figure 4: Age and Management score: mean}
(a) Manufacturing US
(b) Manufacturing Mexico
(c) Services Mexico
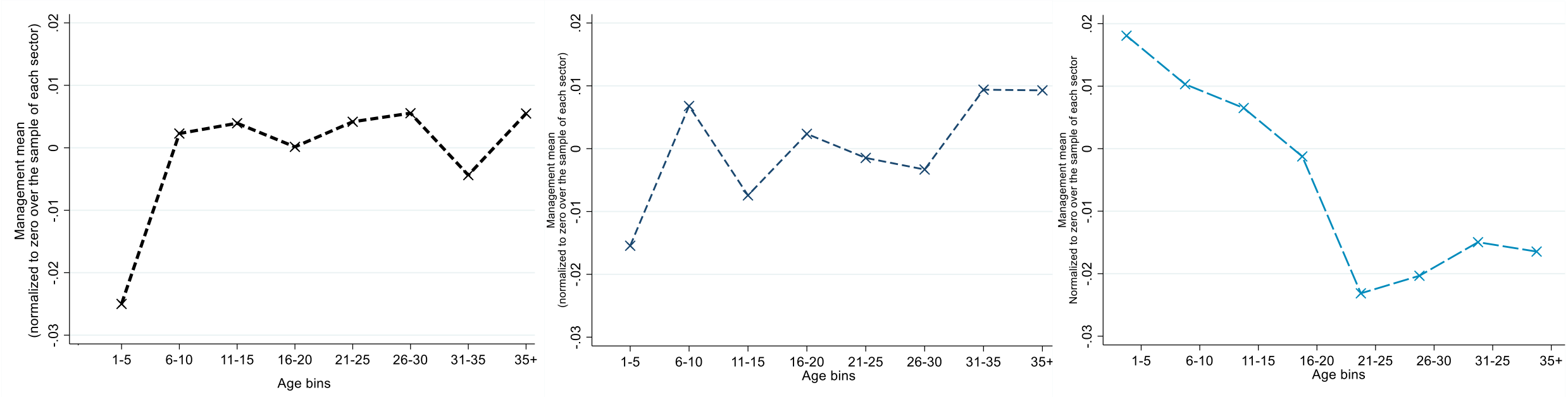

\section{Figure 5: Age and Management score: spread}

(a) Manufacturing US

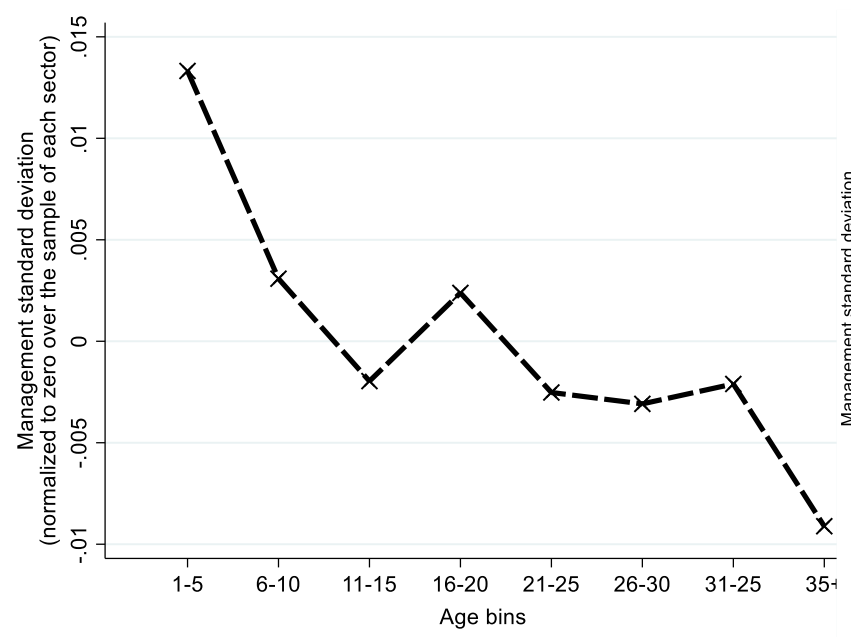

(b) Manufacturing Mexico

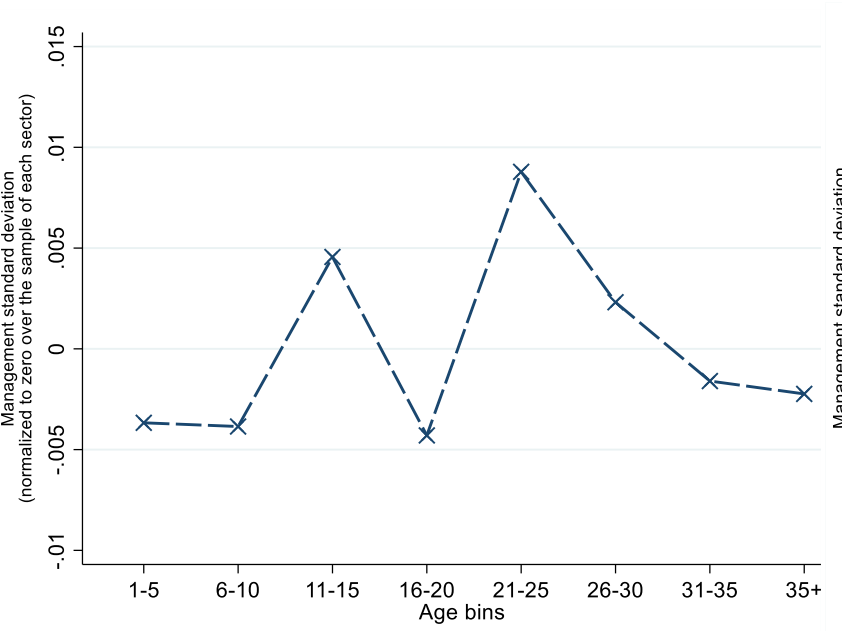

(c) Services Mexico

Notes: The mean and variance of management score as a function of firm age. 6,643 observations on Mexican manufacturing; 17,684 observations on Mexican services; and 32,000 US manufacturing plants. 


\section{Figure 6: Management scores by state}

(a) Manufacturing

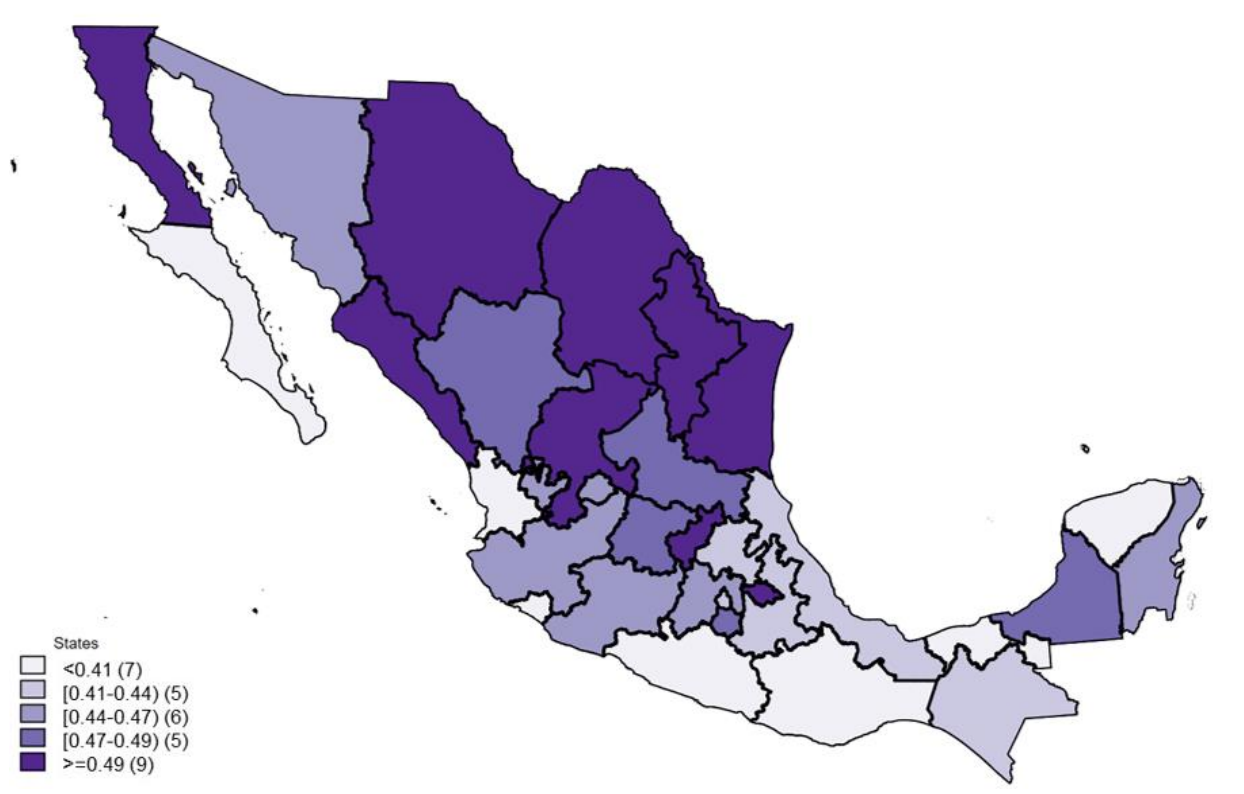

(b) Services

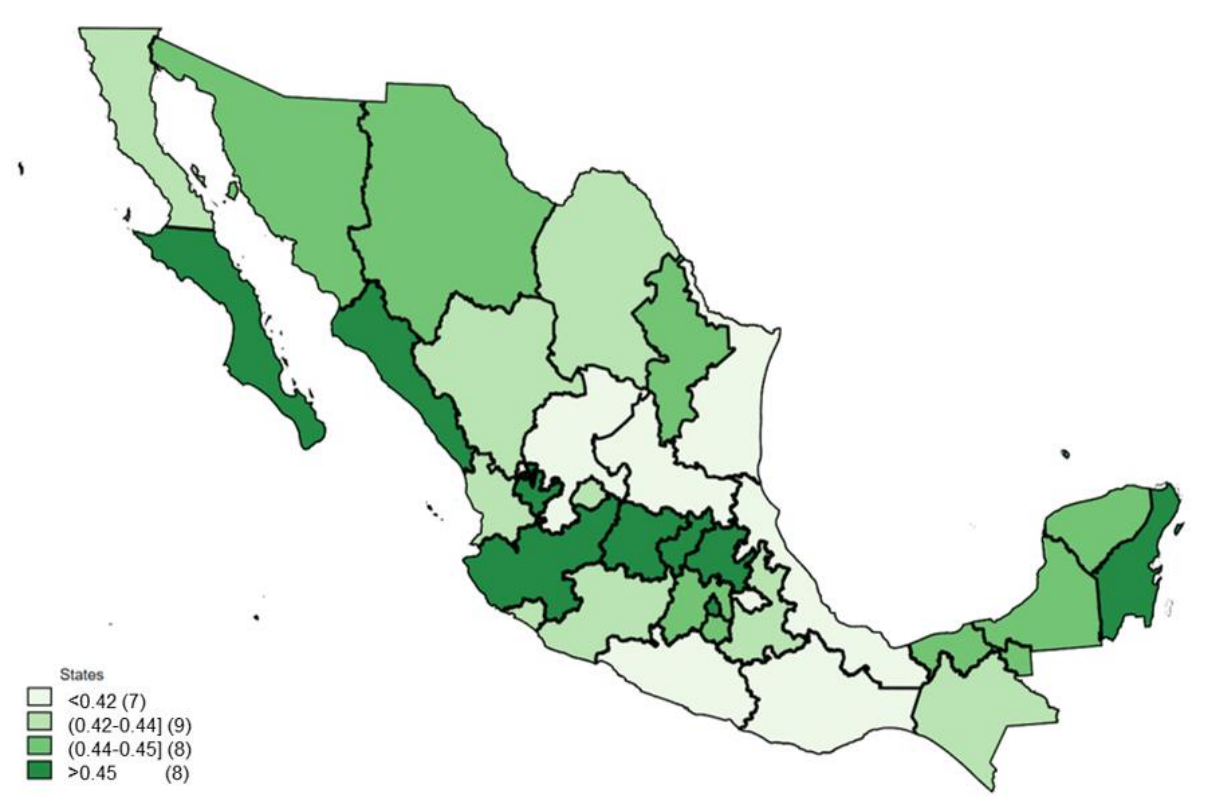

Notes: 6,643 observations on Mexican manufacturing; 17,684 observations on Mexican services. Authors' calculations with data from ENAPROCE 2015 and 2018, INEGI. 


\section{Figure 7: CDFs Management score drive time to the border}

(a) Manufacturing

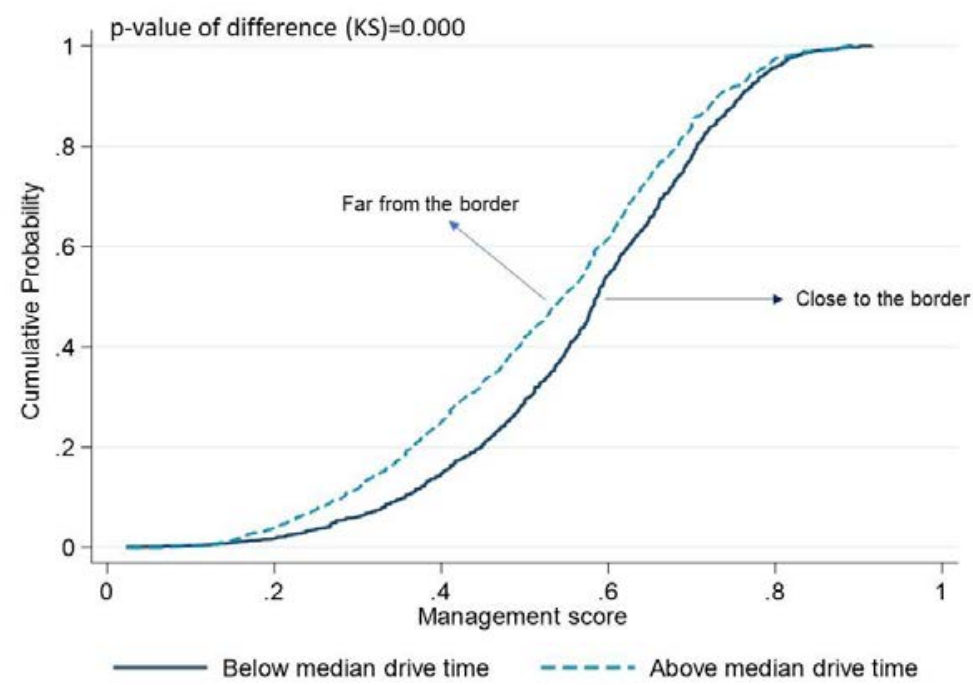

(b) Services

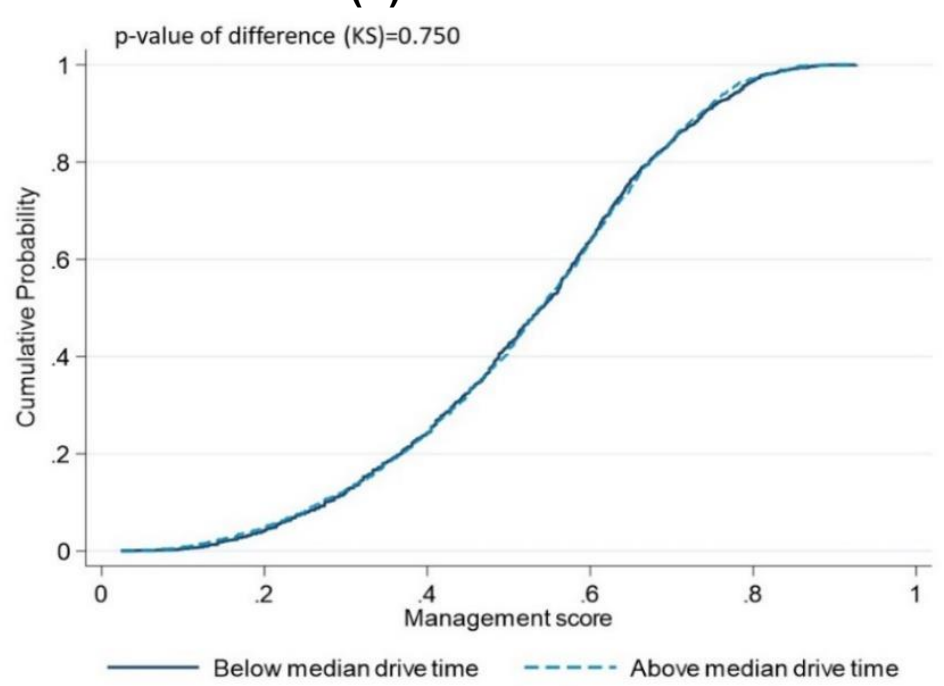

\section{Figure 8: Sources of misallocation: Drive time to the border}

(a) Manufacturing

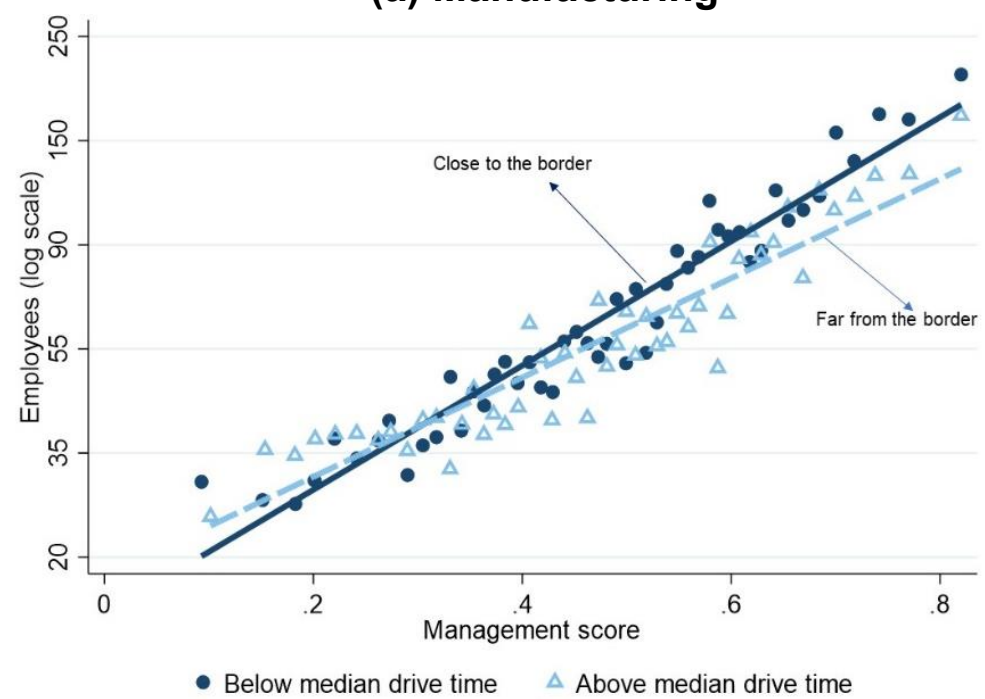

(b) Services

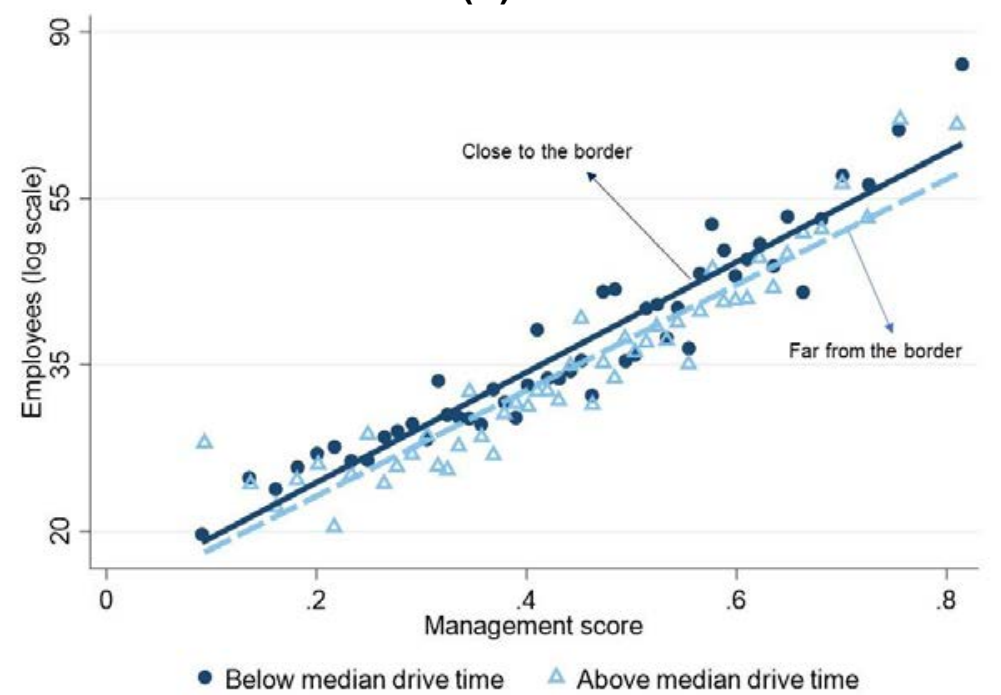

Notes: 6,643 observations on Mexican manufacturing; 17,684 observations on Mexican services. CDFs are weighted by firm employment size. 


\section{Figure 9: CDFs Management score market size}

(a) Manufacturing

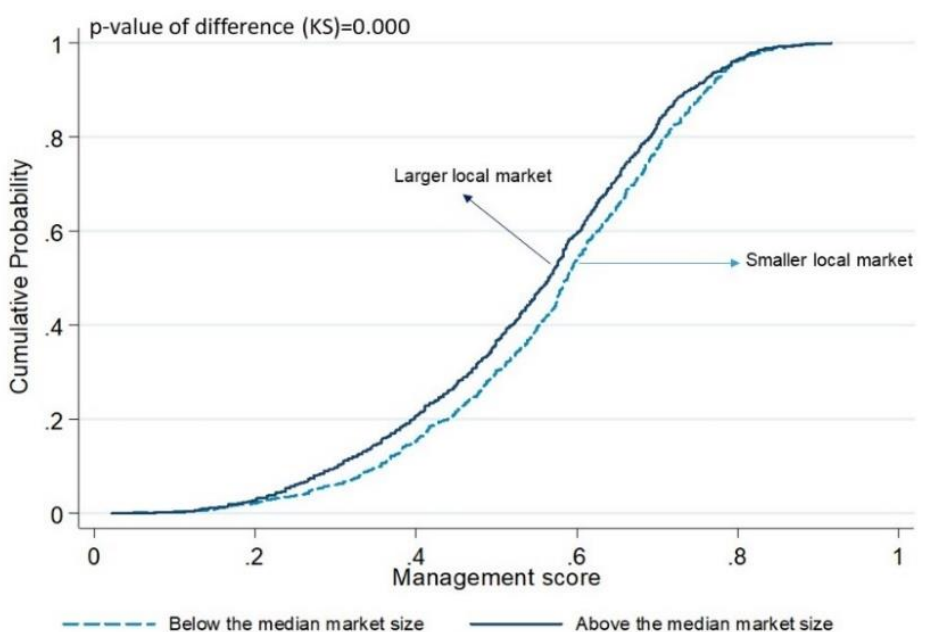

(b) Services

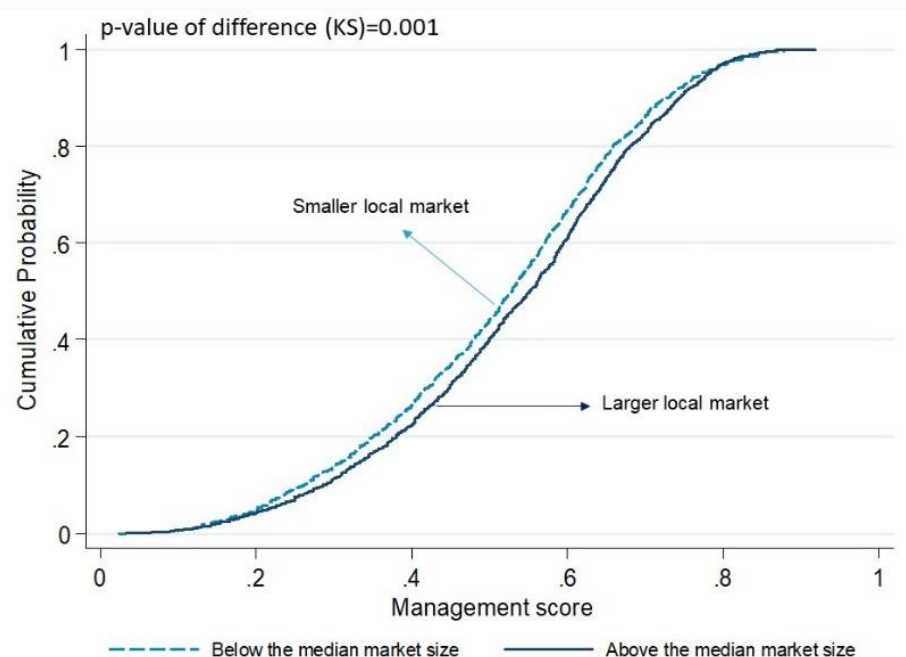

Figure 10: Sources of misallocation: market size
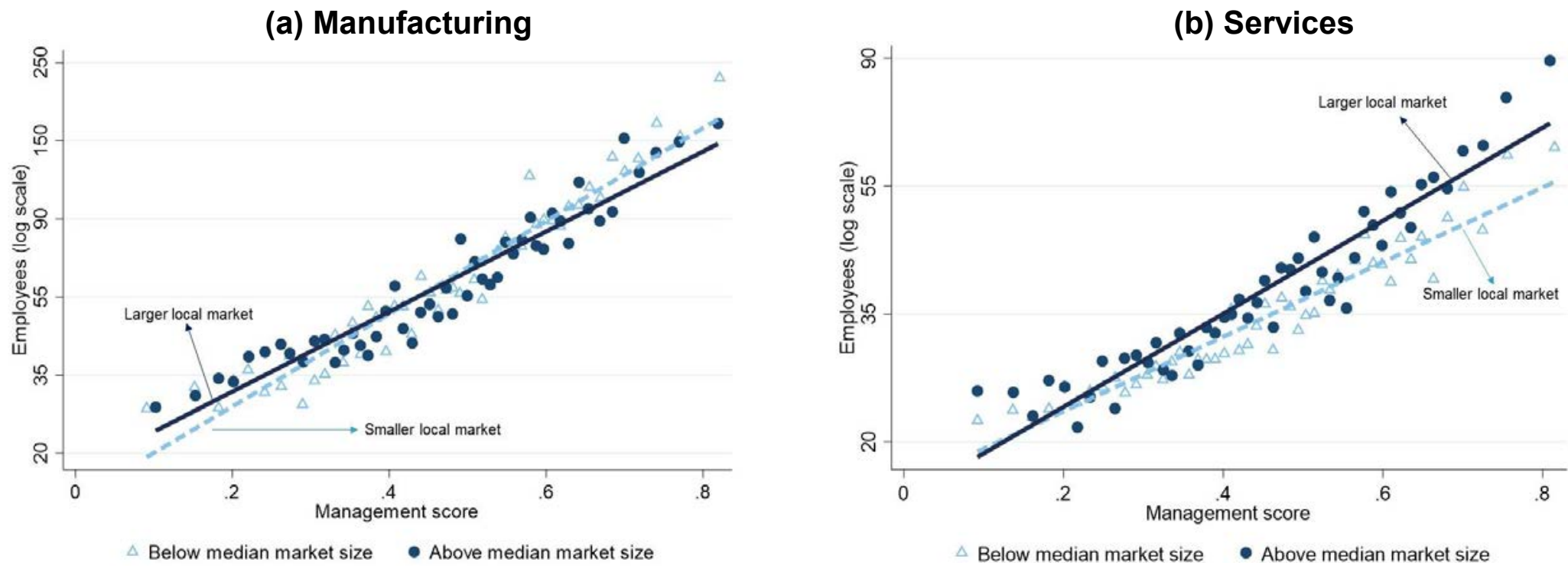

Notes: 6,643 observations on Mexican manufacturing; 17,684 observations on Mexican services. CDFs are weighted by firm employment size. 


\section{Figure 11: CDFs Management score according to institutional strengths}

(a) Contract enforcement problems

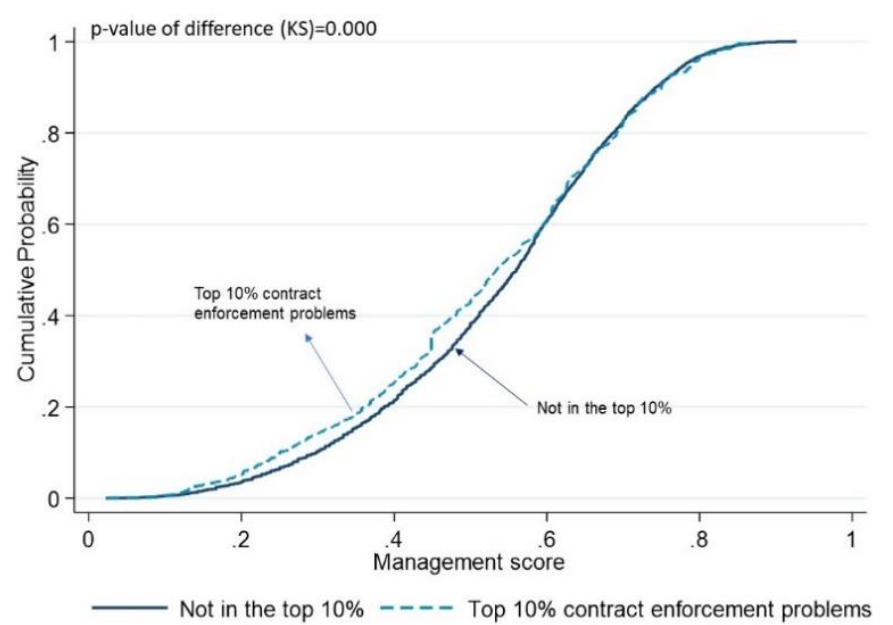

(c) Corruption

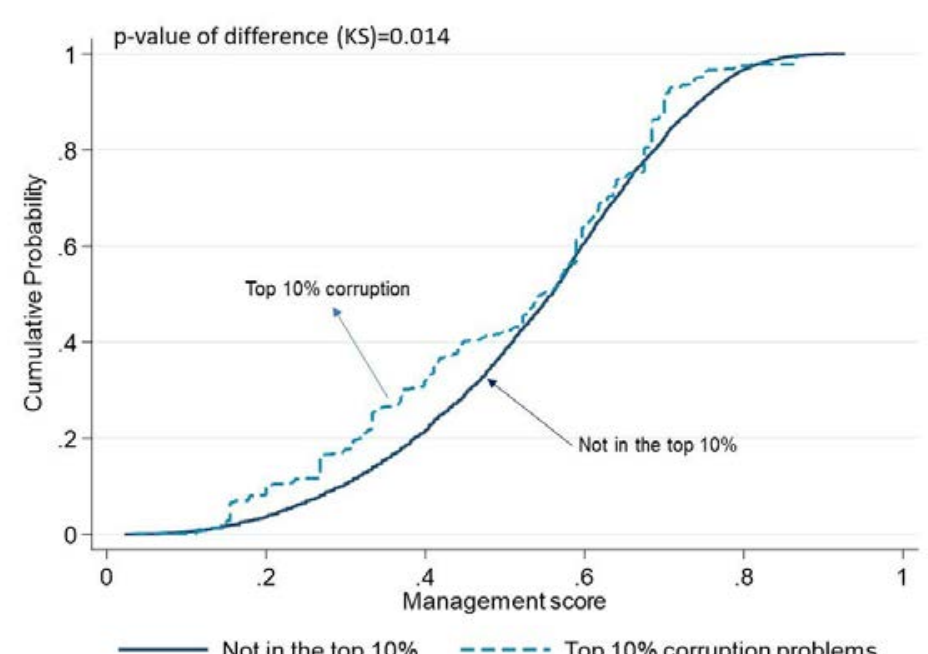

(b) Kidnapping

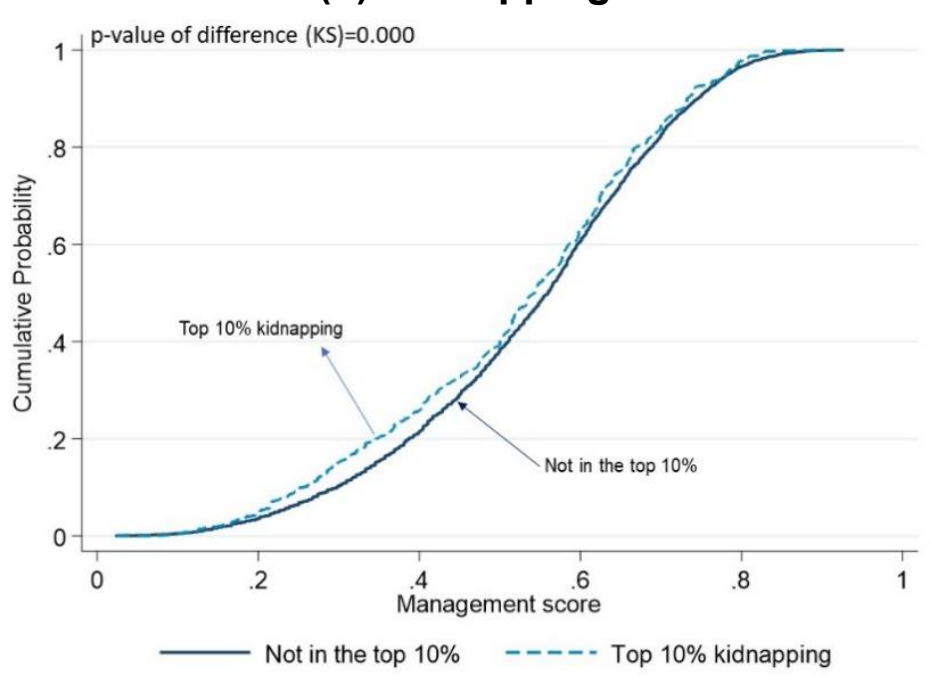

(d) Business crime composite index

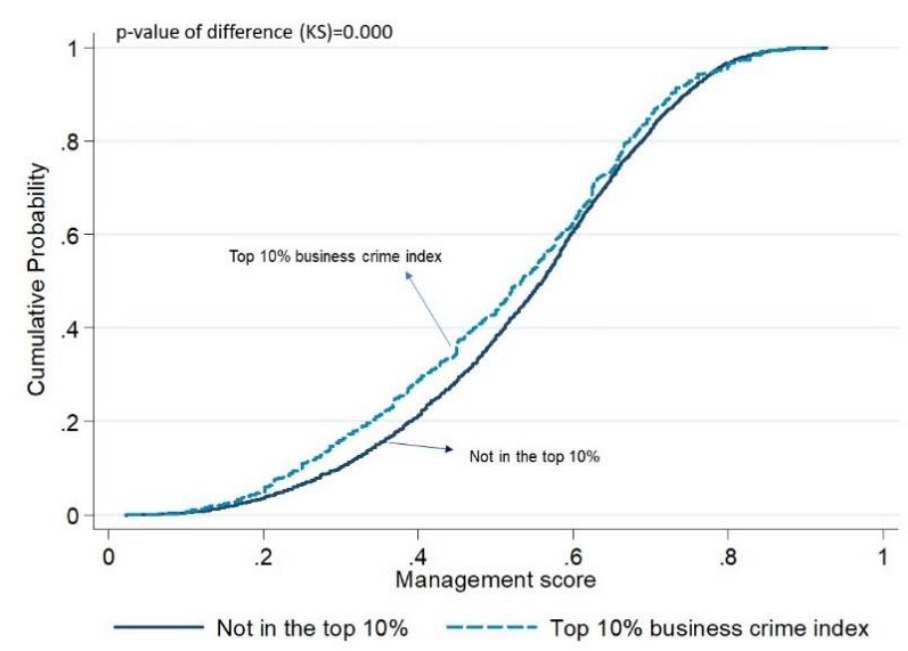

Notes: 6,643 observations on Mexican manufacturing; 17,684 observations on Mexican services. CDFs are weighted by firm employment size. 
Figure 12: Sources of misallocation: Institutional strengths

(a) Contract enforcement problems

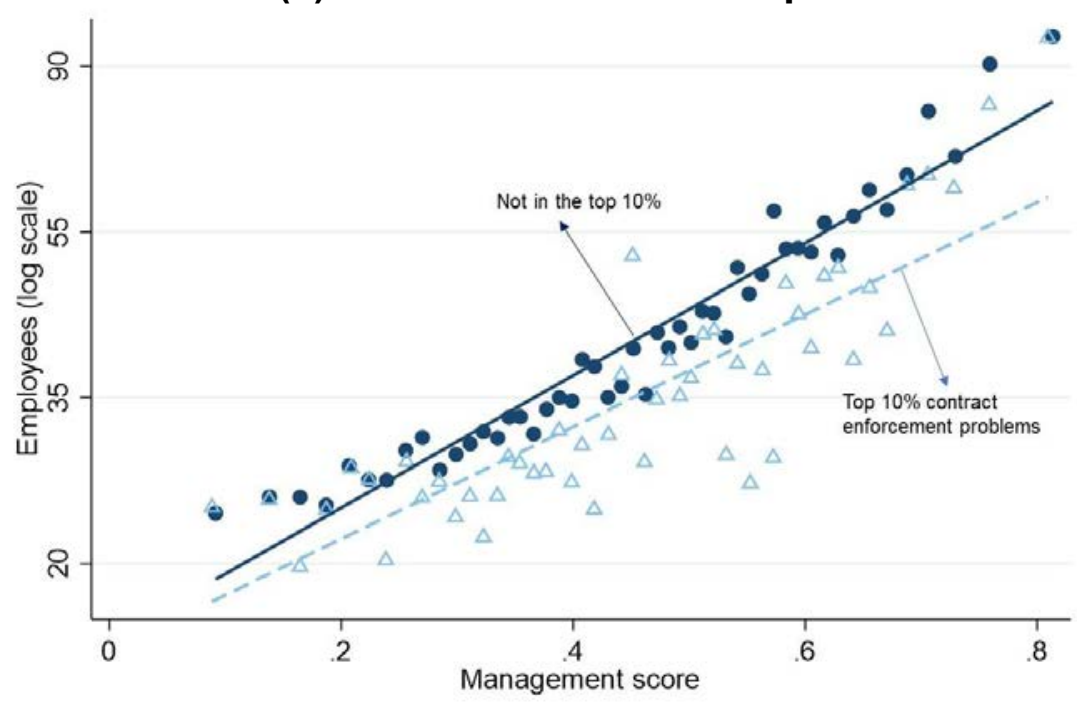

- Not in the top $10 \% \Delta$ Top $10 \%$ contract enforcement problems

(c) Corruption

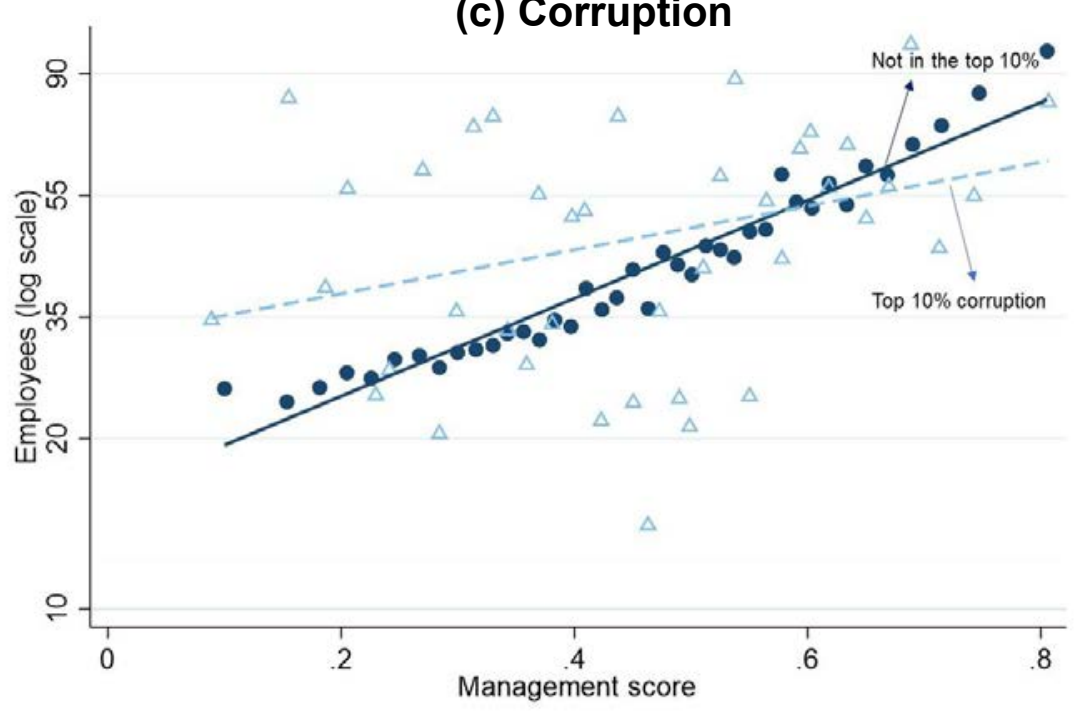

- Not in the top $10 \% \Delta$ Top $10 \%$ frequency corruption problems (b) Kidnapping

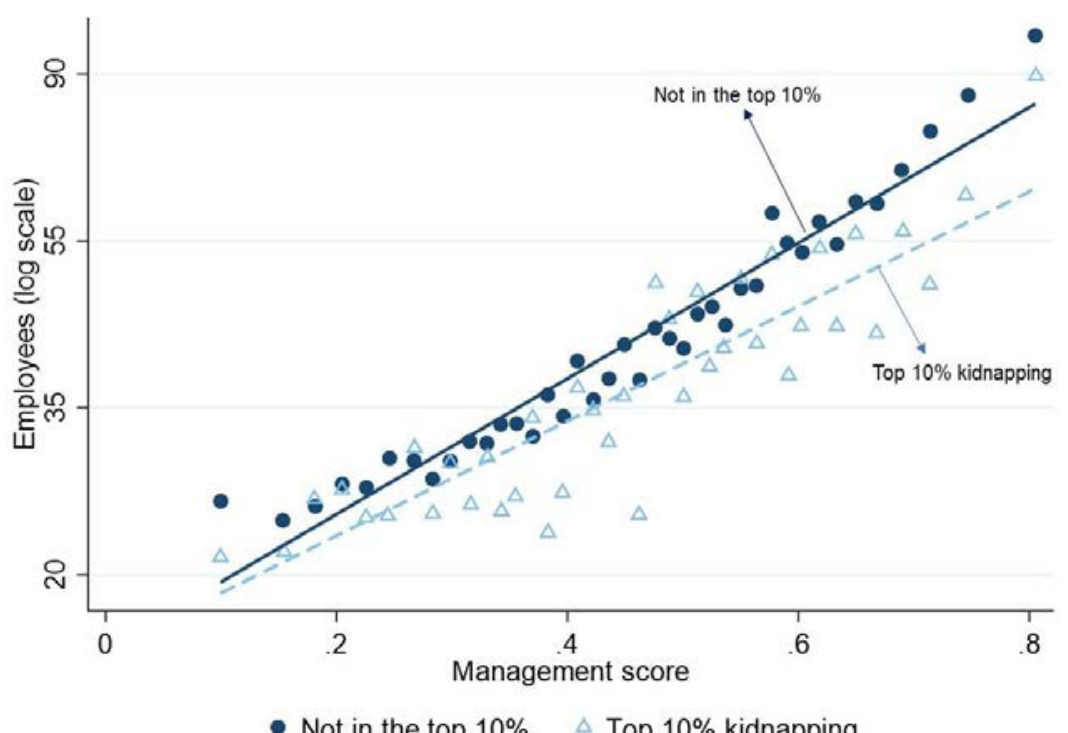

(d) Business crime composite index

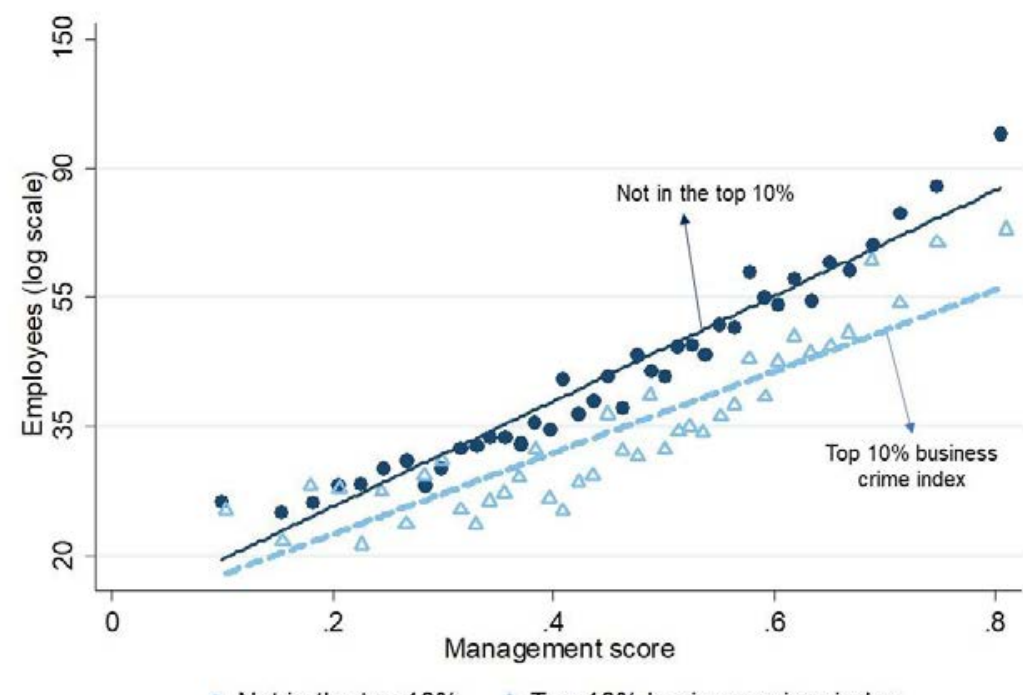

- Not in the top $10 \% \Delta$ Top $10 \%$ business crime index

Notes: 6,643 observations on Mexican manufacturing; 17,684 observations on Mexican services 
Table 1. Management Practices and Firm Performance

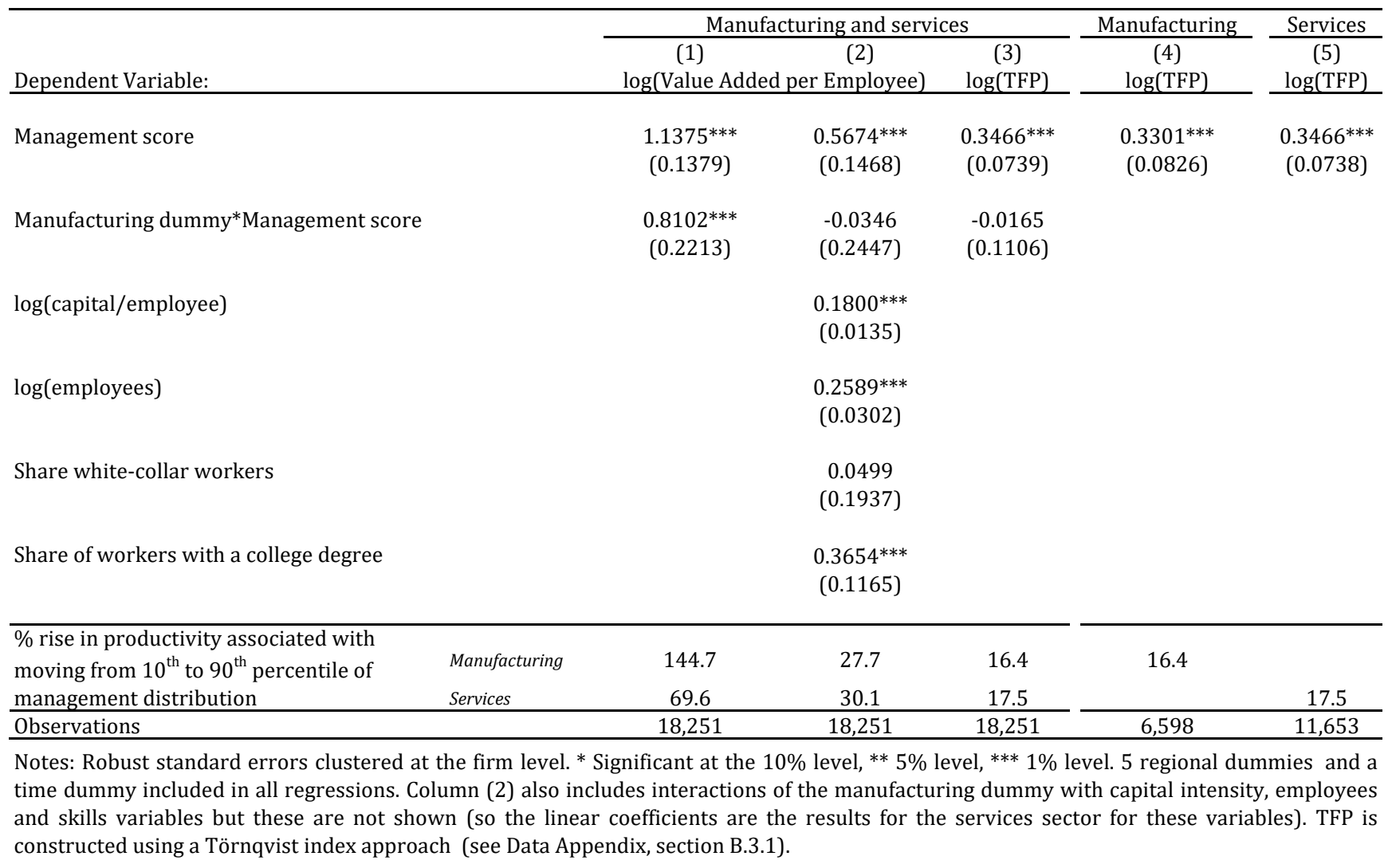


Table 2. Management Practices and Firm Size

\begin{tabular}{|c|c|c|c|c|c|c|}
\hline \multicolumn{7}{|c|}{ Pooled regression } \\
\hline \multirow[t]{2}{*}{ Dependent variable $=\ln$ (workers) } & \multicolumn{2}{|c|}{ Manufacturing and services } & \multicolumn{2}{|c|}{ Manufacturing } & \multicolumn{2}{|c|}{ Services } \\
\hline & (1) & (2) & (3) & (4) & (5) & (6) \\
\hline Management score & $\begin{array}{l}1.622^{* * *} \\
(0.0475)\end{array}$ & $\begin{array}{l}1.380^{* * *} \\
(0.0453)\end{array}$ & $\begin{array}{l}2.752^{* * *} \\
(0.0837)\end{array}$ & $\begin{array}{l}2.219^{* * *} \\
(0.0807)\end{array}$ & $\begin{array}{l}1.621^{* * *} \\
(0.0475)\end{array}$ & $\begin{array}{l}1.380^{* * *} \\
(0.0452)\end{array}$ \\
\hline Manufacturing dummy*Management score & $\begin{array}{l}1.131^{* * *} \\
(0.0967)\end{array}$ & $\begin{array}{l}0.834^{* * *} \\
(0.0918)\end{array}$ & & & & \\
\hline 6-digits NAICS & No & Yes & No & Yes & No & Yes \\
\hline Region & No & Yes & No & Yes & No & Yes \\
\hline Time & Yes & Yes & Yes & Yes & Yes & Yes \\
\hline Skills control & No & Yes & No & Yes & No & Yes \\
\hline Observations & 24,327 & 24,327 & 6,643 & 6,643 & 17,684 & 17,684 \\
\hline
\end{tabular}

Notes: Robust standard errors clustered at the firm level in parentheses. * Significant at the $10 \%$ level, ${ }^{* *} 5 \%$ level, ${ }^{* * *} 1 \%$ level. 5 regional dummies included in all regressions. Column (2) also includes interactions of the manufacturing dummy with skills variables but these are not shown. Skills are measured as the share of workers with a college degree. 
Table 3. Sources of misallocation: Competition \& market size

\begin{tabular}{|c|c|c|c|c|c|}
\hline \multirow[b]{2}{*}{ Dependent variable $=\ln$ (workers) } & \multicolumn{2}{|c|}{ Drive time to the border } & \multirow{2}{*}{$\begin{array}{c}\text { Exports \& drive time } \\
(3) \\
\text { Manufacturing }\end{array}$} & \multicolumn{2}{|c|}{ Market size } \\
\hline & $\begin{array}{c}\text { (1) } \\
\text { Manufacturing }\end{array}$ & $\begin{array}{c}(2) \\
\text { Services } \\
\end{array}$ & & $\begin{array}{c}(4) \\
\text { Manufacturing }\end{array}$ & $\begin{array}{c}(5) \\
\text { Services } \\
\end{array}$ \\
\hline Management score*Share of exports*Drive time below the median & & & $\begin{array}{c}1.970^{*} \\
(1.116)\end{array}$ & & \\
\hline Management score & $\begin{array}{c}1.775^{* * *} \\
(0.109)\end{array}$ & $\begin{array}{c}1.266^{* * *} \\
(0.072)\end{array}$ & $\begin{array}{c}1.543^{* * *} \\
(0.181)\end{array}$ & $\begin{array}{c}2.226^{* * *} \\
(0.184)\end{array}$ & $\begin{array}{l}1.192^{* * *} \\
(0.0634)\end{array}$ \\
\hline Drive time below the median*Management score & $\begin{array}{c}0.469^{* * *} \\
(0.169)\end{array}$ & $\begin{array}{l}0.0851 \\
(0.099)\end{array}$ & $\begin{array}{l}0.0209 \\
(0.269)\end{array}$ & & \\
\hline Management score*Share of exports & & & $\begin{array}{c}1.498^{*} \\
(0.822)\end{array}$ & & \\
\hline Drive time below median*Share of exports & & & $\begin{array}{l}-0.635 \\
(0.561)\end{array}$ & & \\
\hline Market size above the median*Management score & & & & $\begin{array}{l}-0.208 \\
(0.219)\end{array}$ & $\begin{array}{c}0.324^{* * *} \\
(0.108)\end{array}$ \\
\hline 6-digits NAICS & Yes & Yes & Yes & Yes & Yes \\
\hline Municipality fixed effects & Yes & Yes & Yes & Yes & Yes \\
\hline Time & Yes & Yes & Yes & Yes & Yes \\
\hline Observations & 6,643 & 17,684 & 6,643 & 6,643 & 17,684 \\
\hline
\end{tabular}

Notes: Robust standard errors clustered at the municipality level. * Significant at the $10 \%$ level, ${ }^{* *} 5 \%$ level, ${ }^{* * *} 1 \%$ level. 
Table 4. Sources of misallocation: Institutional environment

\begin{tabular}{|c|c|c|c|c|}
\hline Dependent variable $=\ln$ (workers) & $\begin{array}{c}(1) \\
\text { Top 10\% share } \\
\text { firms contract } \\
\text { enforcement } \\
\text { problems }\end{array}$ & $\begin{array}{c}\text { (2) } \\
\text { Top 10\% } \\
\text { kidnapping }\end{array}$ & $\begin{array}{c}\text { (3) } \\
\text { Top 10\% share } \\
\text { firms with gov. } \\
\text { corruption } \\
\text { problems }\end{array}$ & $\begin{array}{c}(4) \\
\text { Top } 10 \% \\
\text { Business } \\
\text { crime } \\
\text { composite } \\
\text { index } \\
\end{array}$ \\
\hline High level*Management score & $\begin{array}{l}-0.256^{*} \\
(0.139)\end{array}$ & $\begin{array}{c}-0.258^{*} \\
(0.135)\end{array}$ & $\begin{array}{c}-1.044^{* * *} \\
(0.170)\end{array}$ & $\begin{array}{c}-0.401^{* * *} \\
(0.125)\end{array}$ \\
\hline Management score & $\begin{array}{l}1.605^{* * *} \\
(0.0583)\end{array}$ & $\begin{array}{l}1.557^{* * *} \\
(0.0527)\end{array}$ & $\begin{array}{l}1.590^{* * *} \\
(0.0557)\end{array}$ & $\begin{array}{l}1.612^{* * *} \\
(0.0389)\end{array}$ \\
\hline Share of firms in municipalities with high-level & $9.58 \%$ & $7.13 \%$ & $8.72 \%$ & $8.76 \%$ \\
\hline 6-digits NAICS & Yes & Yes & Yes & Yes \\
\hline Municipality fixed effects & Yes & Yes & Yes & Yes \\
\hline Time & Yes & Yes & Yes & Yes \\
\hline Observations & 24,327 & 24,327 & 24,327 & 24,327 \\
\hline
\end{tabular}

Notes: Robust standard errors clustered at the municipality level.

* Significant at the $10 \%$ level, ${ }^{* *} 5 \%$ level, ${ }^{* * *}$ 1\% level. 5 regional dummies included.

Data on difficulties to enforce contracts and on whether firms face government corruption was obtained from National Survey on Regulatory Quality and Government Impact on Enterprises (ENCRIGE) 2016.

To construct these variables we used the questions on (a) whether the firms in ENCRIGE experienced problems in terms of contract enforceability, (b) The frequency of corruption practices in their state (highly frequent and frequent).

Kidnapping data was obtained from administrative records on crime, which was calculated at the municipality level.

The Business crime composite index was calculated as the top $10 \%$ of the average of the standardized shares of corruption problems, kidnapping, and problems with contract enforcement. 


\section{Appendix A: English translation of the services questions}

1) In 2014, what best describes what happened at this firm when a problem in its processes arose?

Example: a problem with inventories, problems with transportation, technical failures, human resources management, customer services, etc.

1) We fixed it but did not take further action

2) We fixed it and took action to make sure that it did not happen again

3) We fixed it and took action to make sure that it did not happen again, and had a continuous improvement process to anticipate problems like these in advance

4) No action was taken

2) In 2014, how many key performance indicators were monitored at this firm?

Examples, cost, sales, inventory, customer satisfaction, service levels, energy, absenteeism and deliveries on time

1) 1-2 key performance indicators

2) 3-9 key performance indicators

3) 10 or more key performance indicators

4) No key performance indicators (If no key performance indicators in both years, SKIP to 6)

\section{3) During 2014, how frequently were the key performance indicators reviewed by} managers at this firm?

A manager is someone who has employees directly reporting to them, with whom they meet on a regular basis, and whose pay and promotion they may be involved with, e.g., Marketing Manager, Human Resources Manager, Sales Manager.

1) Yearly

2) Quarterly

3) Monthly

4) Weekly

5) Daily

6) Hourly or more frequently

7) Never

4) During 2014, how frequently were the key performance indicators reviewed by non-managers at this firm?

Non-managers are all employees at the firm who are not managers as defined in 3.

1) Yearly

2) Quarterly

3) Monthly

4) Weekly

5) Daily

6) Hourly or more frequently

7) Never 
5) During 2014, where were the display boards/notice board showing key performance indicators located at this firm?

1) All display boards were located in one place (e.g., at the warehouse, etc.)

2) Display boards were located in multiple places (e.g., multiple areas of the firm)

3) We did not have display boards

6) In 2014, what best describes the time frame of targets at this firm? Examples of targets are: sales, inventories, service levels, efficiency, on-time delivery.

1) Main focus was on short-term (less than one year) targets

2) Main focus was on long-term (less than one year) targets

3) Combination of short-term and long-term targets

4) No targets

7) In 2014, how easy or difficult was it for the firm to achieve its targets?

1) Possible to achieve without much effort

2) Possible to achieve with some effort

3) Possible to achieve with normal amount of effort

4) Possible to achieve with more than normal effort

5) Only possible to achieve with extraordinary effort

8) In 2014, who was aware of the targets at this firm?

1) Only senior managers

2) Most managers and some operational level employees

3) Most managers and most operational level employees

4) All managers and most operational level employees

9) In 2014, what were non-managers' performance bonuses usually based on at this firm?

1) Their own performance as measured by targets.

2) Their team or shift performance as measured by targets.

3) Their establishment's performance as measured by targets.

4) Their company's performance as measured by targets.

5) No performance bonuses

10) In 2014 when targets were met, what percent of non-managers at this firm received performance bonuses?

1) $0 \%$

2) $1-33 \%$

3) $34-66 \%$

4) $67-99 \%$

5) $100 \%$

6) Production targets not met 
11) In 2014, what were managers' performance bonuses usually based on at this firm?

1) Their own performance as measured by targets.

2) Their team or shift performance as measured by targets.

3) Their establishment's performance as measured by targets.

4) Their company's performance as measured by targets.

5) No performance bonuses

12) In 2014 when targets were met, what percent of managers at this firm received performance bonuses?

1) $0 \%$

2) $1-33 \%$

3) $34-66 \%$

4) $67-99 \%$

5) $100 \%$

6) Production targets not met

13) In 2014, what was the primary way non-managers were promoted at this firm?

1) Promotions were based solely on performance and ability

2) Promotions were based partly on performance and ability, and partly on other factors (for example, tenure or family connections)

3) Promotions were based mainly on factors other than performance and ability (for example, tenure or family connections)

4) Non-managers are normally not promoted

14) In 2014, what was the primary way managers were promoted at this firm?

1) Promotions were based solely on performance and ability

2) Promotions were based partly on performance and ability, and partly on other factors (for example, tenure or family connections)

3) Promotions were based mainly on factors other than performance and ability (for example, tenure or family connections)

4) Non-managers are normally not promoted

15) In 2014, when was an under-performing non-manager reassigned or dismissed at this establishment?

1) Within 6 months of identifying non-manager under-performance

2) After 6 months of identifying non-manager under-performance

3) Rarely or never

16) In 2014, when was an under-performing manager reassigned or dismissed at this establishment?

1) Within 6 months of identifying manager under-performance

2) After 6 months of identifying manager under-performance

3) Rarely or never 


\section{Appendix B: Data}

\section{B.1. Main data source: ENAPROCE 2015}

We use data from the National Survey on Productivity and Competitiveness of Micro, Small, and Medium-size Enterprises 2015 (ENAPROCE), which is the first large-scale representative management survey conducted for Mexico. This survey uses the 4,049,051 establishments included in the 2014 Economic Census as the sample frame. The establishments from the Economic Census were grouped into firms, and then 26,538 firms were chosen through random stratification to allow statistical representativeness at the sectoral-state level for SMEs, and at the sectoral-regional level for microenterprises. From this sample, the non-response rate was of just $4 \%$ due to the mandatory nature of the survey as established in article 45 of the Mexican Law of the National System of Statistical and Geographical Information (Appendix Figure A1).

In contrast with the Economic Census and other surveys implemented by INEGI which analyze establishments, ENAPROCE uses the firm as the unit of observation, with a total sample size of $25,456.90 \%$ of the firms in the sample have just one establishment.

Out of the 25,456 firms in the sample, 16,100 have more than ten employees. By design, the ENAPROCE uses a different questionnaire for Microenterprises, considering that these firms have different characteristics. In the case of Management Practices, only a subset of four questions was applied. Therefore, we exclude microenterprises of the analysis to ensure full comparability with the U.S. MOPS.

The sample is further restricted to firms with non-missing sales, employment, capital, and materials data, alongside other key fields like industry classification.

\section{B.1.2. Sectors included in the survey}

Firms included in ENAPROCE 2015 were defined according to the North American Industry Classification System (NAICS) sample and consist of the following two-digits codes.

\begin{tabular}{ll}
\hline \hline NAICS code & Description \\
\hline \hline $31-33$ & $\begin{array}{l}\text { Manufacturing } \\
\text { Services }\end{array}$ \\
43 & Wholesale \\
46 & Retail \\
$48-49$ & Transportation and Warehousing \\
54 & Professional, scientific and technical services \\
56 & Administrative and support, waste management and remediation \\
& services \\
71 & Arts, entertainment and recreation \\
81 & Accommodation and food services \\
\hline \hline
\end{tabular}

*Financial, educational, and government services are excluded from the sample 


\section{B.2. Additional Data Sets}

2014 Economic Census: To analyze the robustness of our estimates of the relation between performance and management, we use information from the 2014 Economic Census, INEGI. This is a good robustness test firstly, because the Economic Census includes data for 2013, while ENAPROCE requests data for 2014, secondly, because the unit of observation of the Census is the Establishment while ENAPROCE analyzes the firm, and finally, because though the sample for ENAPROCE is selected using the Economic Census as its sampling framework, the projects are independent.

As the unit of observation of the Economic Censuses is the establishment, establishments were aggregated into firms to make the data entirely comparable with the one from the ENAPROCE 2015.

The share of exports is also obtained from the 2014 Economic Census, INEGI and it is calculated at the 6-digits NAICS level.

Distance to the U.S. border: we calculate the drive time between the municipality in which each firm is located to any of the three most important border crossings between Mexico and the U.S.: Tijuana, El Paso, and Nuevo Laredo. To construct this indicator, as the exact location of each firm is not included in the data set, we calculate the centroid of each municipality and then compute the drive time between it and each of the three border crossings using openstreet map through the Stata command osrmtime. Finally, we take the minimum time to the border in hours.

2010 Population and Housing Census: We obtained population data at the municipality level from the Census. Additionally, income data from this Census was combined with information from the National Survey of Household Income and Expenses (ENIGH) using the Small Areas Estimates Methodology to construct household per capita income.

US MOPS data: The data from the US MOPS that we present in some of our graphs as a comparator for Mexico, was obtained directly from the graphs presented in Bloom et al. (2019) using a program called Plot Digitizer. We never had direct access to the original data from the US MOPS.

MA definitions were obtained from the National Council of Population (MA), while the source for city size definition is the U.S. Census.

\section{B.3. Variables construction}

\section{B.3.1 Performance}

Value added/worker: Value added is calculated by subtracting the consumption of materials $\left(M_{i}\right)$ and energy $\left(E_{i}\right)$, which consists of electricity and fuels, from the gross value of production of the firm $Q_{i}$, following Bloom et al. (2018b):

$$
V A_{i}=Q_{i}-M_{i}-E_{i}
$$

Where $Q_{i}$ is calculated as the sum of sales and inventories change. Value added is then divided by the total number of employees in the firm. 
Total Factor Productivity (TFPR): To construct our measure of TFP, we follow Aw et al. (2000), and we calculate a Törnqvist index as follows:

$$
\operatorname{lnTFP} P_{i}=\ln \left(Y_{i}\right)-\ln (\bar{Y})-\frac{1}{2}\left[\sum_{j=1}^{k}\left(S_{i j}+\bar{S}_{j}\right)\left(\ln \left(X_{i j}\right)-\ln \left(\bar{X}_{j}\right)\right)\right]
$$

Where

$T F P_{i}=T F P_{i}$ index

$Y_{i}=$ Revenue of firm $i$

$\bar{Y}=$ Revenue of average firm

$S_{i j}=$ Revenue share of input $j$ for firm $i$

$\bar{S}_{j}=$ Average revenue share of input $j$

$j=$ Labor, capital, and materials expenses (raw materials, fuel, electricity, etc.)

$X_{i j}=$ Value of input $j$ at firm $i$

$\bar{X}_{j}=$ Average value of input $j$

Profitability: Profitability is measured as operating profits (value added minus wages and salaries) normalized by sales.

Exporters: In Figure 1, the share of firms that export in each decile is measured as the percentage of firms that report exporting in each decile.

R\&D expenditure per employee: $R \& D$ expenditure is converted into U.S. dollars using the average exchange rate for 2014 (13.03056) and then divided by the number of employees.

Patents: In the case of patents, the question included in ENAPROCE 2015 only asks whether the firm has any patents or not. Therefore, we used this dummy variable to calculate the share of firms in each decile of management practices that have patents.

Number of employees: The number of employees consists of the total number of workers of the firm, including those that do not receive a salary and those that work for the firm but do not have a contract directly with the firm. This is a standard definition of employment in all the projects conducted by INEGI (the Economic Census, other surveys, etc.)

\section{B.3.2 Management score:}

The management score is calculated following Bloom et al. (2019). For each of the 16 questions, a score of 1 is associated to the most structured management practices (the one that is more specific, formal, frequent or explicit) and a score of 0 to the less structured practice, with all responses in between receiving a fraction of the score depending on the order. For example, when there are four possible responses for a question, the possible scores are $0,1 / 3,2 / 3$ and 1 . Once all responses are scored, the overall management score for a firm is calculated as an unweighted average of the 16 questions. We also calculate the two sub-indexes that Bloom et al. (2019) present, which identify 
monitoring practices (i.e., data-driven performance monitoring) and human resources practices (i.e. incentives and targets).

\section{B.3.3 Other characteristics of the firm}

Drive time to the border (hrs): As previously mentioned in the data sources, we calculated drive time to the border in hours using the drive time between the centroid of the municipality in which each firm is located to any of the three most important border crossings between Mexico and the U.S.: Tijuana, El Paso, and Nuevo Laredo. Then, we calculated the minimum value of these three drive times and that is the indicator we use in our regressions.

Share of exports from the 2014 Economic Census: As we want to measure the exposure of each sector to the external sector, we wanted to obtain a measure from a different source than ENAPROCE 2015. Therefore, we calculated this using the 2014 Economic Census. We calculate this share using information at the NAICS 6-digits level and it is calculated as exports divided by total sales. Therefore, a 1 percentage point change in this variable is a change of 0.01 .

Foreign Direct Investment (FDI): As shown in Table A1 (Descriptive Statistics), we construct two alternative measures of FDI, FDI1, which takes a value of one if the firm has any participation of FDI, and FDI2, which indicates $50 \%$ or more of FDI in the firm.

Capital-per-worker: Capital stock of structures and equipment (at present or replacement value) divided by the total number of employees in the firm. As we are only considering one year (2014), our measure does not face the problems of differences in accounting methods over the years.

Share of white-collar workers: It is calculated as the ratio of white-collar workers over total workers.

Share of workers with a college degree: It is calculated as the ratio of workers that obtained a college degree over total workers.

Population density: Population density at the Metropolitan Area (MA) level was obtained by aggregating municipality data on population and the extension of the municipality (in square kilometers) for the municipalities that compose each MA.

Average income: Average income is obtained as an MA level average of the household per capita income estimates at the municipality level using the Small Areas Estimates Methodology, which combines the 2010 Population and Housing Census with information from the 2010 National Survey of Household Income and Expenses (ENIGH).

City size: We follow the definition from the US Census and classify cities according to their population.

Small urban area=population less than or equal to 200,000

Medium urban area=population higher than 200,000 and less than or equal to 500,000

Metropolitan area $=$ population higher than 500,000 and less than or equal to $1,000,000$

Large metropolitan area $=$ population higher than 1,000,000

It is important to note that the definition from the OECD is very similar to the one we use. 
Regions:_Regions used as controls in this paper are based on the classification used by INEGI on its National Account System to summarize the trimester indicator of state economic activity. The regions are defined as follows:

North: Baja California, Baja California Sur, Coahuila, Chihuahua, Nuevo Leon, Sinaloa, Sonora, and Tamaulipas.

Central-North: Aguascalientes, Colima, Durango, Guanajuato, Jalisco, Nayarit, San Luis Potosí, and Zacatecas.

Centre: Mexico City and the State of Mexico.

Central-South: Guerrero, Hidalgo, Michoacan, Morelos, Puebla, Queretaro, and Tlaxcala.

South-Southeast: Campeche, Chiapas, Oaxaca, Quintana Roo, Tabasco, Veracruz, and Yucatan.

After constructing these indicators, all continuous variables were winsorized at the $1 \%$ and $99 \%$ levels by sectors. For the cases in which there are many zero values in a variable that uses a logarithmic function, we use the inverse hyperbolic sine transformation.

\section{Appendix C: Other results ${ }^{1}$}

\section{Correlates of Management}

We also briefly analyze some other results that confirm previous studies and a few novel ones that could not be studied previously because of data limitations.

First, we confirm strong differences in management practices by ownership type. In particular, family-owned firms with family CEOs tend to have the worst management practices, while foreign-owned or publicly listed (small shareholder) owned firms tend to have the best management practices. These results are generally robust to controls for industry, size, skills, and capital intensity.

Second, we find strong relationships between employee training and management practices. Firms that report providing training to their employees have significantly higher management scores. This result is robust to a full range of firm and industry controls, including employee education (which training could potentially be a proxy for).

\section{Dynamic analysis of misallocation: Robustness test}

To test the robustness of the results presented in Table A4, we analyze an alternative definition of exit. Besides firms that closed permanently and those that couldn't be found, we include firms that have closed temporarily. Our results are not sensitive to the difference in definition; the relationship between management and exit is tighter for manufacturing firms, indicating once again that the selection mechanism is not working that well in the service

\footnotetext{
${ }^{1}$ Results for this Appendix are not shown here, but are available upon request.
} 
sector, and employment grows more in manufacturing as management practices improve. As in Table A4, we obtain similar results when using labor productivity instead of management.

Finally, we analyze if the results for management are robust to controlling for other measures of performance like labor productivity (value-added per worker) and capital-per-worker. Management remains a relevant measure for both the manufacturing and service sectors, even after accounting for the other performance variables. Furthermore, the coefficients of the management score are still lower for the service sector for both growth and exit, once again indicating that selection and employment growth are lower in this sector, which, as mentioned in the text, can be explained by greater frictions.

\section{Reallocation and Proximity to the US Border: Robustness Tests}

First, we test the robustness of our results on the size-management relationship according to proximity to the US border and local market size (Table 3 in the text). Our results do not change much if we exclude our sectoral and geographical controls. The magnitudes of the coefficients associated with the drive time-management and market size-management interactions are very similar to the original specification, and the sectoral differences remain. Furthermore, measuring drive time and market size as continuous variables, as an alternative to our above/below the median dummies, yields qualitatively similar results. Once again, manufacturing firms closer to the US border (especially export-intensive industries) and services firms in larger local markets exhibit a stronger relationship between management and size. Finally, our main results are robust to further controlling for the interactions of our drive-time and market-size dummy variables with other variables correlated with management (capital, share of white-collar workers, and education).

Following our analysis of the differences in management practices according to proximity to the border (Figure 7), we further tested the robustness of these results in a regression framework. We estimated regressions of our management score on drive time (hours), including interactions of a manufacturing dummy with drive time as well as with other standard covariates. The coefficient of the manufacturing and drive time interaction is an order of magnitude larger than the linear drive time coefficient. Our results indicate that higher proximity to the US (measured as a lower drive time) is related to a higher management score only in the manufacturing sector. A decrease from the 90 th to the 10 th percent in drive time is associated with an increase of 0.05 in the management score and a $15 \%$ increase in TFP. In services, we see no relationship.

In order to analyze whether the effects of the distance drive our results to the US or by a selection problem in which better-managed firms decided to locate closer to the US border after the entry into force of NAFTA, we restrict our sample to those firms that were alive in 1990 or earlier. Estimating the same equations for this subsample, the results hold, as the coefficient of the drive time to the border variable is only statistically significant for the manufacturing firms, and the magnitudes observed are basically identical to the ones obtained for the whole sample. Repeating this analysis using TFP as the dependent variable, reassuringly, leads to very similar results to those using management, being an almost order of magnitude larger in manufacturing than services. 
As our sample is not at the establishment level but at the firm level and the location of the firm for multi-establishment firms is defined as the municipality in where the head office is located, we test the robustness of our results by restricting our sample to those firms that do not have more than one establishment ( $90 \%$ of the sample). Our results are robust to restricting the analysis only to single-plant firms confirming that firms with multiple plants and which location is assigned to their head office are not biasing our results. ${ }^{2}$

We further tested the relevance of being near the US border by constructing a dummy variable that takes the value of one if the municipality is located along the US border or if it is a neighbor of a municipality that shares a border with the US. We identified 72 municipalities that fulfill this requirement. Out of our sample of 16,100 firms for 2014, only 1,315 are located in this area. Once again, we observe that manufacturing firms, without controlling for other factors, tend to have better practices than firms from the services sector, but manufacturing firms located in the border area tend to have more structured practices.

As another robustness test of drive time to the US border as a proxy for market access, we analyzed a variable that takes the minimum between flight time and drive time to the US. The idea is that if proximity represents greater ease of monitoring by a US HQ (see Giroud, 2013), US customers, or even lower costs of obtaining valuable service inputs such as US management consulting, then it should be flight times that dominate. Horse races show that including this variable along with drive time, market access (drive time) is what really matters for manufacturing. Since drive time is most relevant for manufacturing goods, this again supports the competition interpretation of proximity.

\section{Exposure to trade within the Manufacturing sector}

The contrast of the proximity results across manufacturing and services is interesting, but of course, there are many other differences between these broad sectors that could be generating the heterogeneity of the drive time coefficient that we have not controlled for. To better test our hypothesis, we build a NAICS-6 digit industry-level indicator of the export share of sales. If our hypothesis that proximity to the US reflects the stronger effects of competition from a bigger market, then the proximity coefficient should be stronger for firms in industries that are more open to international trade.

Adding an interaction between the industries' export intensity and drive time (along with interactions with other observable covariates) shows that US proximity has a significantly stronger association with management for the more export-intensive sectors. We observe the same relationships for TFP as for management.

We tested the robustness of all these results by re-estimating this equation using a ten-year average sectoral share of exports with information from the 2004 and 2014 Economic Censuses as well as export averages using the 2004 and the 2009 Economic Censuses. The results are robust to these changes in the measure of sectoral export orientation.

\footnotetext{
${ }^{2}$ We also tested the robustness of our result using a different definition of regions, and we observe that the results do not change.
} 
An additional concern is that the results might be driven by the importance of two main states: Mexico City, which is located in the central region of the country, and Nuevo Leon, which is located near the Northern border of the country. According to the 2014 Economic Census, these two states account for 17\% of Manufacturing Gross Product and 34\% of Services Gross Product. The results do not change significantly when we estimate the same equations but exclude these states.

\section{City Density and Reallocation in the Service Sector: Robustness Tests}

Testing the robustness of our results on market size, we estimate the relationship between management and market size in a regression framework. The coefficient on the linear city size variable is small, negative, and insignificant, whereas the interaction between the services dummy and market size is positive, large, and statistically significant. A similar pattern holds when we condition on other covariates or split the sample by manufacturing and service sectors. We further assess the robustness of these results by using alternative proxies for market size based on population size. We use a dummy that indicates whether the municipalities are small urban areas, medium, metropolitan areas, or large metropolitan areas. As the municipalities grow in market size, the management score for the services sector improves, but the same is not observed for manufacturing.

In an alternative specification using the TFP index as the dependent variable, we find that local city size matters for productivity in services, but not in manufacturing. The absence of a city-size effect on productivity may appear surprising, as there is a vast economic geography literature that argues for higher productivity effects in large cities. It is worth noting, however, that most individuals and firms are not in manufacturing, so some of the existing empirical studies are likely driven by the services sector. ${ }^{3}$ Furthermore, most of the studies are in high-wage countries where agglomeration effects may be stronger than in a middle-income country like Mexico.

One concern with our results is that the average income could reflect the presence of more skilled potential employees. We disaggregate our market size measures by including income and population density as separate variables to address this. We find that our local size effects are driven by population density that has a similar statistically significant coefficient, but income is insignificant. ${ }^{4}$

It is possible that these results are driven by reverse causality or omitted location-specific confounders. To partially address this, we use population density and income in the 1990 Population and Housing Census as an instrument for the 2010 market size data. The results do not change much.

Finally, we estimated the same equations again, excluding Mexico City and Nuevo Leon, and confirm that our results are robust to excluding these two main cities.

\footnotetext{
${ }^{3}$ A smaller literature uses plant and firm level data in manufacturing. Some of these studies do find significant and positive city size effects, but all the ones that we know of are in high wage countries (e.g., Combes et al., 2012).

${ }^{4}$ As before, the variables are insignificant in the manufacturing sector.
} 


\section{Institutional Frictions and Misallocation: Robustness Tests}

We analyze the robustness of the results presented in Figure 12 and Table 4, by using a different threshold (5\%) to define a high level of contract enforcement problems, kidnapping, corruption, and our business crime composite index. Our results are robust to using this alternative threshold.

\section{Appendix D: Municipalities analysis}

As previously mentioned, out of the 2,456 municipalities in Mexico, the sample of SMEs and large manufacturing and services firms covers only 254 municipalities. Furthermore, in the case of the Manufacturing sector, 100 municipalities cover $89 \%$ of the firms in the sample. Except for Mexico City, State of Mexico, Jalisco, Nuevo Leon, and Guanajuato, all the states have five municipalities or less among these 100 municipalities.

Similar information is observed for the Services sector, where 100 municipalities concentrate $88.3 \%$ of the sample. Ten states have more than ten municipalities with firms of the services and commerce sectors. Furthermore, most of these main 100 municipalities are the same identified for manufacturing.

Considering this distribution of firms across municipalities and states, we decided to use regional effects in our estimates instead of state effects.

\section{Appendix E: A Simple Model}

\section{Baseline Model}

Consider a Production Function for firm $i$ in an industry (for brevity, we keep the industry subscripts on parameters implicit):

$$
Q_{i}=M_{i} L_{i}^{\alpha}
$$

Where $Q$ is output, $L$ is labor, and $M$ is managerial quality. This follows the Lucas (1978) span of control model where $\alpha$ is the managerial span of control $(\alpha<1$ represents the degree of managerial overload which generates decreasing returns to scale).

We allow for imperfect competition in the product market. Consider monopolistic competition with Dixit-Stiglitz preferences. This generates an iso-elastic product demand function:

$$
Q_{i}=B P_{i}^{-\eta}
$$

Where $B$ is a demand shifter ${ }^{5}, P$ is product price, and $\eta$ is consumer price-sensitivity, $\eta>1$.

\footnotetext{
${ }^{5}$ This would be $B=\tilde{B} \mathrm{QP}^{\eta}$ in the model of Alessandria and Choi (2007) where $\mathrm{Q}=$ industry output and $\mathrm{P}=$ industry price.
} 
We assume that input markets are competitive, so firms face a common equilibrium wage $(W)$. We model distortions as an implicit tax on revenues, as many/most regulations explicitly or implicitly bite more strongly on larger firms. ${ }^{6}$ Formally, denote this implicit tax, $\tau \geq 1$ if $\tau=1$ we are in an undistorted economy, but as $\tau$ gets larger, the economy is increasingly distorted through a higher implicit tax. Hence, profits for a firm are:

$$
\Pi_{i}=\left(P_{i} Q_{i}\right)^{\frac{1}{\tau}}-W L_{i}
$$

Substituting in the (inverse) demand function for price $\left(P_{i}=B^{\frac{1}{\eta}} Q_{i}^{-\frac{1}{\eta}}\right)$

$$
\Pi_{i}=\mathrm{B}^{\frac{1}{\tau \eta}} Q_{i}^{\frac{\eta-1}{\tau \eta}}-W L_{i}
$$

Maximizing profits with respect to labor gives the first-order condition:

$$
l_{i}=w+\left(\frac{\eta-1}{\tau \eta}\right) q_{i}+\frac{1}{\tau \eta} b+\ln \alpha+\ln \left(\frac{1}{\tau}-\frac{1}{\tau \eta}\right)
$$

where lower case letters denote $\operatorname{logs}($ e.g., $q=\log Q)$.

Now using the production function to substitute for output, $q$, and simplifying, we obtain:

$$
l_{i}=\frac{\frac{1}{\eta \tau} b+\ln \alpha+\ln \left(\frac{\eta-1}{\tau \eta}\right)}{1-\alpha\left(\frac{\eta-1}{\tau \eta}\right)}+\frac{\left(\frac{\eta-1}{\tau \eta}\right)}{1-\alpha\left(\frac{\eta-1}{\tau \eta}\right)} m_{i}-\frac{1}{1-\alpha\left(\frac{\eta-1}{\tau \eta}\right)} w
$$

or

$$
l_{i}=\kappa+\frac{1}{d-\alpha} m_{i}-\frac{\alpha}{d-\alpha} w
$$

where $\kappa=\frac{\frac{1}{\eta} b+\ln \alpha+\ln \left(\frac{\eta-1}{\tau \eta}\right)}{1-\alpha\left(\frac{\eta-1}{\tau \eta}\right)}, d=\frac{\tau}{\left(1-\frac{1}{\eta}\right)}$ and $\mu=\frac{P}{c}=\frac{1}{\left(1-\frac{1}{\eta}\right)}$ is the firm's price-cost margin that increases as competition falls. We can think of $d$ as a composite of frictions from the product market (i.e., monopoly power indexed by $\mu$ ) and/or from regulatory/institutional distortions $(\tau)$. In the absence of frictions $d=1$.

Proposition 1. $\frac{\partial l_{i}}{\partial m_{i}}>0$ Better Managed firms will be larger

\footnotetext{
${ }^{6}$ This is because many smaller firms are exempt from regulations - see the discussion in Garicano et al (2016) on labor laws for example. Moreover, even when laws and regulations are not explicitly size contigent, they tend to be enforced more strictly for larger firms who are more visible to the authorities. See also Levy (2018) on the Latin American case and Hsieh and Olken (2014) for a general discussion. For similar approaches to modelling regulations see, for example, Guner et al (2006, 2008).
} 
Proof. The elasticity of log employment size, $l$ with respect to management quality, $m$ is $\frac{\partial l}{\partial m_{i}}=\frac{1}{d-\alpha}$. Since $d \geq 1$ and $\alpha<1$, this is positive.

Proposition 2. $\frac{\partial^{2} l_{i}}{\partial m_{i} \partial d}<0$. The impact of management quality on firm employment size is decreasing in the degree of frictions.

Proof. This can be directly seen from Proposition 1. The magnitude of the employmentmanagement elasticity is decreasing with the size of frictions, $d$.

Corollary. $\frac{\partial^{2} l_{i}}{\partial m_{i} \partial \mu}<0$ and $\frac{\partial^{2} l_{i}}{\partial m \partial \tau}<0$. Increases in firm market power (falls in $\eta$ cause a rise in margins $\mu$ ) and increases in distortions $(\tau)$ reduce the elasticity of employment with respect to managerial quality. This is the key idea: as frictions increase, the impact of better management on firm size, although remaining positive, will decline.

\section{Mapping the model to the empirics}

There is a straightforward mapping of this set-up to the empirics. Table 1 on the production functions is the multi-factor extension to equation (E1) where we also allow for capital and skills to be other factors of production (this is a trivial extension to the production function). Propositions (1) - (2) are unaffected by including extra factors, so long as they are all statically optimized (see below for a discussion of adjustment costs and dynamic factors). ${ }^{7}$

The positive relationship between employment and management is shown in all of the tables as well as Figures 1 and 3. The intuition behind the stronger relationship between employment and management in the US than Mexico is that competition is higher and market distortions lower in the US, as in Proposition 2. In this case, $\tau$ and $\mu$ have (implicitly) country-specific subscripts. Similarly, the stronger relationship between size and management in the Mexican Manufacturing sector than in the Services sector (Table 2 and Figure 3 ) is that competition is stronger (due to international trade) and distortions lower (due to fewer regulations) in manufacturing. In this case, $\tau$ and $\mu$ have (implicitly) sectorspecific subscripts.

The bulk of the paper uses other observables to shift $\tau$ and $\mu$. In Table 3, we argue that the drive time to the border is a municipality-specific indicator of competition. Firms located closer to the US face effectively a greater degree of potential competition from US firms, with a larger substitution possible for consumers (Proposition 2). Hence, $\mu$ is lower, for these Mexican firms, so the relationship between employment size and management is stronger. This is equivalent to introducing an area subscript, i.e., $\tau=\tau_{0}+\tau$ Drive $_{m}$ where Drive $_{m}$ is the drive time to the US border in municipality $m$. Similarly, the argument that a larger market size in a city $c$ will mean greater density and therefore more spatial competition in

\footnotetext{
${ }^{7}$ There are analogous conditions for capital inputs and output. Capital is harder to measure of course as it the volume of output as we do not have firm specific price deflators. This is why we prefer to focus on labor as our key firm size measure.
} 
the Service sector (which, unlike manufacturing, is predominately locally traded), assumes $\mu=\mu_{0}+\mu$ Size $_{c}$. Finally, the frictions in Table 4 are also assuming that the distortions are shifted by the institutional environment in a geographical area.

\section{Some Theoretical Extensions}

There are multiple extensions one could make to the baseline model.

First, the simplest approach to extending the model, is to consider a sunk cost to entry before firms observe their realization of (stochastic) management as in the Melitz (2003) model. In this way, we observe young firms for a period before they exit if they have a low draw of management. The implication of this type of model is that (i) older surviving firms will have on average higher management scores and (ii) the variance of management practices for a cohort will shrink over time, as the lower tail of worst managed firms exits. The empirical moments in Figure 4 are consistent with point (i) and those of Figure 5 with point (ii).

Second, note that the set-up in Bartelsman et al. (2013) is close to our approach here as it emphasizes the robustness of the "Olley-Pakes moment" - the positive relationship between relative size and productivity - as a measure of reallocation. This is the same as our approach, except we have explicitly substituted in management rather than used productivity proxies as they do. Their framework generalizes our approach as in addition to the sunk cost of entry (as in the previous paragraph), they also allow for adjustment costs in capital. This creates a dynamic optimization problem for capital investments. Since there is no closed-form solution, they use numerical simulations to show similar results to our Proposition 2: in environments with greater distortions, there will be a weaker relationship between management (TFP in their model) and firm size.

Bartelsman et al. (2013) keep TFP/management exogenous. Bloom et al. (2017) generalize their approach even further by allowing management to be endogenously chosen with adjustment costs (like capital investment). The dynamic optimization problem generates a policy correspondence for the investment decisions of both dynamic factors. The state variables are managerial capital, non-managerial capital, and TFP (which is modelled as an exogenous Markov process). Even in this much more complex set-up, they show that the key intuition behind propositions (1) and (2) as well as the dynamic implications between firm age and the level and variance of management in Figures 4 and 5. 


\section{Appendix Figures}




\section{Figure A1: Articles of the Law of the National System of Statistical and Geograhical information}

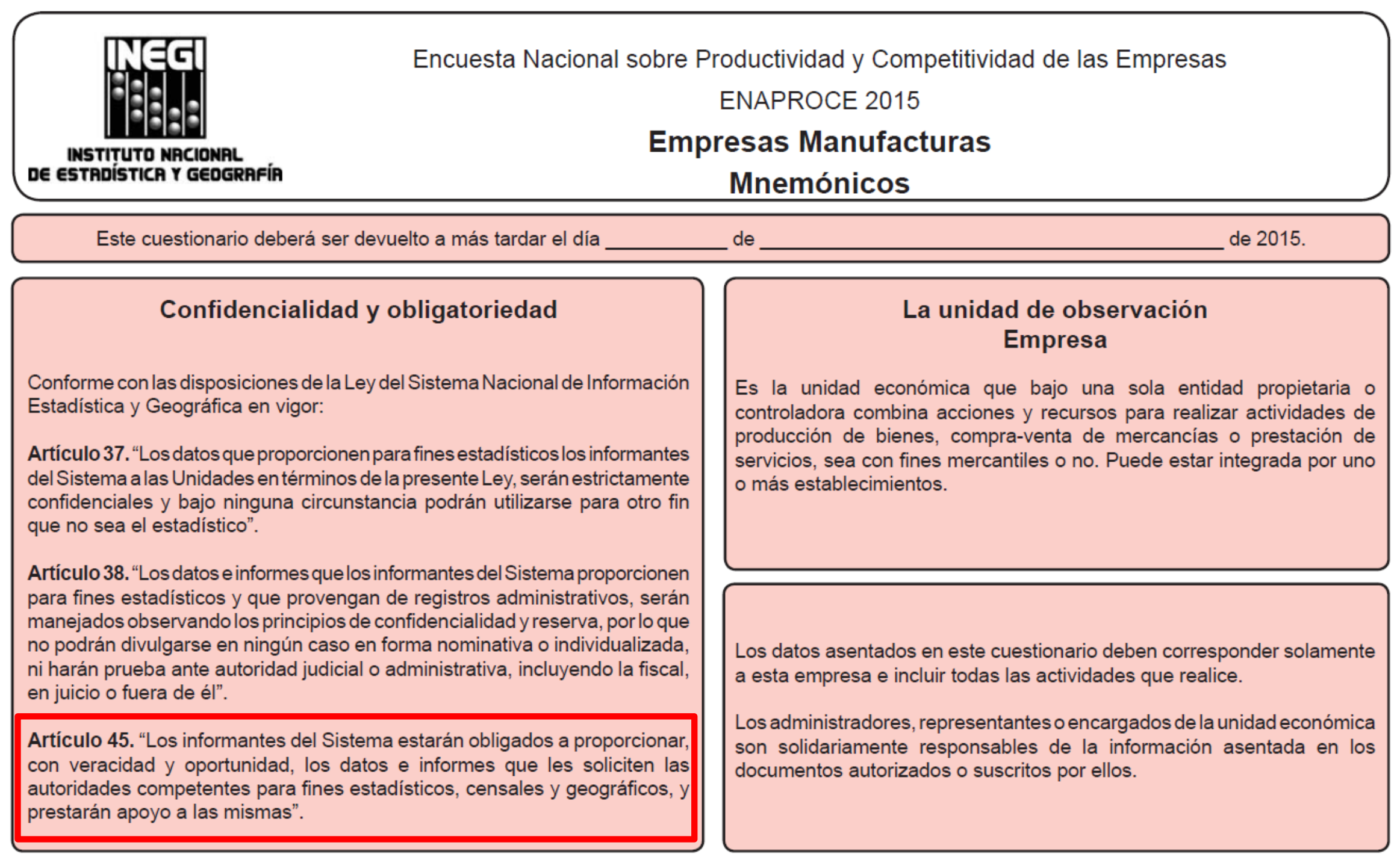


Figure A2: Exit analysis 2014-2017

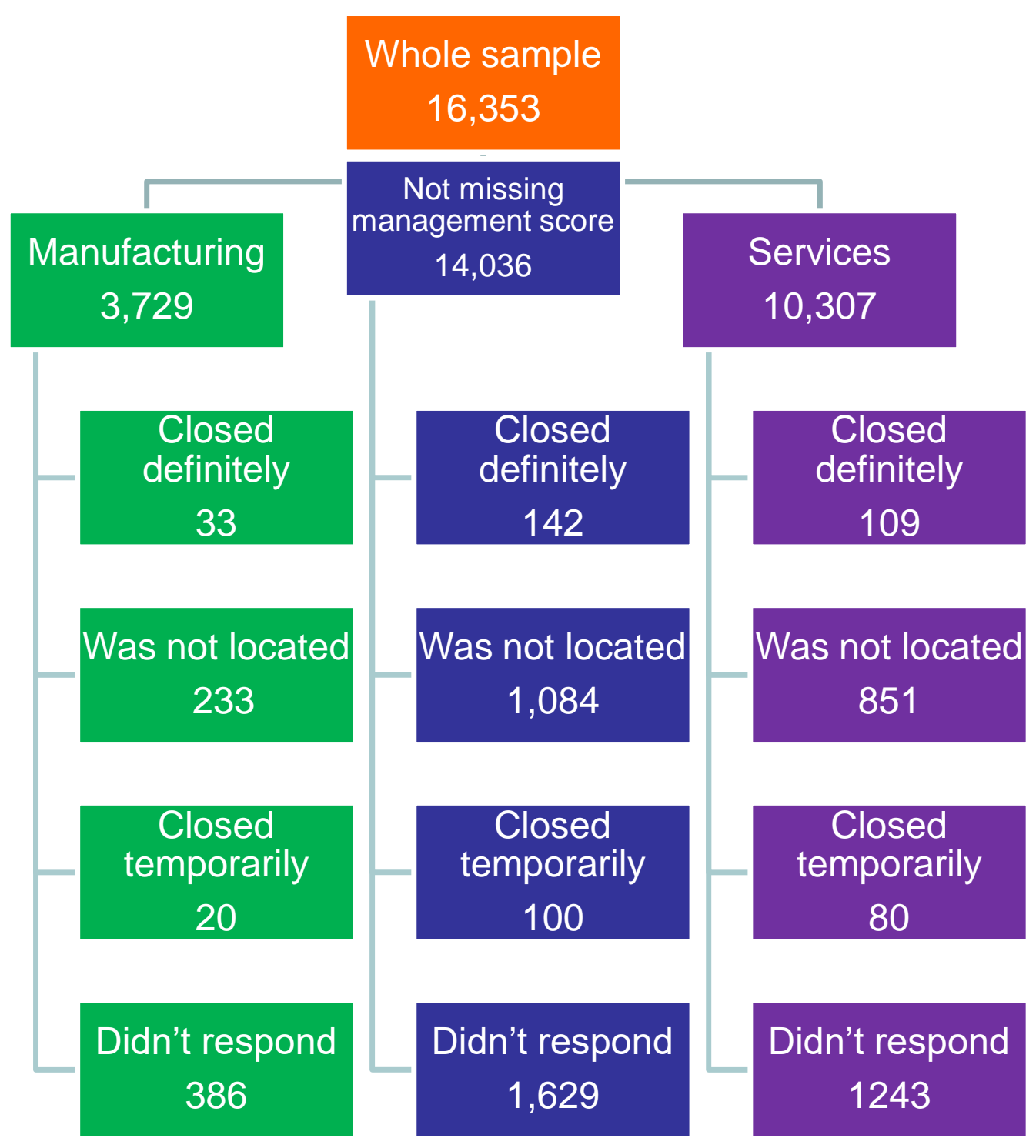

Notes: Based on information from the 2015 and 2018 waves of ENAPROCE. 
Figure A3: Management distribution - Manufacturing

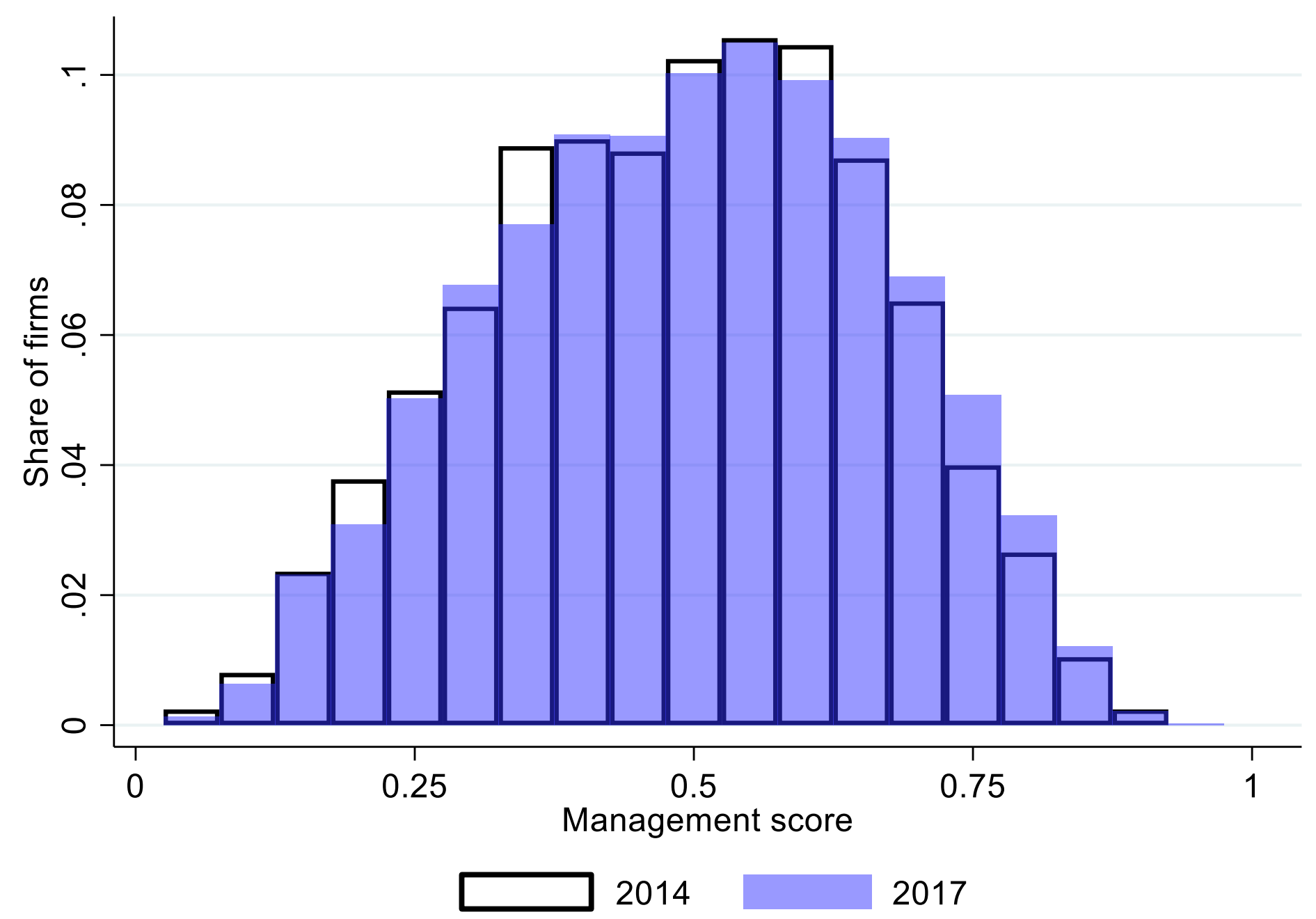

Notes: Plots of sample of 3,707 Mexican manufacturing firms in 2014, and 2,936 in 2017 
Figure A4: Management distribution - Services

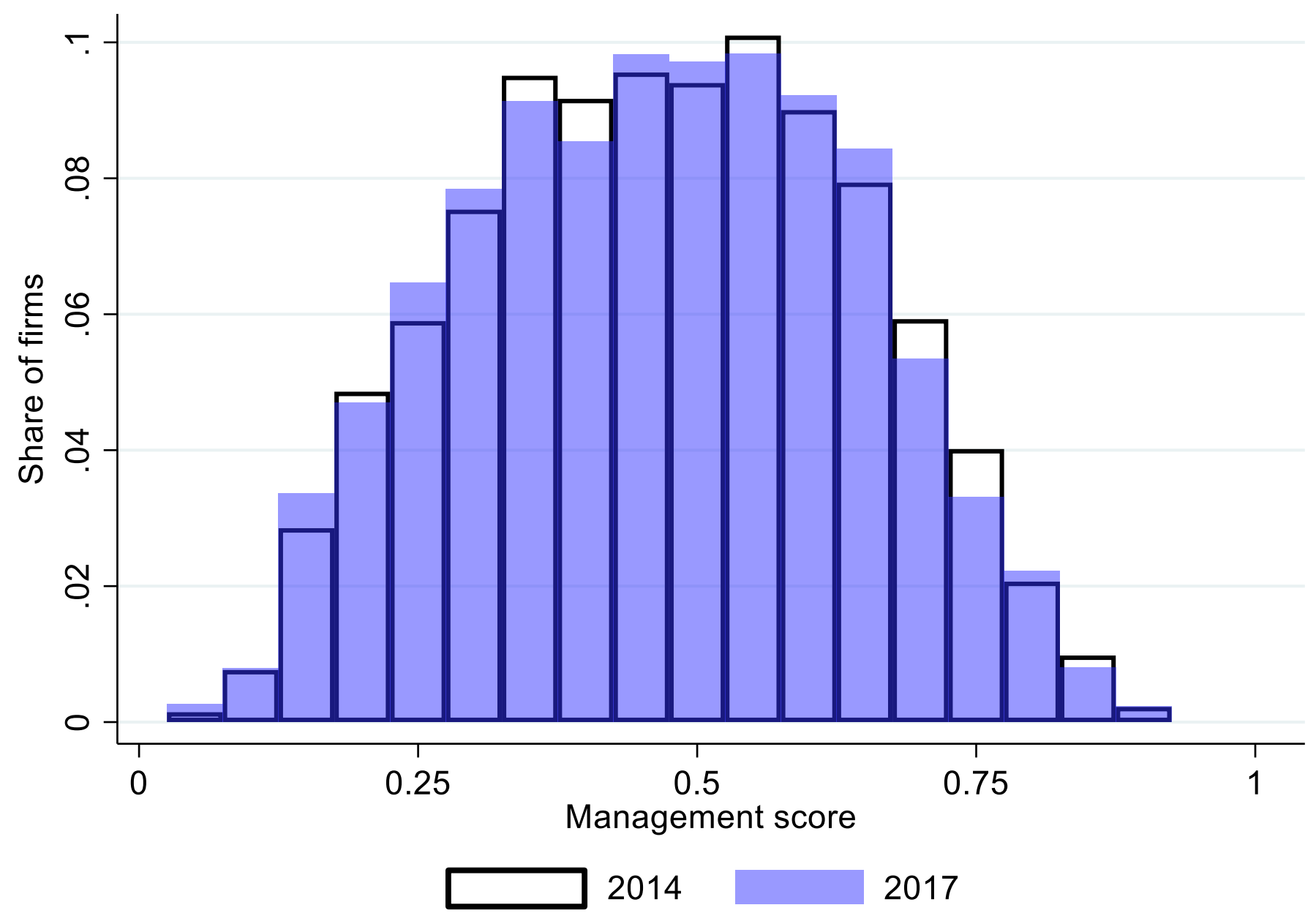

Notes: 6,643 observations on Mexican manufacturing; 17,684 observations on Mexican services 


\section{Figure A5: States included in the sample}

(a) Number of firms in the sample by state: Manufacturing

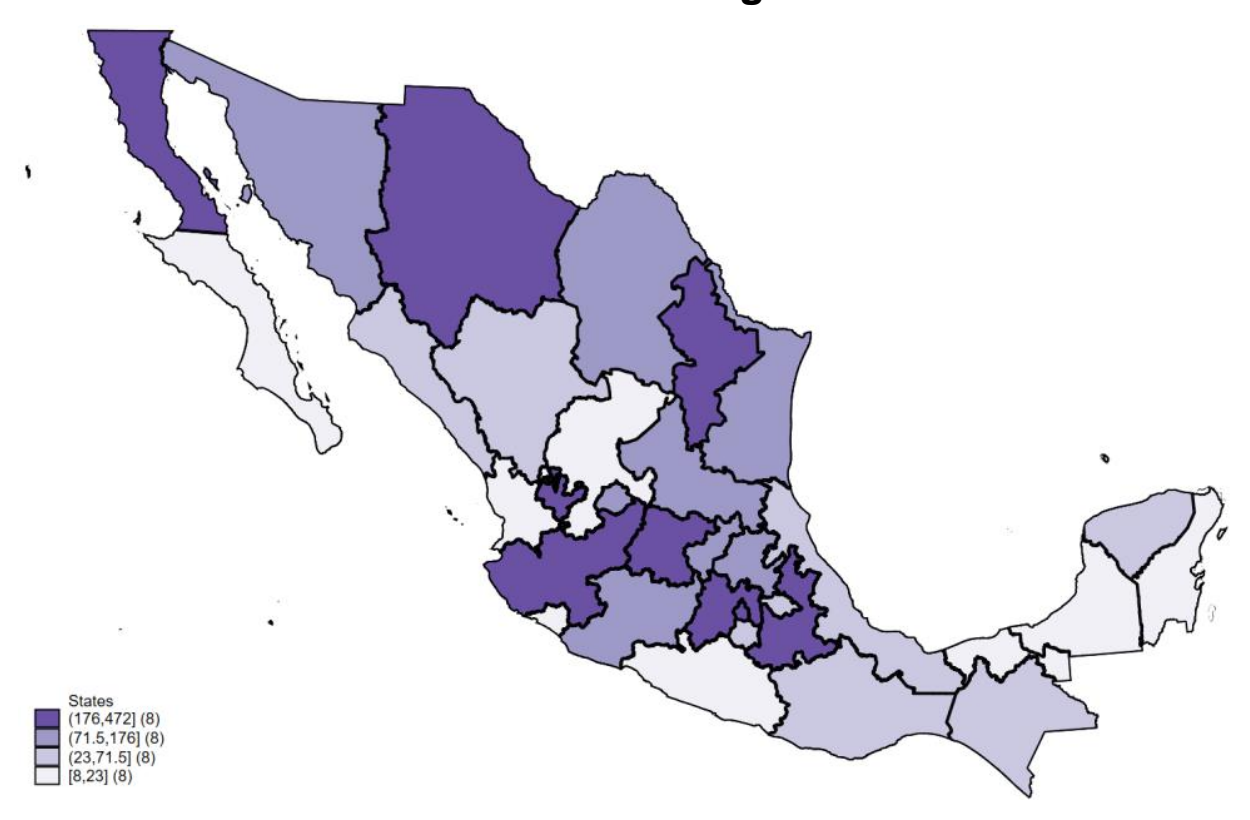

(b) Number of firms in the sample by municipality: Services

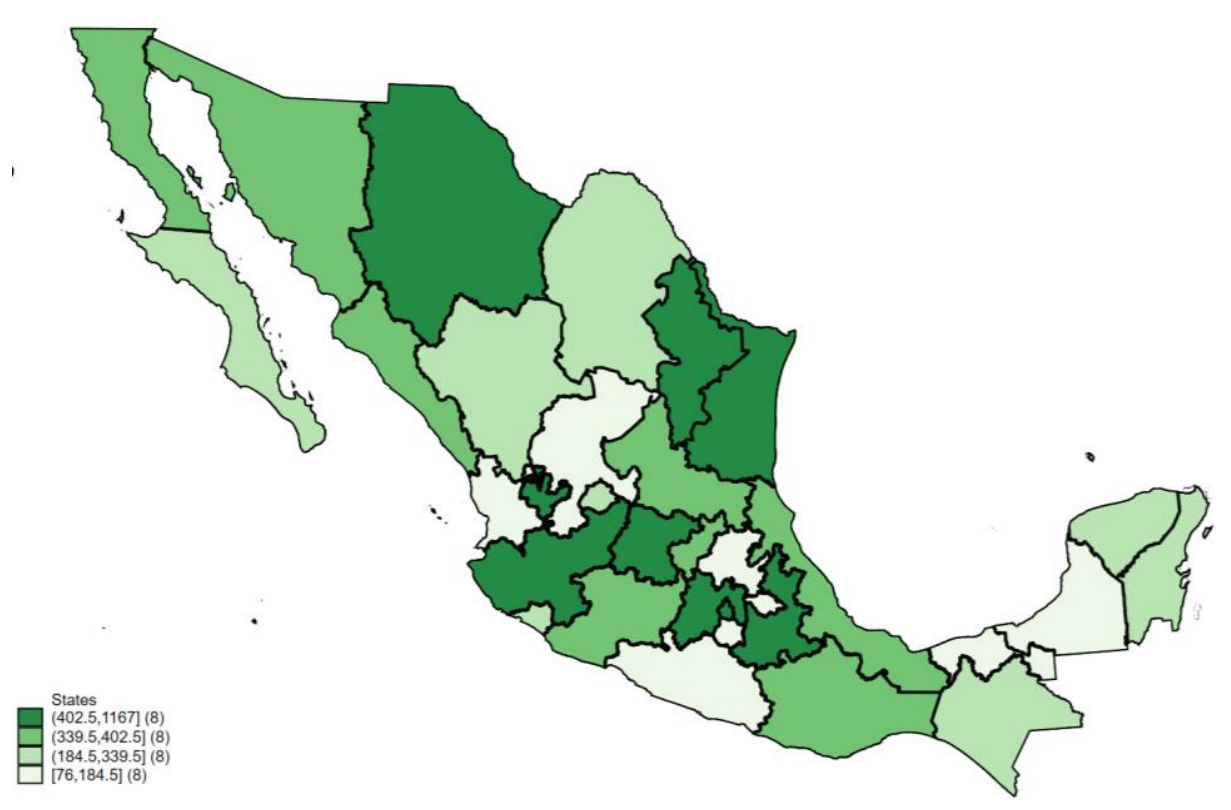

Source: Authors' calculations with data from ENAPROCE 2015 and 2018, INEGI. 


\section{Figure A6: Age and log(value added per employee): mean}

(a) Manufacturing MX

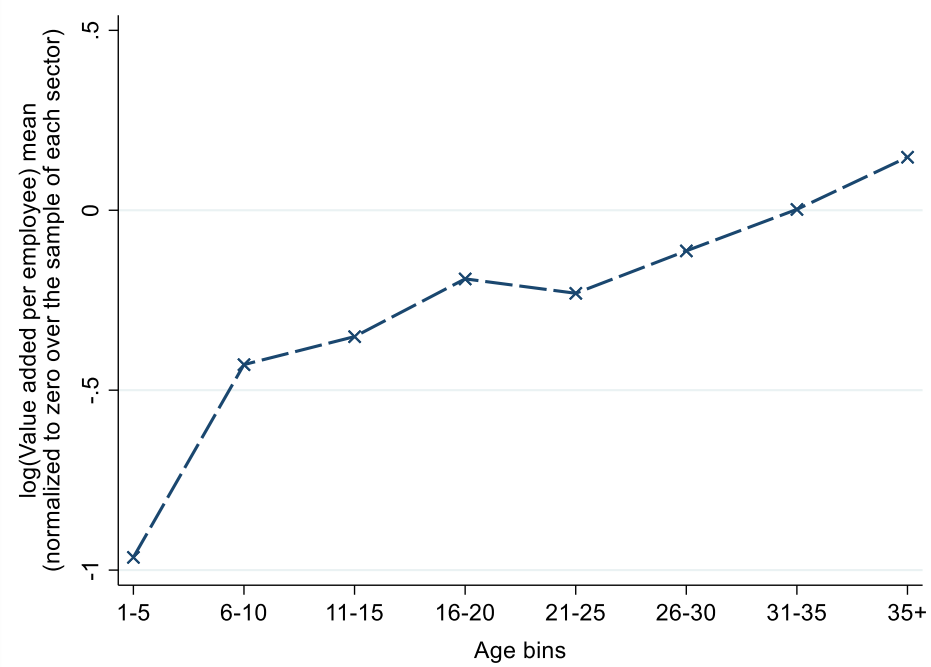

(b) Services MX

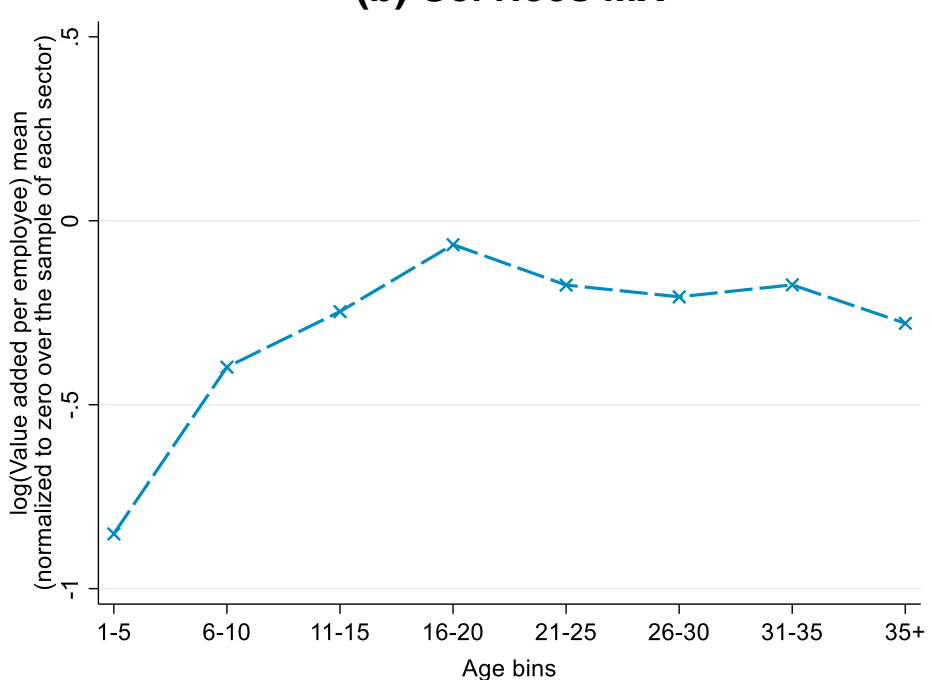

Figure A7: Age and log(value added per employee): spread

(a) Manufacturing MX

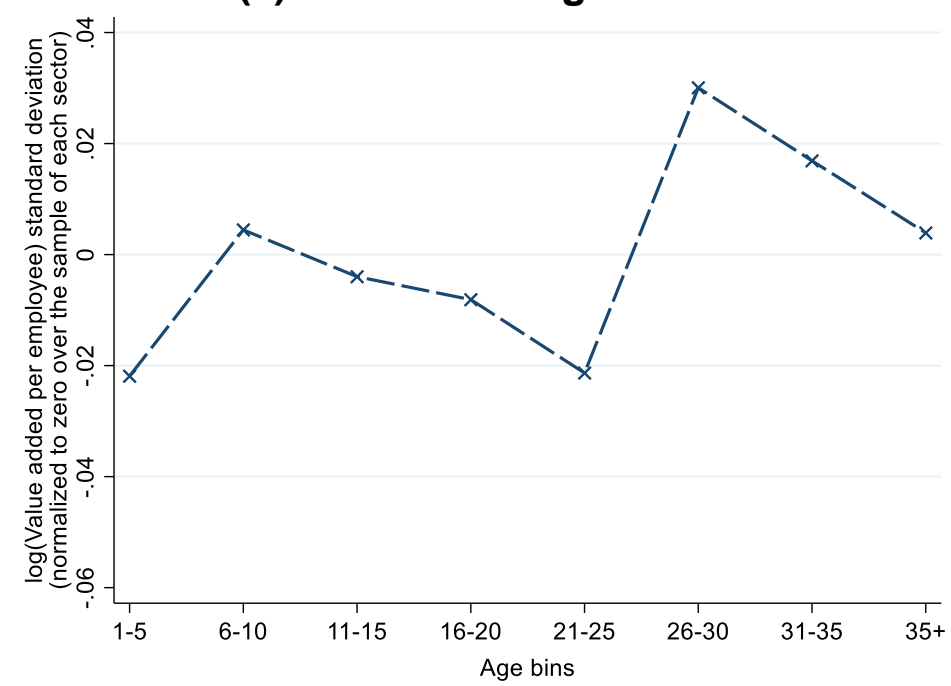

(b) Services MX

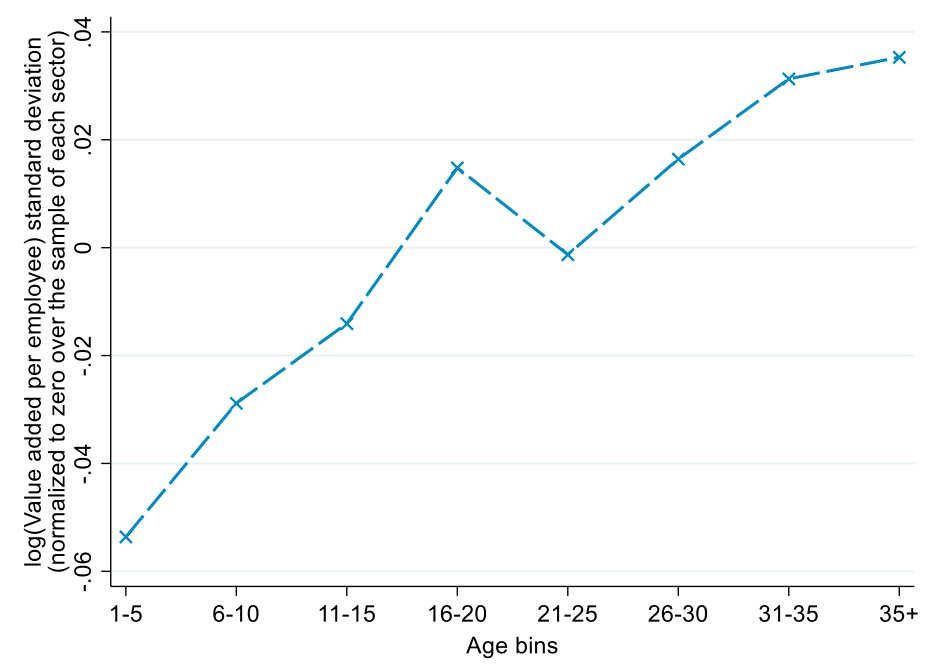

Notes: 6,643 observations on Mexican manufacturing; 17,684 observations on Mexican services 


\section{Figure A8: Age and log(TFP): mean}

(a) Manufacturing MX

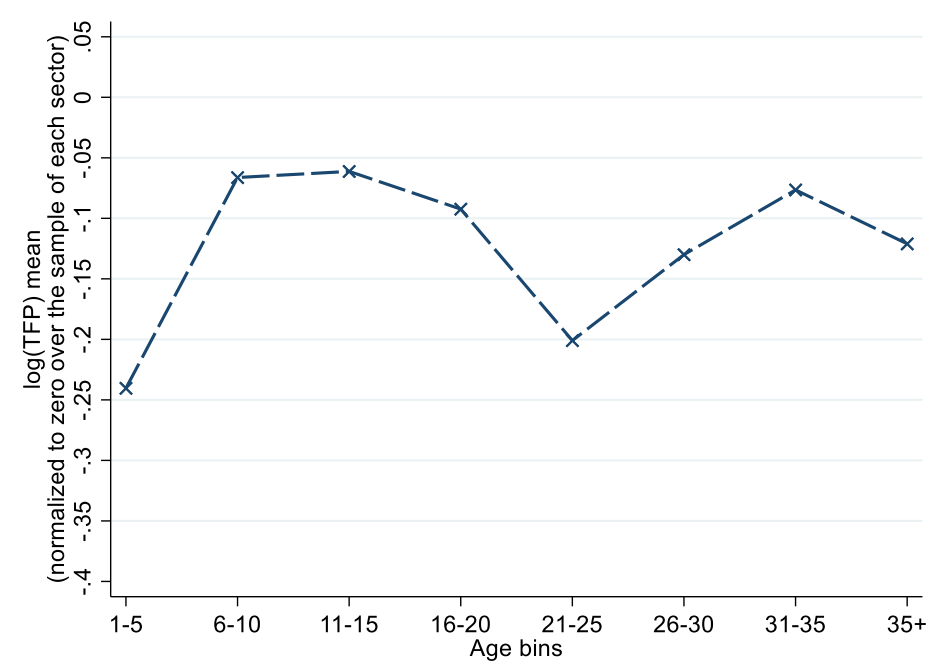

(b) Services MX

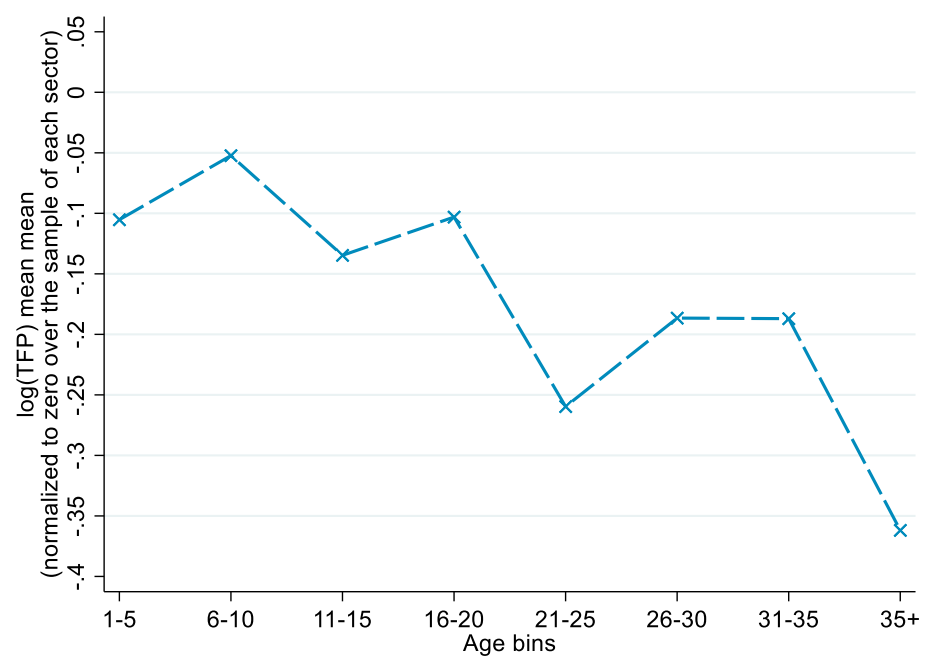

Figure A9: Age and log(TFP): spread

(a) Manufacturing MX

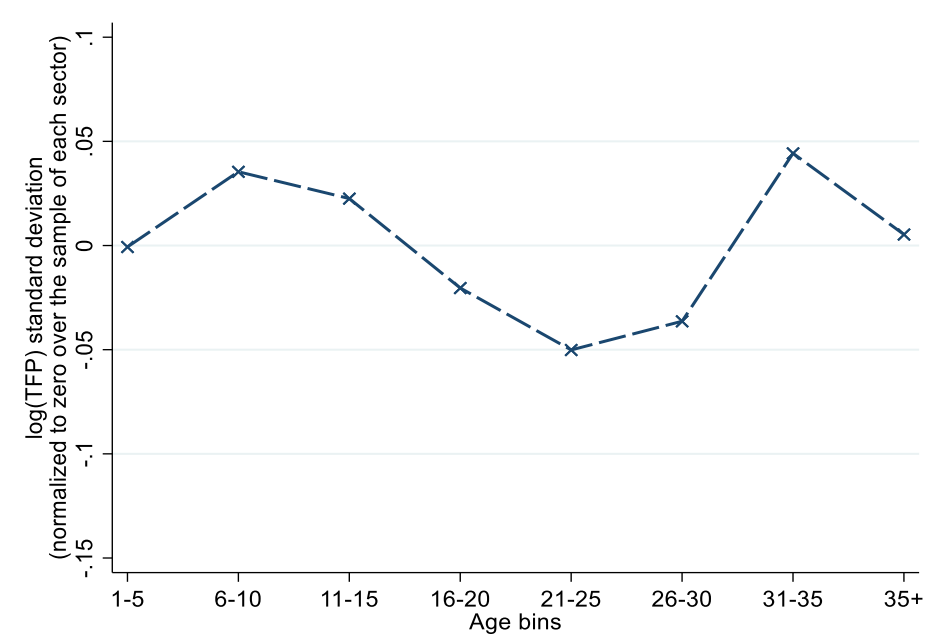

(b) Services MX

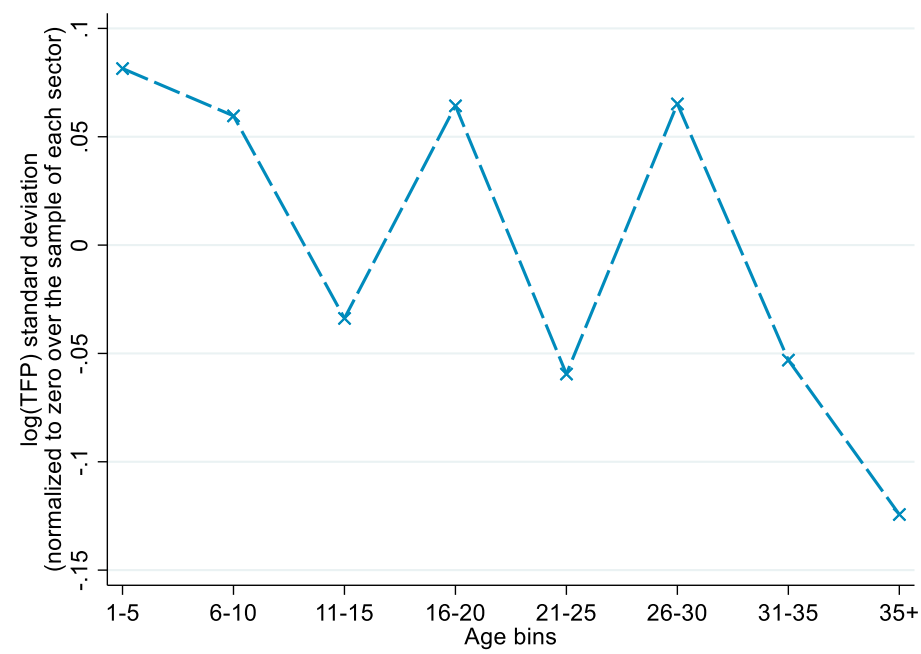

Notes: 6,643 observations on Mexican manufacturing; 17,684 observations on Mexican services. 
Figure A10: CDFs Management score according to drive time (unweighted)

(a) Manufacturing

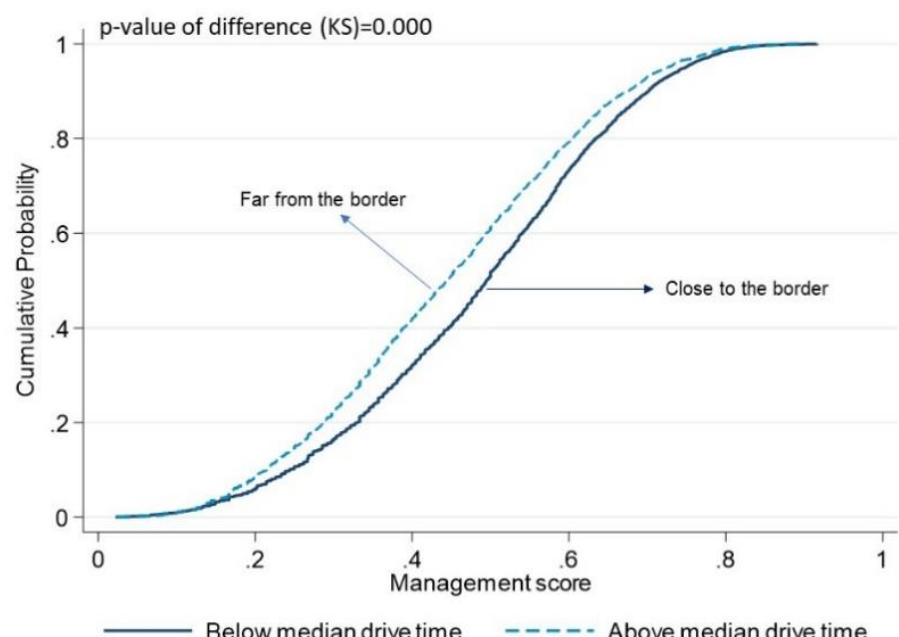

(b) Services

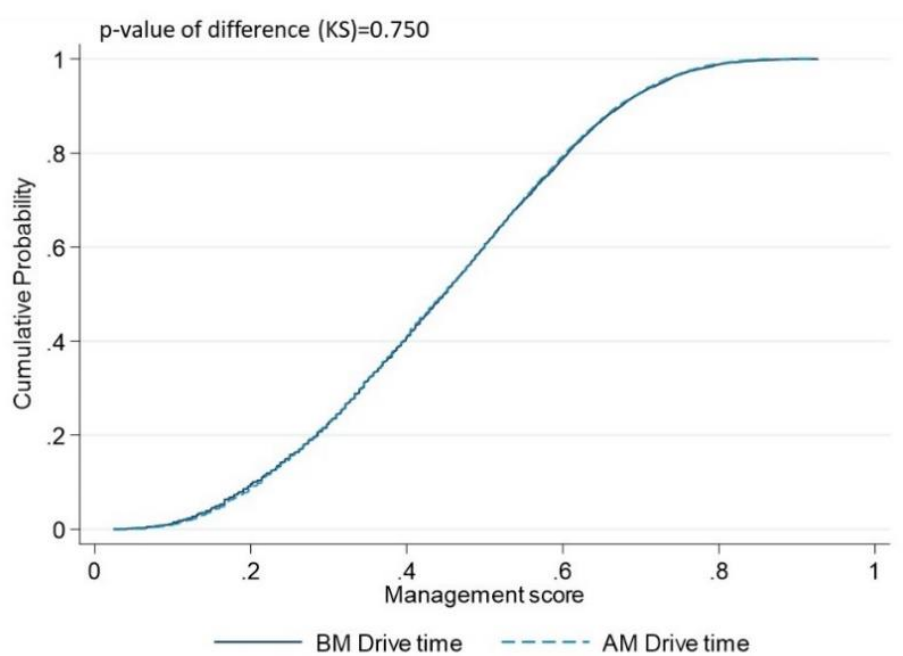

Figure A11: CDFs Management score according to market size (unweighted)

(a) Manufacturing

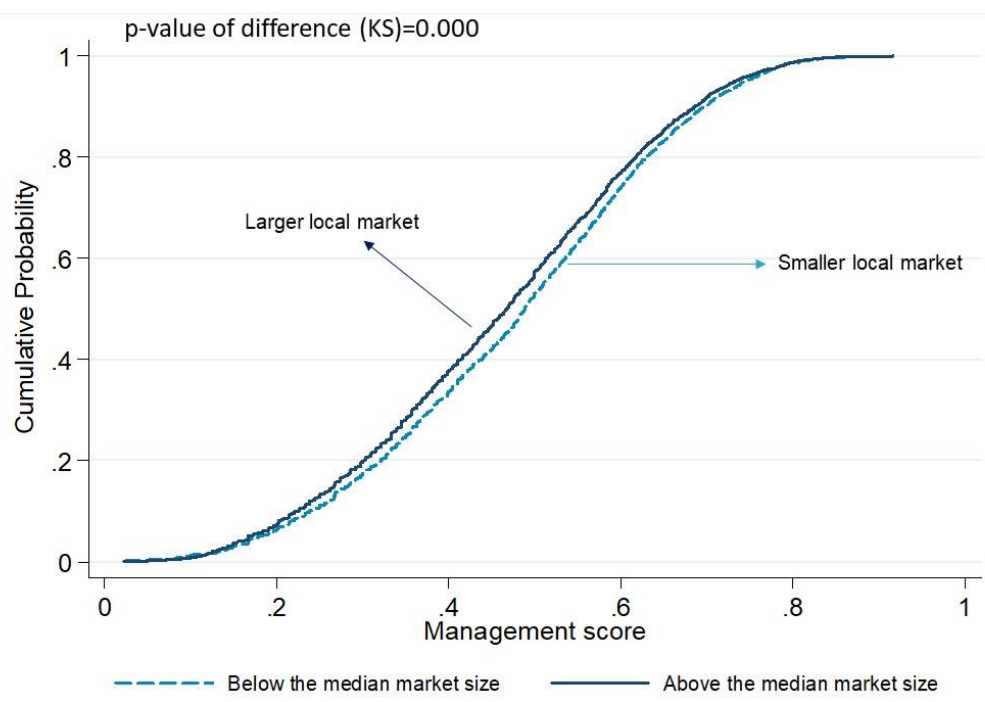

(b) Services

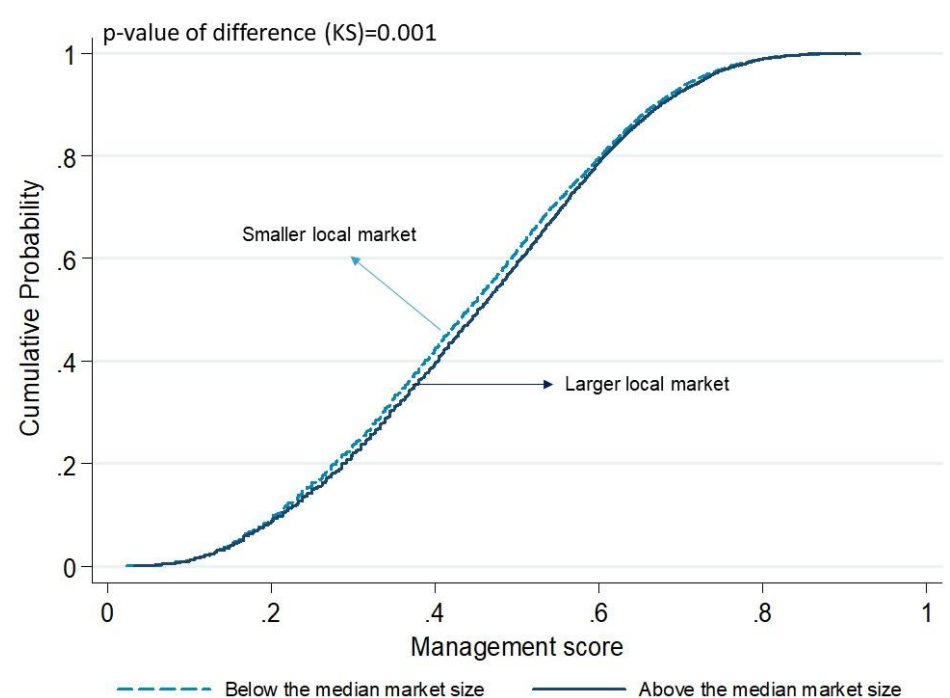

Notes: 6,643 observations on Mexican manufacturing; 17,684 observations on Mexican services 
(a) Contract enforcement problems

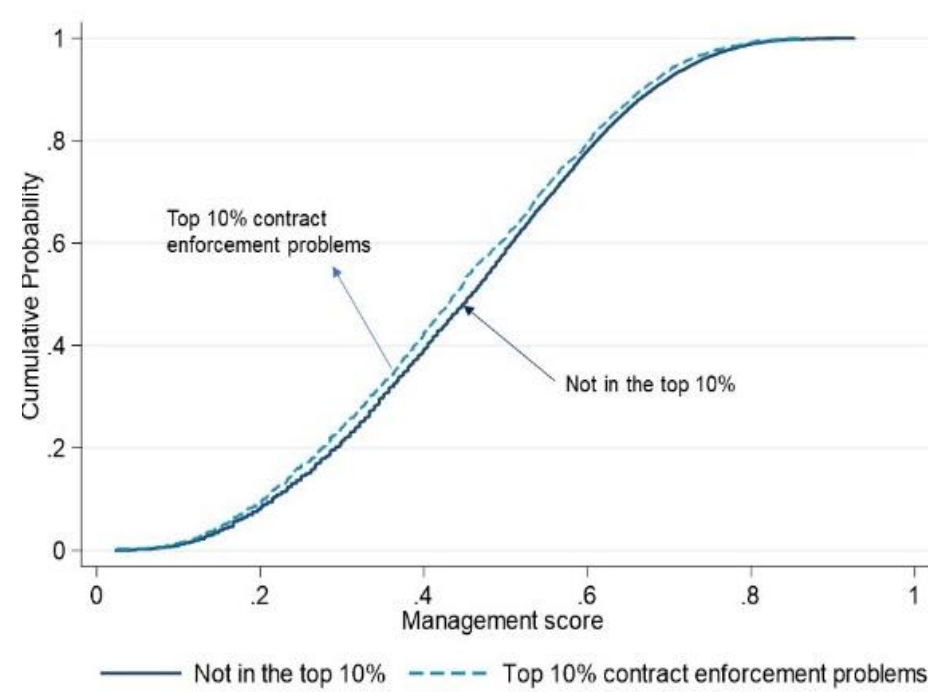

(c) Corruption

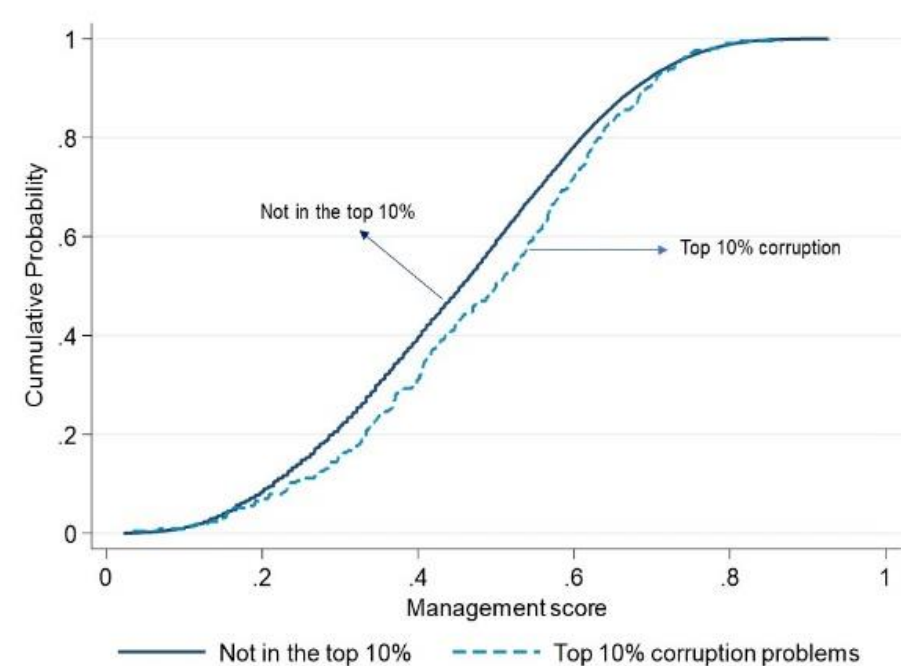

(b) Kidnapping

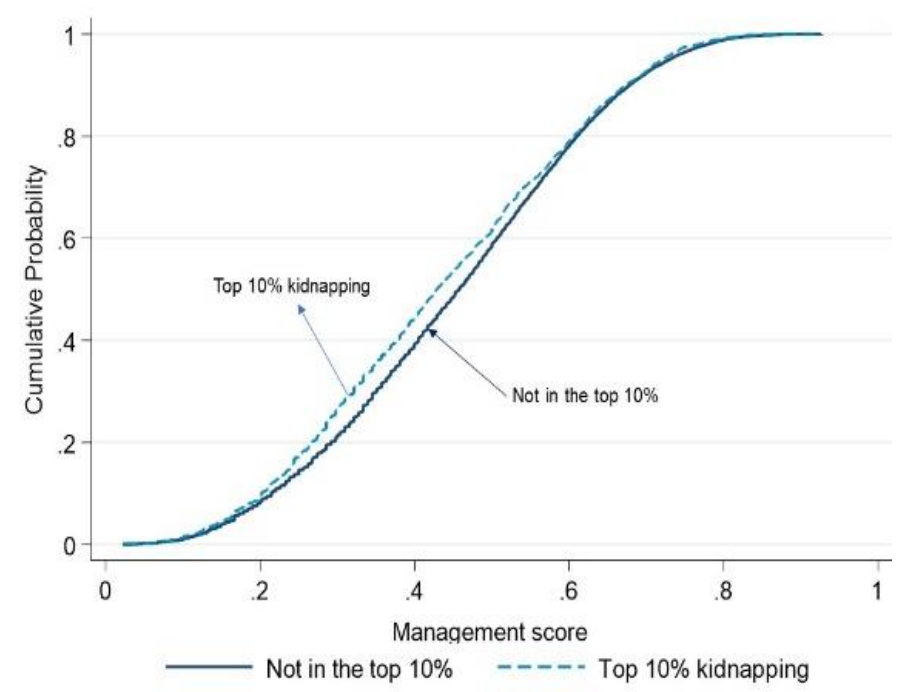

(d) Business crime composite index

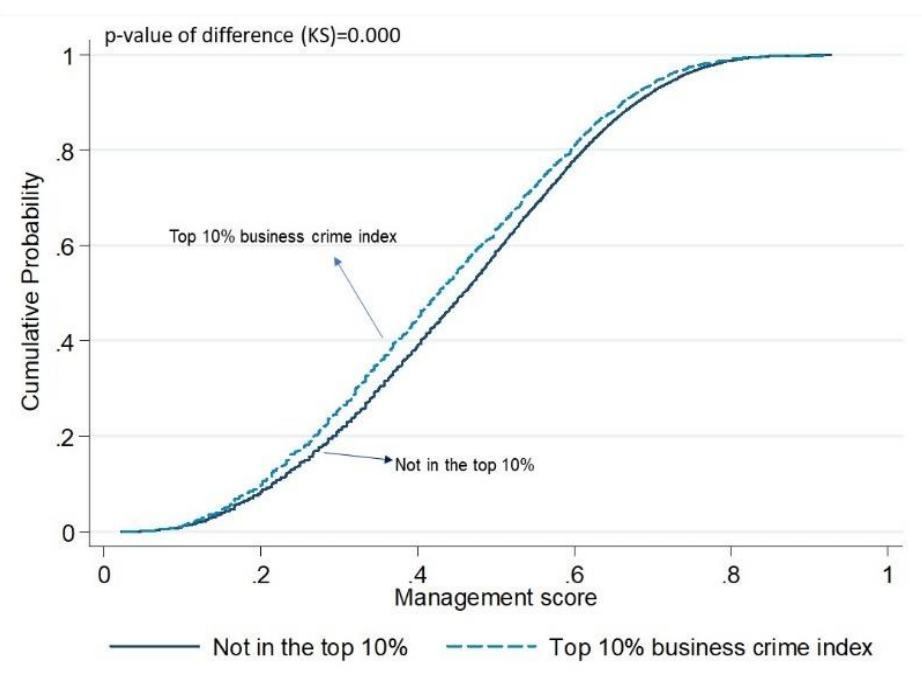

Notes: 6,643 observations on Mexican manufacturing; 17,684 observations on Mexican services 


\section{Online Appendix Tables}

Table A1. Descriptive Statistics by sector

\begin{tabular}{|c|c|c|c|c|c|c|c|c|}
\hline & Mean & S.D. & p10 & p25 & p50 & p75 & p90 & $\mathrm{N}$ \\
\hline \multicolumn{9}{|c|}{ Manufacturing } \\
\hline \multicolumn{9}{|c|}{2014} \\
\hline \multicolumn{9}{|l|}{ A. Management } \\
\hline Management score & 0.462 & 0.171 & 0.226 & 0.339 & 0.472 & 0.589 & 0.685 & 3,707 \\
\hline Data driven performance monitoring & 0.515 & 0.197 & 0.222 & 0.389 & 0.528 & 0.667 & 0.750 & 3,707 \\
\hline Incentives and targets & 0.421 & 0.218 & 0.135 & 0.248 & 0.417 & 0.588 & 0.713 & 3,707 \\
\hline \multicolumn{9}{|l|}{ B. Firm characteristics } \\
\hline Size (number of employees) & 117 & 185 & 13 & 21 & 50 & 125 & 260 & 3,707 \\
\hline Firm age & 19.637 & 15.038 & 4.000 & 8.000 & 16.000 & 27.000 & 40.000 & 3,707 \\
\hline Exporter & 0.345 & 0.476 & 0.000 & 0.000 & 0.000 & 1.000 & 1.000 & 3,707 \\
\hline Share of exports & 0.130 & 0.276 & 0.000 & 0.000 & 0.000 & 0.058 & 0.595 & 3,707 \\
\hline FDI1* & 0.159 & 0.366 & 0.000 & 0.000 & 0.000 & 0.000 & 1.000 & 3,707 \\
\hline FDI2* & 0.145 & 0.353 & 0.000 & 0.000 & 0.000 & 0.000 & 1.000 & 3,707 \\
\hline Share of FDI & 14.142 & 34.004 & 0.000 & 0.000 & 0.000 & 0.000 & 100.000 & 3,707 \\
\hline Share college degree & 0.160 & 0.144 & 0.017 & 0.065 & 0.125 & 0.216 & 0.340 & 3,707 \\
\hline Share white collar & 0.166 & 0.103 & 0.050 & 0.089 & 0.149 & 0.222 & 0.313 & 3,707 \\
\hline \multicolumn{9}{|l|}{ C. Other control variables } \\
\hline Drive time to border (hrs) & 10.0 & 5.8 & 2.5 & 4.4 & 10.8 & 12.8 & 14.3 & 3,707 \\
\hline Population density (inhabitans $/ \mathrm{km}^{2}$ ) & 926.9 & 832.5 & 95.2 & 373.0 & 603.7 & $1,133.1$ & $2,548.3$ & 3,707 \\
\hline MA average household monthly per capita income (pesos) & $2,912.6$ & 874.3 & $2,141.8$ & $2,367.4$ & $2,847.0$ & $3,347.0$ & $3,558.8$ & 3,707 \\
\hline Share of exports (NAICS 6-digits exports/sales) & 0.183 & 0.160 & 0.007 & 0.066 & 0.144 & 0.256 & 0.415 & 3,707 \\
\hline \multicolumn{9}{|c|}{2017} \\
\hline \multicolumn{9}{|l|}{ A. Management } \\
\hline Management score & 0.474 & 0.173 & 0.238 & 0.345 & 0.483 & 0.607 & 0.700 & 2,936 \\
\hline Data driven performance monitoring & 0.515 & 0.187 & 0.250 & 0.389 & 0.528 & 0.667 & 0.750 & 2,936 \\
\hline Incentives and targets & 0.441 & 0.223 & 0.135 & 0.260 & 0.445 & 0.608 & 0.742 & 2,936 \\
\hline \multicolumn{9}{|l|}{ B. Firm characteristics } \\
\hline Size (number of employees) & 133 & 204 & 15 & 25 & 58 & 145 & 310 & 2,936 \\
\hline Firm age & 22.269 & 14.523 & 7.000 & 11.000 & 19.000 & 30.000 & 42.000 & 2,936 \\
\hline Exporter & 0.370 & 0.483 & 0.000 & 0.000 & 0.000 & 1.000 & 1.000 & 2,936 \\
\hline Share of exports & 0.135 & 0.279 & 0.000 & 0.000 & 0.000 & 0.078 & 0.623 & 2,936 \\
\hline FDI1* & 0.168 & 0.374 & 0.000 & 0.000 & 0.000 & 0.000 & 1.000 & 2,936 \\
\hline FDI2* & 0.154 & 0.361 & 0.000 & 0.000 & 0.000 & 0.000 & 1.000 & 2,936 \\
\hline Share of FDI & 15.214 & 35.172 & 0.000 & 0.000 & 0.000 & 0.000 & 100.000 & 2,936 \\
\hline Share college degree & 0.165 & 0.153 & 0.023 & 0.067 & 0.128 & 0.214 & 0.342 & 2,936 \\
\hline Share white collar & 0.167 & 0.126 & 0.043 & 0.080 & 0.140 & 0.219 & 0.326 & 2,936 \\
\hline \multicolumn{9}{|l|}{ C. Other control variables } \\
\hline Drive time to border (hrs) & 9.9 & 5.8 & 2.5 & 4.4 & 10.7 & 12.8 & 14.3 & 2,936 \\
\hline Population density (inhabitans $/ \mathrm{km}^{2}$ ) & 918.7 & 821.8 & 95.2 & 373.0 & 603.7 & $1,133.1$ & $2,548.3$ & 2,936 \\
\hline MA average household monthly per capita income (pesos) & $2,918.6$ & 883.7 & $2,141.8$ & $2,367.4$ & $2,847.0$ & $3,347.0$ & $3,558.8$ & 2,936 \\
\hline Share of exports (NAICS 6-digits exports/sales) & 0.186 & 0.163 & 0.007 & 0.058 & 0.149 & 0.264 & 0.417 & 2,936 \\
\hline \multicolumn{9}{|c|}{ Services } \\
\hline \multicolumn{9}{|c|}{2014} \\
\hline \multicolumn{9}{|l|}{ A. Management } \\
\hline Management score & 0.446 & 0.172 & 0.214 & 0.317 & 0.447 & 0.577 & 0.674 & 10,175 \\
\hline Data driven performance monitoring & 0.465 & 0.195 & 0.167 & 0.333 & 0.500 & 0.611 & 0.708 & 10,175 \\
\hline Incentives and targets & 0.428 & 0.222 & 0.135 & 0.250 & 0.427 & 0.600 & 0.730 & 10,175 \\
\hline \multicolumn{9}{|l|}{ B. Firm characteristics } \\
\hline Size (number of employees) & 68 & 147 & 12 & 15 & 25 & 53 & 120 & 10,175 \\
\hline Firm age & 16.235 & 13.629 & 3.000 & 6.000 & 13.000 & 22.000 & 33.000 & 10,175 \\
\hline Exporter & 0.061 & 0.240 & 0.000 & 0.000 & 0.000 & 0.000 & 0.000 & 10,175 \\
\hline Share of exports & 0.015 & 0.094 & 0.000 & 0.000 & 0.000 & 0.000 & 0.000 & 10,175 \\
\hline FDI1* & 0.041 & 0.198 & 0.000 & 0.000 & 0.000 & 0.000 & 0.000 & 10,175 \\
\hline FDI2* & 0.034 & 0.180 & 0.000 & 0.000 & 0.000 & 0.000 & 0.000 & 10,175 \\
\hline Share of FDI & 3.277 & 17.041 & 0.000 & 0.000 & 0.000 & 0.000 & 0.000 & 10,175 \\
\hline Share college degree & 0.271 & 0.273 & 0.000 & 0.077 & 0.176 & 0.368 & 0.762 & 10,175 \\
\hline Share white collar & 0.159 & 0.102 & 0.043 & 0.082 & 0.143 & 0.217 & 0.300 & 10,175 \\
\hline C. Other control variables & & & & & & & & \\
\hline Drive time to border (hrs) & 12.4 & 7.1 & 2.6 & 8.4 & 12.6 & 14.3 & 22.3 & 10,175 \\
\hline Population density (inhabitans $/ \mathrm{km}^{2}$ ) & 812.9 & 832.8 & 62.9 & 173.0 & 532.3 & 993.3 & $2,548.3$ & 10,175 \\
\hline MA average household monthly per capita income (pesos) & $3,174.8$ & $1,226.5$ & $2,229.5$ & $2,525.4$ & $2,921.7$ & $3,357.7$ & $4,314.1$ & 10,175 \\
\hline Share of exports (NAICS 6-digits exports/sales) & 0.014 & 0.026 & 0.000 & 0.000 & 0.002 & 0.020 & 0.041 & 10,175 \\
\hline
\end{tabular}


2017

\begin{tabular}{|c|c|c|c|c|c|c|c|c|}
\hline \multicolumn{9}{|l|}{ A. Management } \\
\hline Management score & 0.443 & 0.173 & 0.208 & 0.314 & 0.446 & 0.577 & 0.669 & 7,509 \\
\hline Data driven performance monitoring & 0.455 & 0.190 & 0.167 & 0.333 & 0.472 & 0.597 & 0.694 & 7,509 \\
\hline Incentives and targets & 0.429 & 0.226 & 0.135 & 0.250 & 0.438 & 0.604 & 0.730 & 7,509 \\
\hline \multicolumn{9}{|l|}{ B. Firm characteristics } \\
\hline Size (number of employees) & 68 & 136 & 12 & 16 & 28 & 60 & 131 & 7,509 \\
\hline Firm age & 18.447 & 12.686 & 6.000 & 9.000 & 16.000 & 24.000 & 34.000 & 7,509 \\
\hline Exporter & 0.064 & 0.244 & 0.000 & 0.000 & 0.000 & 0.000 & 0.000 & 7,509 \\
\hline Share of exports & 0.013 & 0.086 & 0.000 & 0.000 & 0.000 & 0.000 & 0.000 & 7,509 \\
\hline FDI1* & 0.039 & 0.193 & 0.000 & 0.000 & 0.000 & 0.000 & 0.000 & 7,509 \\
\hline FDI2* & 0.032 & 0.177 & 0.000 & 0.000 & 0.000 & 0.000 & 0.000 & 7,509 \\
\hline Share of FDI & 3.172 & 16.874 & 0.000 & 0.000 & 0.000 & 0.000 & 0.000 & 7,509 \\
\hline Share college degree & 0.269 & 0.284 & 0.000 & 0.071 & 0.167 & 0.353 & 0.814 & 7,509 \\
\hline Share white collar & 0.166 & 0.131 & 0.041 & 0.078 & 0.138 & 0.214 & 0.320 & 7,509 \\
\hline \multicolumn{9}{|l|}{ C. Other control variables } \\
\hline Drive time to border (hrs) & 12.6 & 7.2 & 2.6 & 8.5 & 12.6 & 14.3 & 23.6 & 7,509 \\
\hline Population density (inhabitans $/ \mathrm{km}^{2}$ ) & 795.6 & 814.0 & 62.7 & 173.0 & 532.3 & 993.3 & $2,548.3$ & 7,509 \\
\hline MA average household monthly per capita income (pesos) & $3,132.0$ & $1,160.5$ & $2,229.5$ & $2,525.4$ & $2,910.1$ & $3,352.3$ & $4,130.4$ & 7,509 \\
\hline Share of exports (NAICS 6-digits exports/sales) & 0.014 & 0.027 & 0.000 & 0.000 & 0.002 & 0.020 & 0.041 & 7,509 \\
\hline
\end{tabular}

Notes: *FDI1 is defined as a firm with any participation of FDI and FDI2 indicates 50\% or more FDI. 
Table A2. Firm performance and management scores using data from 2014 Economic Census

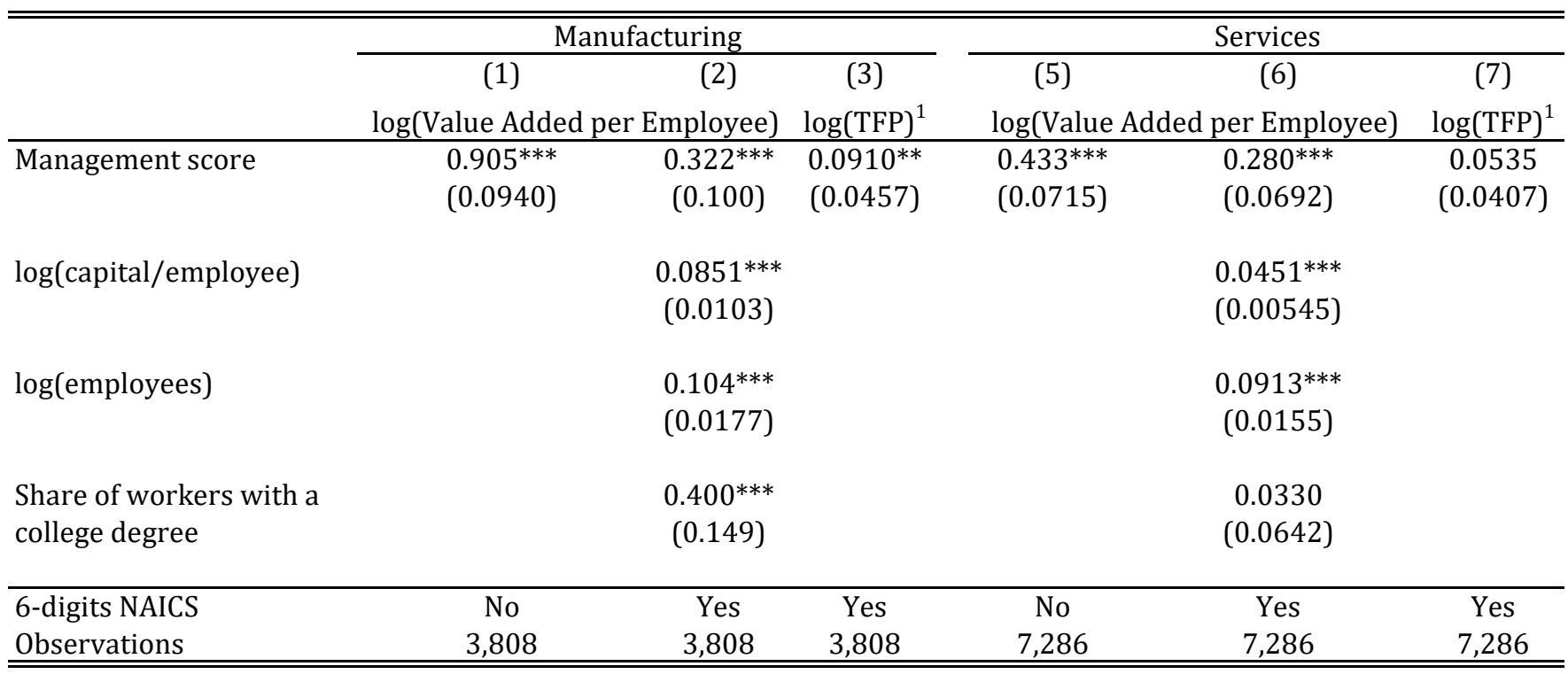

Notes: Robust standard errors in parentheses; ${ }^{*}$ Significant at the $10 \%$ level, ${ }^{* *} 5 \%$ level, ${ }^{* * *} 1 \%$ level. TFP is constructed using a Törnqvist index approach (see Data Appendix, section B.3.1). 
Table A3. Management Practices and Firm Performance in Microenterprises

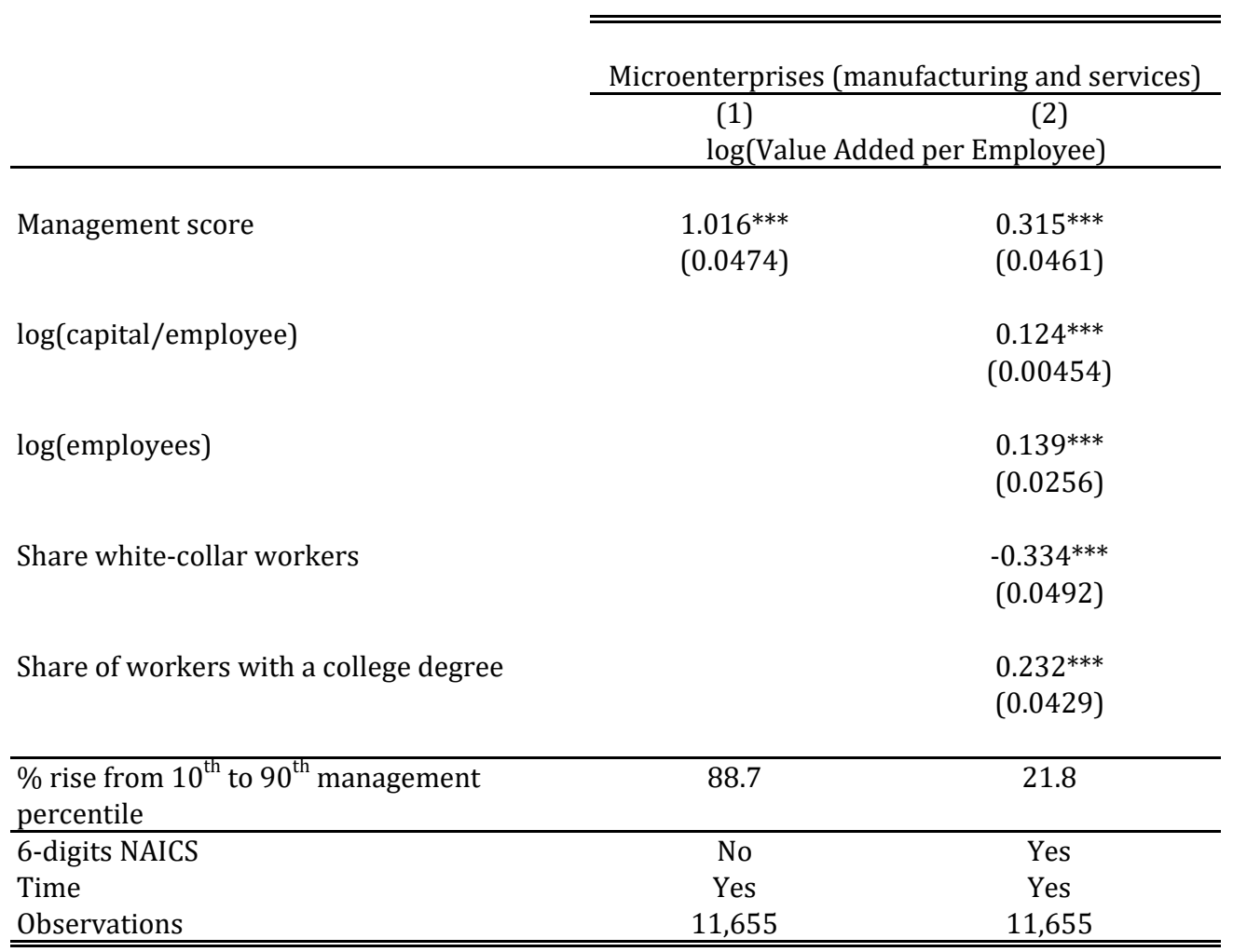

Notes: Robust standard errors in parentheses clustered at the firm level; * Significant at the $10 \%$ level, ${ }^{* *} 5 \%$ level, ${ }^{* * *} 1 \%$ level. 
Table A4. Management Practices, Exit, and Employment growth

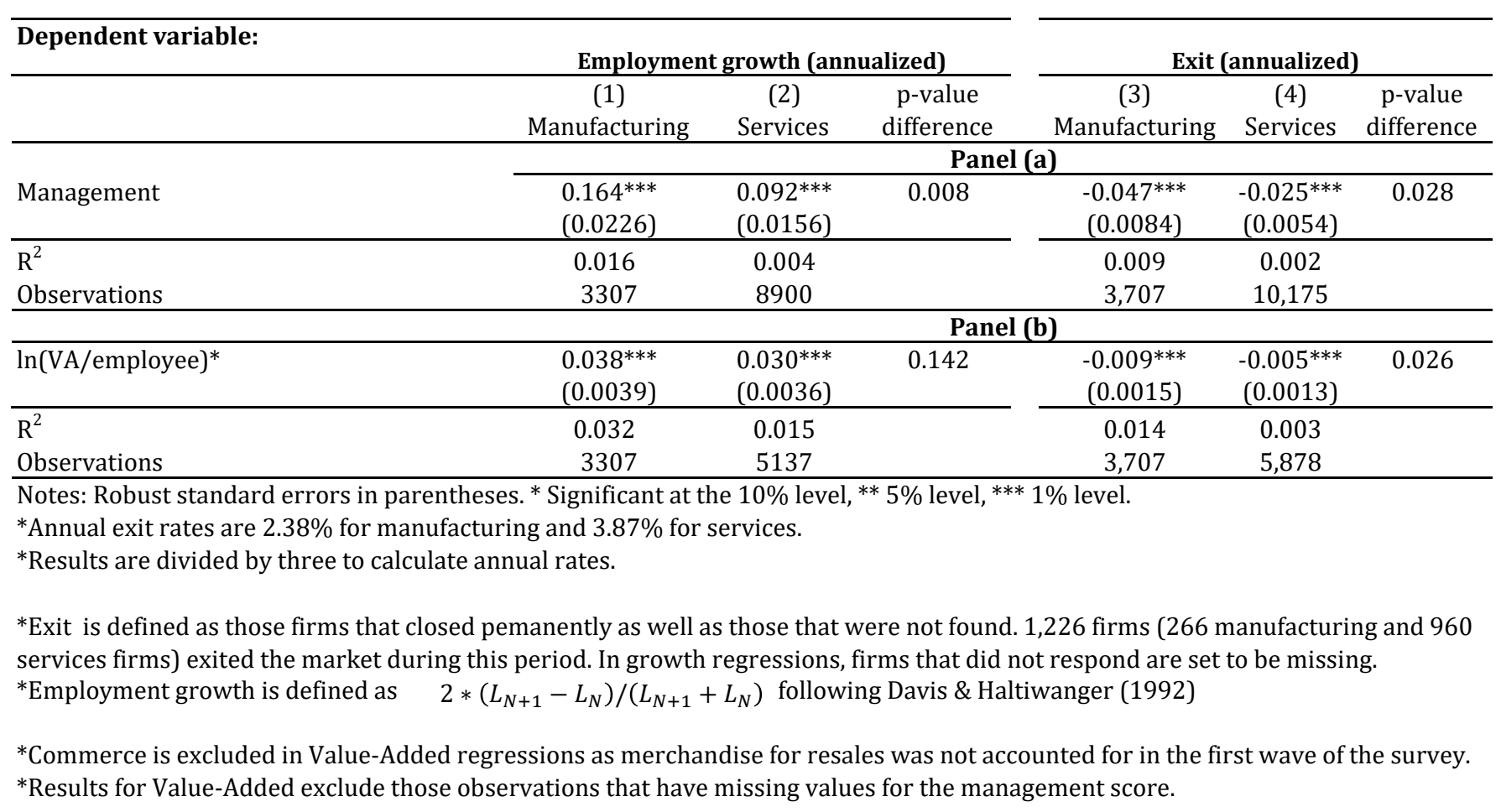

